\title{
The value of catheter-based cryoablation for the management of cardiac arrhythmias
}

Citation for published version (APA):

Manusama, R. J. (2012). The value of catheter-based cryoablation for the management of cardiac arrhythmias. [Doctoral Thesis, Maastricht University]. Datawyse / Universitaire Pers Maastricht. https://doi.org/10.26481/dis.20120316rm

Document status and date:

Published: 01/01/2012

DOI:

10.26481/dis.20120316rm

Document Version:

Publisher's PDF, also known as Version of record

\section{Please check the document version of this publication:}

- A submitted manuscript is the version of the article upon submission and before peer-review. There can be important differences between the submitted version and the official published version of record.

People interested in the research are advised to contact the author for the final version of the publication, or visit the DOI to the publisher's website.

- The final author version and the galley proof are versions of the publication after peer review.

- The final published version features the final layout of the paper including the volume, issue and page numbers.

Link to publication

\footnotetext{
General rights rights.

- You may freely distribute the URL identifying the publication in the public portal. please follow below link for the End User Agreement:

www.umlib.nl/taverne-license

Take down policy

If you believe that this document breaches copyright please contact us at:

repository@maastrichtuniversity.nl

providing details and we will investigate your claim.
}

Copyright and moral rights for the publications made accessible in the public portal are retained by the authors and/or other copyright owners and it is a condition of accessing publications that users recognise and abide by the legal requirements associated with these

- Users may download and print one copy of any publication from the public portal for the purpose of private study or research.

- You may not further distribute the material or use it for any profit-making activity or commercial gain

If the publication is distributed under the terms of Article $25 \mathrm{fa}$ of the Dutch Copyright Act, indicated by the "Taverne" license above, 


\section{The value of catheter-based cryoablation for the management of cardiac arrhythmias}


(C) Copyright Randy Manusama, Maastricht 2012

\section{ISBN 9789461591272}

Production: Datawyse | Universitaire Pers Maastricht 


\title{
The value of catheter-based cryoablation for the management of cardiac arrhythmias
}

\author{
PROEFSCHRIFT \\ ter verkrijging van de graad van doctor aan de Universiteit Maastricht, \\ op gezag van de Rector Magnificus, Prof. mr. G.P.M.F. Mols, \\ volgens het besluit van het College van Decanen, \\ in het openbaar te verdedigen, \\ op vrijdag 16 maart 2012 om 10:00 uur
}

door

Randolph John Manusama

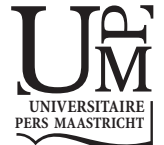




\section{Promotor}

Prof. Dr. H.J.G.M Crijns

\section{Co-promotor}

Dr. C.C.M.M. Timmermans

\section{Beoordelingscommissie}

Prof. Dr. M. Allessie (voorzitter)

Prof. Dr. A.P.M. Gorgels

Prof. Dr. R.N.W. Hauer, Universitair Medisch Centrum Utrecht

Prof. Dr. M.J. Schalij, Leids Universitair Medisch Centrum

Prof. Dr. H.J.J. Wellens

This study was performed in the Maastricht University Medical Center, the Netherlands and supported bij a grant from ZonMw. Financial support by 'Stichting hartsvrienden RESCAR Maastricht and Maastricht University Medical Center for the publication of this thesis is gratefully acknowledged. 
Nil Volentibus Arduum

(niets is onmogelijk voor hen die willen) 



\section{Contents}

Introduction $\quad 9$

$\begin{array}{lll}\text { Chapter I Developments in cryoablation } & 17\end{array}$

Chapter II Catheter-based cryoablation permanently cures patients 29 with common atrial flutter

Chapter III Single cryothermia applications of less than 5 minutes $\quad 41$ produce permanent cavotricuspid isthmus block in humans

Chapter IV Typical atrial flutter can effectively be treated using single 53 one-minute of cryoablation: results from a repeat electrophysiological study

Chapter V Comparison of 6.5-mm, 10-mm and 15-mm cryoablation 67 catheter-tip for the treatment of common atrial flutter

Chapter VI Long-term follow-up after cryothermic ostial pulmonary vein isolation in patient with paroxysmal atrial fibrillation

Chapter VII Catheter-based cryoablation of post-infarction and idiopathic ventricular tachycardia: initial experience in a selected population

Chapter VIII General discussion and future perspective 107

Summary

Samenvatting

Dankwoord

Curriculum vitae

Publications 



\section{Introduction}

Arrhythmia treatment has been a challenge for many decades. The effectiveness of quinine and related alkaloids (as used in anti-malarial concoctions) in suppressing atrial arrhythmias was noted in the $1800 \mathrm{~s}$, but it was not until Wenckebach personally observed (in 1914) and described the use of the isomer of quinine, quinidine. ${ }^{1}$ This was the first of several drugs that offered antiarrhythmic therapy with a (temporary) relief of symptoms, but on the other hand obliged life-long commitment and the risk of life-threatening side effects. ${ }^{2}$, 3 With the advent of an invasive therapy to treat arrhythmias a permanent cure was at hand. The first surgical attempt of permanent ablation was performed in 1968 when a right free-wall accessory pathway was successfully divided in a 31year-old fisherman. ${ }^{4}$ Many were to follow, extending surgical techniques to include His-bundle interruption for AV-nodal reentry tachycardia 5 , left atrial isolation for atrial tachycardia ${ }^{6}$ and endocardial ventriculotomy ${ }^{7}$ to treat drugrefractory ischemic ventricular tachycardia. The first clinical experience with catheter ablation in the early 1980s was related to a high-energy DC shock and illustrated its potential as a closed-chest procedure. ${ }^{8,9}$ However, due to a relatively high morbidity and low efficacy, ${ }^{10}$ this modality lost interest. By creating a localized area of extreme heat through an unmodulated sine-wave AC at frequencies of 500 to $1,000 \mathrm{kHz}$., radiofrequency catheter ablation has shown to be highly effective in a variety of arrhythmias, ${ }^{11-15}$ offering a better safety profile compared to its predecessor. In the following years radiofrequency energy had become the principal energy source in catheter ablation, expelling most rhythm disorders from the operating room. However, serious side effects may occur ${ }^{16-18}$ and encouraged some operators to investigate alternative energy sources.

Cryothermia, i.e. the ability to induce tissue necrosis through intense freezing, has shown to be an effective and versatile tool. From the early sixties, its unique feature to cause tissue injury while preserving its architecture became clear. While most evidence was gathered from in vitro studies directed at cryopreservation and from experimental and clinical work on frostbite, ${ }^{19-21}$ it provided the basic features of cryosurgery i.e. rapid freezing, slow thawing, and a repetition of the freeze-thaw cycle that still remain valid to date. ${ }^{22-24}$ Following the technical developments in instrumentation, its usefulness expanded to serve cardiac surgery in arrhythmia treatment. As it matured into a meaningful clinical application, previous insights were reevaluated to proclaim its cardioprotective properties and to ensure maximum tissue injury at the lowest expense of energy delivery and complications. Early experiences in transthoracic surgery demonstrated its potential in arrhythmia management as lesions were homoge- 
neous, ${ }^{25,} 26$ non-arrhythmogenic ${ }^{25}$ and well circumscribed. ${ }^{26,}{ }^{27}$ Ongoing biomedical engineering resulted in the development of catheter-based cryoablation. Several authors using percutaneous cryoablation confirmed that cryothermia is a safe energy source, because of the preservation of tissue architecture, ${ }^{26}$, 28 the low thrombogenicity 29,30 and the ability to permit total recovery of previously affected tissue at suboptimal $\left(-21^{\circ} \mathrm{C}\right)$ temperatures (cold-mapping)..$^{31,32} \mathrm{In}$ the first study performed in patients, percutaneous cryoablation, directed at the AV-node of 12 patients with drug-refractory atrial fibrillation was found to be both feasible and safe. ${ }^{33}$ To ensure procedural success and a high long-term efficacy, applications lasted for 5 minutes and were repeated per site, mainly to overcome the warming effect of the circulating blood surrounding the cathetertip. To provide a freezing regimen with a shorter ablation duration more studies involving other arrhythmias were necessary. Lesion formation during cryoablation has proven to be a complex process, involving multiple factors of variable importance that limit the ability to predict the amount of tissue loss based on a single parameter. Cooper et al. already emphasized in 1970 the complexity of cryoablation in his analytical prediction of the temperature field emanating from cryosurgical cannula. ${ }^{34}$ During the steady state of a cryodelivery more than a dozen parameters like heat of the (un)frozen tissue, blood flow, thermal conductivity of the (un)frozen tissue, probe radius and application time, were involved in a complex equation to ultimately define the lesion size. Although this theoretical background lacked any clinical verification, it actually gave a nice overview of the many factors thought to participate in cryo-injury. The use of an ablation catheter instead of a surgical probe even added more variables to this equation since other factors i.e. superfusate flow, tip pressure and catheter orientation may play a role in lesion formation.

\section{Aim of this thesis}

Early data showed the feasibility and safety of catheter-based cryoablation in a small group of patients. ${ }^{33}$ In previous studies from cryosurgery, ${ }^{26,} 35$ a relatively long application duration was used compared to radiofrequency ablation. In addition, cryoapplications were repeated at every site to obtain a high acute and long-term efficacy. The purpose of this thesis is to report on the safety and efficacy of catheter-based cryoablation of a variety of arrhythmias. Emphasis was made on a reduction of the cryoablation time to obtain a shorter procedure duration while maintaining clinical efficacy.

In Chapter I a historical overview of cryoablation is given. Experience gained from cryosurgery and developments that underlie the introduction of catheter-based cryoablation are summarized.

The first clinical application of catheter-based cryoablation was directed at the AV-node to create permanent AV-block in patients with chronic atrial fibril- 
lation and inadequate rate control. Located at the apex of Kochs triangle and underlying the endocardial surface with just a small border of atrial myocardial transitional cells, ${ }^{36}$ the compact $\mathrm{AV}$-node is an ideal target for catheter ablation. It remains questionable if other anatomic structures are also suitable for catheter-based cryoablation. Mapping studies have reported that the cavotricuspid isthmus located between the inferior caval vein and the tricuspid annulus represent an obligatory route for typical atrial flutter. 37,38 Linear ablation at the cavotricuspid isthmus to permanently interrupt the flutter circuit has become a worldwide standard since it is associated with a high acute and long-term efficacy. ${ }^{39-41}$ The short-term success rate and safety obtained with catheter-based cryoablation for atrial flutter have shown to be comparable to those for radiofrequency ablation. ${ }^{42}$ However, it is unclear if catheter-based cryoablation has a high efficacy during long-term follow-up. In Chapter II the safety and both the short and long-term efficacy of catheter-based cryoablation for the treatment of common atrial flutter is studied.

To produce large focal lesions, cryoablation is generally applied using long application durations with repeated freeze-thaw cycles per site. Initial studies used included double freezes of 5-minute duration per site. ${ }^{43}, 44$ However, stable ice ball formation has been reported at 3 minutes $^{26,31,44}$ and correlates with maximal tissue injury. ${ }^{26}$ This reduction in cryoablation time may decrease the procedure time while maintaining a high clinical efficacy. In Chapter III the effect of a single application of 3 minutes duration versus double applications of 3 minutes for the treatment of typical atrial flutter is evaluated. Special emphasis is made on the impact of the two freezing schemes on the overall procedure time.

It is unknown if procedural and long-term efficacy remain unaffected if short cryoapplication durations (similar to radiofrequency) are used. Ongoing biomedical engineering has enabled lower freezing temperatures and catheter refinements that may provide a reduction of the application duration. In addition, other factors like contact pressure, catheter-tip orientation and tip-size have proven to play an important role in catheter-based cryoablation and may influence lesion formation. ${ }^{45}{ }^{46}$ In Chapter IV the acute and long-term efficacy of catheter-based cryoablation of typical atrial flutter using single 1-minute applications are prospectively evaluated.

Several studies using different sizes of radiofrequency catheter-tips have shown that larger catheter-tips have superior procedural efficacy compared to conventional 4- or 5-mm catheter-tips. ${ }^{4-49}$ In Chapter V we prospectively evaluated the safety and efficacy of catheter-based cryoablation of the cavotricuspid isthmus for the treatment of atrial flutter using a $6.5-\mathrm{mm}$, a $10-\mathrm{mm}$ and a $15-\mathrm{mm}$ tip. A larger cryoablation catheter-tip may require fewer freezes and may shorten the procedure time.

Atrial fibrillation is the most common sustained arrhythmia in clinical practice. Its prevalence increases with age, from $0.1 \%$ in people younger than 55 
years to more than $10 \%$ by the age of $70 . .^{50}$ In an early stage, atrial fibrillation predominantly occurs paroxysmal and in non-sustained episodes. In this stage, ectopic foci, mostly located in the pulmonary veins, trigger the onset of atrial fibrillation. ${ }^{51}$ Over time, atrial remodeling starts to occur, and more substrate becomes available to sustain longer episodes. ${ }^{52}$ Therefore, an invasive treatment early in the disease may be more successful. Catheter ablation in this stage of the disease is intended to either eliminate or isolate the triggers. In contrast to radiofrequency ablation, ${ }^{53-57}$ the ability of cryothermia to create homogeneous lesions that preserve tissue architecture prevents pulmonary vein narrowing during ostial ablation..$^{58}$

In Chapter VI the effect of a segmental ablation strategy using catheterbased cryoablation is evaluated in patients with paroxysmal atrial fibrillation in an early stage of the disease. One disadvantage of catheter-based cryoablation in general is the handling characteristics of the catheter. Cryocatheters have a double lumen to transport precooled refrigerant to and from the catheter-tip, where a liquid-to-gas exchange takes place to obtain the required drop in temperature. As a result cryocatheters are larger in diameter compared to radiofrequency catheters and consequently more rigid with lower torque transmission and maneuverability. While this does not significantly limit the treatment of supraventricular arrhythmias, in the more confined space of the ventricle and the serpentine manipulations necessary to reach certain areas of desired ablation, these characteristics may be a limitation for ablation of ventricular tachycardia. In Chapter VII we evaluated the feasibility and safety of catheter-based cryoablation for the treatment of sustained monomorphic, right- or left-sided, post-infarction and idiopathic ventricular tachycardia.

The last chapter (Chapter VIII) gives a general discussion about the safety and overall efficacy of catheter-based cryoablation. The increasing applicability of catheter-based cryoablation is highlighted and future perspectives are proposed. 


\section{References}

1. Levy S, Azoulay S: Stories about the origin of quinquina and quinidine. J Cardiovasc Electrophysiol 1994; 5:635-636.

2. Ruskin JN: The cardiac arrhythmia suppression trial (CAST). N Engl J Med 1989; 321:386-388.

3. Dessertenne F, Fabiato A, Coumel P: [A new chapter in electrocardiography: progressive variations in the amplitude of the electrocardiogram]. Actual Cardiol Angeiol Int (Paris) 1966; 15:241-258.

4. Cobb FR, Blumenschein SD, Sealy WC, Boineau JP, Wagner GS, Wallace AG: Successful surgical interruption of the bundle of Kent in a patient with Wolff-Parkinson-White syndrome. Circulation 1968; 38:1018-1029.

5. Sealy WC, Gallagher JJ, Kasell J: His bundle interruption for control of inappropriate ventricular responses to atrial arrhythmias. Ann Thorac Surg 1981; 32:429-438.

6. Williams JM, Ungerleider RM, Lofland GK, Cox JL: Left atrial isolation: new technique for the treatment of supraventricular arrhythmias. J Thorac Cardiovasc Surg 1980; 80:373-380.

7. Guiraudon G, Fontaine G, Frank R, Escande G, Etievent P, Cabrol C: Encircling endocardial ventriculotomy: a new surgical treatment for life-threatening ventricular tachycardias resistant to medical treatment following myocardial infarction. Ann Thorac Surg 1978; 26:438-444.

8. Hartzler GO: Electrode catheter ablation of refractory focal ventricular tachycardia. J Am Coll Cardiol 1983; 2:1107-1113.

9. Jackman WM, Friday KJ, Scherlag BJ, Dehning MM, Schechter E, Reynolds DW, Olson EG, Berbari EJ, Harrison LA, Lazzara R: Direct endocardial recording from an accessory atrioventricular pathway: localization of the site of block, effect of antiarrhythmic drugs, and attempt at nonsurgical ablation. Circulation 1983; 68:906-916.

10. Evans GT, Jr., Scheinman MM, Zipes DP, Benditt D, Breithardt G, Camm AJ, el-Sherif N, Fisher J, Fontaine G, et al.: The Percutaneous Cardiac Mapping and Ablation Registry: final summary of results. Pacing Clin Electrophysiol 1988; 11:1621-1626.

11. Jackman WM, Wang XZ, Friday KJ, Roman CA, Moulton KP, Beckman KJ, McClelland JH, Twidale N, Hazlitt HA, Prior MI, et al.: Catheter ablation of accessory atrioventricular pathways (WolffParkinson-White syndrome) by radiofrequency current. N Engl J Med 1991; 324:1605-1611.

12. Jackman WM, Wang XZ, Friday KJ, Fitzgerald DM, Roman C, Moulton K, Margolis PD, Bowman AJ, Kuck KH, Naccarelli GV, et al.: Catheter ablation of atrioventricular junction using radiofrequency current in 17 patients. Comparison of standard and large-tip catheter electrodes. Circulation 1991; 83:1562-1576.

13. Jazayeri MR, Hempe SL, Sra JS, Dhala AA, Blanck Z, Deshpande SS, Avitall B, Krum DP, Gilbert CJ, Akhtar M: Selective transcatheter ablation of the fast and slow pathways using radiofrequency energy in patients with atrioventricular nodal reentrant tachycardia. Circulation 1992; 85:13181328.

14. Klein LS, Shih HT, Hackett FK, Zipes DP, Miles WM: Radiofrequency catheter ablation of ventricular tachycardia in patients without structural heart disease. Circulation 1992; 85:16661674.

15. Kay GN, Chong F, Epstein AE, Dailey SM, Plumb VJ: Radiofrequency ablation for treatment of primary atrial tachycardias. J Am Coll Cardiol 1993; 21:901-909.

16. Dubin AM, Van Hare GF: Radiofrequency catheter ablation: indications and complications. Pediatr Cardiol 2000; 21:551-556.

17. Saad EB, Rossillo A, Saad CP, Martin DO, Bhargava M, Erciyes D, Bash D, Williams-Andrews M, Beheiry S, Marrouche NF, Adams J, Pisano E, Fanelli R, Potenza D, Raviele A, Bonso A, Themistoclakis S, Brachmann J, Saliba WI, Schweikert RA, Natale A: Pulmonary vein stenosis after radiofrequency ablation of atrial fibrillation: functional characterization, evolution, and influence of the ablation strategy. Circulation 2003; 108:3102-3107.

18. Scanavacca MI, D'Avila A, Parga J, Sosa E: Left atrial-esophageal fistula following radiofrequency catheter ablation of atrial fibrillation. J Cardiovasc Electrophysiol 2004; 15:960-962.

19. Kreyberg L: [Damage Due to Cold and Frostbite.]. Nord Med 1965; 73:281-283. 
20. Kreyberg L: Development of acute tissue damage due to cold. Physiol Rev 1949; 29:156-167.

21. Meryman HT: Mechanics of freezing in living cells and tissues. Science 1956; 124:515-521.

22. Cahan WG: Cryosurgery of Malignant and Benign Tumors. Fed Proc 1965; 24:S241-248.

23. Cooper IS: Cryogenic Surgery for Cancer. Fed Proc 1965; 24:S237-240.

24. Gage AA, Koepf S, Wehrle D, Emmings F: Cryotherapy for cancer of the lip and oral cavity. Cancer 1965; 18:1646-1651.

25. Wetstein L, Mark R, Kaplan A, Mitamura H, Sauermelch C, Michelson EL: Nonarrhythmogenicity of therapeutic cryothermic lesions of the myocardium. J Surg Res 1985; 39:543-554.

26. Hunt GB, Chard RB, Johnson DC, Ross DL: Comparison of early and late dimensions and arrhythmogenicity of cryolesions in the normothermic canine heart. J Thorac Cardiovasc Surg 1989; 97:313-318.

27. Ohkawa S, Hackel DB, Mikat EM, Gallagher JJ, Cox JL, Sealy WC: Anatomic effects of cryoablation of the atrioventricular conduction system. Circulation 1982; 65:1155-1162.

28. Timmermans C, Rodriguez LM, Van Suylen RJ, Leunissen J, Vos M, Ayers GM, Crijns HJ, Wellens HJ: Catheter-based cryoablation produces permanent bidirectional cavotricuspid isthmus conduction block in dogs. J Interv Card Electrophysiol 2002; 7:149-155.

29. Khairy P, Chauvet P, Lehmann J, Lambert J, Macle L, Tanguay JF, Sirois MG, Santoianni D, Dubuc M: Lower incidence of thrombus formation with cryoenergy versus radiofrequency catheter ablation. Circulation 2003; 107:2045-2050.

30. van Oeveren W, Crijns HJ, Korteling BJ, Wegereef EW, Haan J, Tigchelaar I, Hoekstra A: Blood damage, platelet and clotting activation during application of radiofrequency or cryoablation catheters: a comparative in vitro study. J Med Eng Technol 1999; 23:20-25.

31. Dubuc M, Roy D, Thibault B, Ducharme A, Tardif JC, Villemaire C, Leung TK, Talajic M: Transvenous catheter ice mapping and cryoablation of the atrioventricular node in dogs. Pacing Clin Electrophysiol 1999; 22:1488-1498.

32. Rodriguez LM, Leunissen J, Hoekstra A, Korteling BJ, Smeets JL, Timmermans C, Vos M, Daemen M, Wellens HJ: Transvenous cold mapping and cryoablation of the AV node in dogs: observations of chronic lesions and comparison to those obtained using radiofrequency ablation. J Cardiovasc Electrophysiol 1998; 9:1055-1061.

33. Dubuc M, Khairy P, Rodriguez-Santiago A, Talajic M, Tardif JC, Thibault B, Roy D: Catheter cryoablation of the atrioventricular node in patients with atrial fibrillation: a novel technology for ablation of cardiac arrhythmias. J Cardiovasc Electrophysiol 2001; 12:439-444.

34. Cooper TE, Trezek GJ: Analytical prediction of the temperature field emanating from a cryogenic surgical cannula. Cryobiology 1970; 7:79-83.

35. Gill W, Fraser J, Carter DC: Repeated freeze-thaw cycles in cryosurgery. Nature 1968; 219:410413.

36. Anderson RH, Ho SY: Anatomy of the AV node. J Cardiovasc Electrophysiol 1994; 5:309-312.

37. Cosio FG, Lopez-Gil M, Goicolea A, Arribas F, Barroso JL: Radiofrequency ablation of the inferior vena cava-tricuspid valve isthmus in common atrial flutter. Am J Cardiol 1993; 71:705-709.

38. Nakagawa H, Lazzara R, Khastgir T, Beckman KJ, McClelland JH, Imai S, Pitha JV, Becker AE, Arruda M, Gonzalez MD, Widman LE, Rome M, Neuhauser J, Wang X, Calame JD, Goudeau MD, Jackman WM: Role of the tricuspid annulus and the eustachian valve/ridge on atrial flutter. Relevance to catheter ablation of the septal isthmus and a new technique for rapid identification of ablation success. Circulation 1996; 94:407-424.

39. Cosio FG, Goicolea A, Lopez-Gil M, Arribas F: Catheter ablation of atrial flutter circuits. Pacing Clin Electrophysiol 1993; 16:637-642.

40. Fischer B, Haissaguerre M, Garrigues S, Poquet F, Gencel L, Clementy J, Marcus FI: Radiofrequency catheter ablation of common atrial flutter in 80 patients. J Am Coll Cardiol 1995; 25:1365-1372.

41. Poty H, Saoudi N, Abdel Aziz A, Nair M, Letac B: Radiofrequency catheter ablation of type 1 atrial flutter. Prediction of late success by electrophysiological criteria. Circulation 1995; 92:13891392. 
42. Timmermans C, Ayers GM, Crijns HJ, Rodriguez LM: Randomized study comparing radiofrequency ablation with cryoablation for the treatment of atrial flutter with emphasis on pain perception. Circulation 2003; 107:1250-1252.

43. Rodriguez LM, Geller JC, Tse HF, Timmermans C, Reek S, Lee KL, Ayers GM, Lau CP, Klein HU, Crijns HJ: Acute results of transvenous cryoablation of supraventricular tachycardia (atrial fibrillation, atrial flutter, Wolff-Parkinson-White syndrome, atrioventricular nodal reentry tachycardia). J Cardiovasc Electrophysiol 2002; 13:1082-1089.

44. Skanes AC, Dubuc M, Klein GJ, Thibault B, Krahn AD, Yee R, Roy D, Guerra P, Talajic M: Cryothermal ablation of the slow pathway for the elimination of atrioventricular nodal reentrant tachycardia. Circulation 2000; 102:2856-2860.

45. Tse HF, Ripley KL, Lee KL, Siu CW, Van Vleet JF, Pelkey WL, Lau CP: Effects of temporal application parameters on lesion dimensions during transvenous catheter cryoablation. J Cardiovasc Electrophysiol 2005; 16:201-204.

46. Montenero AS, Bruno N, Antonelli A, Mangiameli D, Barbieri L, Andrew P, Zumbo F: Comparison between a 7 French $6 \mathrm{~mm}$ tip cryothermal catheter and a 9 French $8 \mathrm{~mm}$ tip cryothermal catheter for cryoablation treatment of common atrial flutter. J Interv Card Electrophysiol 2005; 13:59-69.

47. Feld G, Wharton M, Plumb V, Daoud E, Friehling T, Epstein L: Radiofrequency catheter ablation of type 1 atrial flutter using large-tip 8- or 10-mm electrode catheters and a high-output radiofrequency energy generator: results of a multicenter safety and efficacy study. J Am Coll Cardiol 2004; 43:1466-1472.

48. Tsai CF, Tai CT, Yu WC, Chen YJ, Hsieh MH, Chiang CE, Ding YA, Chang MS, Chen SA: Is 8-mm more effective than 4-mm tip electrode catheter for ablation of typical atrial flutter? Circulation 1999; 100:768-771.

49. Rodriguez LM, Nabar A, Timmermans C, Wellens HJ: Comparison of results of an 8-mm split-tip versus a 4-mm tip ablation catheter to perform radiofrequency ablation of type I atrial flutter. Am J Cardiol 2000; 85:109-112, A109.

50. Kannel WB, Abbott RD, Savage DD, McNamara PM: Epidemiologic features of chronic atrial fibrillation: the Framingham study. N Engl J Med 1982; 306:1018-1022.

51. Haissaguerre M, Jais P, Shah DC, Takahashi A, Hocini M, Quiniou G, Garrigue S, Le Mouroux A, Le Metayer P, Clementy J: Spontaneous initiation of atrial fibrillation by ectopic beats originating in the pulmonary veins. N Engl J Med 1998; 339:659-666.

52. Goette A, Honeycutt C, Langberg JJ: Electrical remodeling in atrial fibrillation. Time course and mechanisms. Circulation 1996; 94:2968-2974.

53. Tamborero D, Mont L, Nava S, de Caralt TM, Molina I, Scalise A, Perea RJ, Bartholomay E, Berruezo A, Matiello M, Brugada J: Incidence of pulmonary vein stenosis in patients submitted to atrial fibrillation ablation: a comparison of the Selective Segmental Ostial Ablation vs the Circumferential Pulmonary Veins Ablation. J Interv Card Electrophysiol 2005; 14:21-25.

54. Neumann T, Sperzel J, Dill T, Kluge A, Erdogan A, Greis H, Hansel J, Berkowitsch A, Kurzidim K, Kuniss M, Hamm CW, Pitschner HF: Percutaneous pulmonary vein stenting for the treatment of severe stenosis after pulmonary vein isolation. J Cardiovasc Electrophysiol 2005; 16:1180-1188.

55. Purerfellner $\mathrm{H}$, Martinek M: Pulmonary vein stenosis following catheter ablation of atrial fibrillation. Curr Opin Cardiol 2005; 20:484-490.

56. Dong J, Vasamreddy CR, Jayam V, Dalal D, Dickfeld T, Eldadah Z, Meininger G, Halperin HR, Berger R, Bluemke DA, Calkins H: Incidence and predictors of pulmonary vein stenosis following catheter ablation of atrial fibrillation using the anatomic pulmonary vein ablation approach: results from paired magnetic resonance imaging. J Cardiovasc Electrophysiol 2005; 16:845-852.

57. Berkowitsch A, Neumann T, Ekinci O, Greiss H, Dill T, Kurzidim K, Kuniss M, Schneider HJ, Pitschner HF: A decrease in pulmonary vein diameter after radiofrequency ablation predicts the development of severe stenosis. Pacing Clin Electrophysiol 2005; 28 Suppl 1:S83-85. 


\section{INTRODUCTION}

58. Tse HF, Reek S, Timmermans C, Lee KL, Geller JC, Rodriguez LM, Ghaye B, Ayers GM, Crijns HJ, Klein HU, Lau CP: Pulmonary vein isolation using transvenous catheter cryoablation for treatment of atrial fibrillation without risk of pulmonary vein stenosis. J Am Coll Cardiol 2003; 42:752-758. 


\section{Chapter I \\ Developments in cryoablation}

Randy Manusama, MD 


\section{First use of cold applications}

The benefits of cold have been appreciated for many thousands of years. The ancient Egyptians, and later Hippocrates, were aware of the analgesic and antiinflammatory properties of cold. Over the past 200 years cold treatment has evolved from generalized application such as hydrotherapy to specific, focal destruction of tissue, today's surgical and percutaneous cryoablation. James Arnott (1797 \pm 1883$)$, an English physician was the first person to use extreme cold locally for the destruction of tissue. By using a mixture of salt and crushed ice for palliation of tumors, he managed to reduce pain and local haemorrhage at temperatures of $-24^{\circ} \mathrm{C} .{ }^{1} \mathrm{He}$ contemplated the beneficial effect of cold applications and stated that "a very low temperature will arrest every inflammation, which is near enough to the surface to be accessible to its influence." However, salt/ice mixtures were not capable of reducing tissue temperatures sufficiently to treat tumors effectively. With the introduction of refrigerants, tissues could be frozen at much lower temperatures. In 1877 Cailletet demonstrated at the French Academy of Science that oxygen and carbon monoxide could be liquefied under high pressure. ${ }^{2}$ At the same time Pictet demonstrated the liquefaction of oxygen in Geneve by making use of a "cascade" process, in which the refrigeration cycles of three different cooling media with successively lower critical temperatures were arranged in series, so that the gas liquefied first would act as a coolant in the liquefaction of the next. ${ }^{3}$ Finally, Von Linde invented a continuous process for the production of large quantities of liquid air (mostly nitrogen and oxygen) in 1895, which led the way to its widespread introduction.

\section{Clinical use of refrigerants}

\section{Liquid air}

Campbell White of New York was the first person to use refrigerants for medical application. He successfully treated a large range of conditions including lupus erythematosus, herpes zoster, chancroid, naevi, warts, varicose leg ulcers, carbuncles and epitheliomas by means of liquid air at the end of the $19^{\text {th }}$ century.4, Whitehouse reviewed the effects of liquid air on normal skin, finding it to be especially useful for epitheliomata, lupus erythematosus and vascular naevi.6 $\mathrm{In}$ his opinion liquid air outranked some of the remedies on which was placed great reliance. He treated recurrences of epitheliomata after radiotherapy and found liquid air to be more effective than repeat radiotherapy. Bowen and Towle reported the successful use of liquid air for vascular lesions in 1907. ${ }^{7}$ 


\section{Liquid carbon dioxide}

Humphrey Davy and Michael Faraday were the first to liquefy carbon dioxide at elevated pressures in 1823, but it remained for Charles Thilorier in 1834 to give the earliest description of solid carbon dioxide or solid ice. ${ }^{8}$ The liquid carbon dioxide gas was supplied in steel cylinders under pressure. When the gas was allowed to escape, rapid expansion caused a fall in temperature (the JouleThompson effect) and a fine snow was formed. The snow was easily compressed into various shapes, known as pencils, suitable for different treatments. William Pusey of Chicago used solidified carbon dioxide for the treatment of various skin lesions around the time that liquid air was investigated. ${ }^{9}$ He recommended this cryogen because of its easy availability (thanks to its use by manufacturers of mineral waters), contrary to liquid air, which was very difficult to obtain at that time. By successfully treating naevi, warts and lupus erythematosus, he was amongst the first to recognize the low scarring potential of cryosurgery (although he attributed this to regeneration of residual epidermal cells rather than to collagen's resistance to cold). Major John Hall-Edwards, of Birmingham, a renowned radiotherapist, first described his carbon dioxide collection model in the Lancet in 1911.10 Hall-Edward's monograph, written later in 1913, described in detail the uses of carbon dioxide and methods of collection. ${ }^{11} \mathrm{He}$ described many conditions in which treatment was effective, being particularly struck by the efficacy of carbon dioxide in rodent ulcers. At the same time Cranston-Low, a physician of the Edinburgh skin department, was likewise promoting the use of carbon dioxide snow. ${ }^{12}$ He speculated that the direct injury to tissues, the resultant inflammatory response and local thrombosis all acted together to produce the effects of freezing.

Solid carbon dioxide applied directly to the skin could achieve a surface temperature as low as $-79^{\circ} \mathrm{C}$, which proved very successful for a wide variety of benign skin conditions. Carbon dioxide slush, a mixture of carbon dioxide and acetone, was used extensively for acne. As the use of carbon dioxide snow became more widespread so did the range of conditions treated. De Quervain reported the successful use of carbonic snow for bladder papillomas and bladder cancers in $1917 .{ }^{13}$

\section{Liquid oxygen}

The debate on the best cryogen to use persisted for much of the first half of the twentieth century as more gases were liquefied to obtain deeper cooling temperatures. Liquid oxygen $\left(-182.9^{\circ} \mathrm{C}\right)$ came into clinical use in the 1920 s. Irving and Turnacliff described good results with warts, lichen planus, and other skin conditions. ${ }^{14}$ Although it was readily available in the following years, liquid oxygen was hazardous because it was combustible and eventually became into disuse. In 1948 Kile and Welsh wrote one of the last reports on the use of liquid 
oxygen in a case series of over 1,000 patients with a variety of noncancerous diseases and mucosal diseases, including warts, hemangiomas, keratoses and leukoplakia. ${ }^{15}$

\section{Liquid nitrogen}

Prior to the 1960s, the devices used for cryosurgery were not efficient and were able to freeze only to a depth of several millimeters. Therefore, with a few exceptions, freezing was used primarily for the treatment of superficial layers of undesirable tissue, most often in the fields of dermatology and gynecology. After the Second World War, liquid nitrogen $\left(-196^{\circ} \mathrm{C}\right)$ became freely available and was preferable to liquid oxygen with its explosive potential. In 1950, Allington was the first to bring liquid nitrogen into clinical practice. ${ }^{16}$ He recognized that the properties of liquid nitrogen were very similar to those of liquid air and oxygen. By using a cotton swab he was able to treat various benign lesions but poor heat transfer between swab and skin meant this method was insufficient for tumor treatment. In contrast, Dr Irving S Cooper, an American neurosurgeon based in New York, designed a liquid nitrogen probe already in 1913 that was capable of achieving temperatures of $-196^{\circ} \mathrm{C} .17$ Using this probe he treated Parkinson's disease and other movement disorders by freezing the thalamus and previously inoperable brain tumors. His work led to an explosion of interest in liquid nitrogen and its acceptance as a standard treatment in many specialties.

\section{Cryoapplications and storage facilities}

Arnotts initial design to apply his salt/ice mixture to the skin, consisting of a waterproof cushion for local application, two long flexible tubes to convey water to and from the affected part, a reservoir for the salt/ice mixture and a sump. The ensuing refrigerants were generally applied either by painting directly onto the skin or by use of cotton wool twisted around a piece of cane that had been dipped into the refrigerant of choice. Some ingenious devices were developed including Campbell White's roller for treatment of erysipelas. ${ }^{5}$ Grimmett highlighted the limitations of a cotton wool applicator, showing that the depth of freeze was insufficient to treat tumors. ${ }^{18}$ Whitehouse, a New York dermatologist, developed a spray in 1907 which allowed much lower cooling temperatures. ${ }^{6}$ His simple design consisted of two glass tubes inserted into a cork stopper of a laboratory wash bottle, operated by finger control. Whitehouse used his spray to treat skin lesions including cancers but abandoned it because of the difficulty in limiting the area of the spray. Sir James Dewar solved the problems of transportation and storage of liquefied refrigerants by inventing a flask made of two walls of glass with a vacuum in between. ${ }^{11}$ Even today the containers used for 
refrigerants have much the same design. However, the biggest leap in refrigerant containment and applicability came through the collaborative work of Irving Cooper, and an engineer Arnold Lee. They designed a cryosurgical probe that became the prototype from which every subsequent liquid nitrogen cryosurgical probe was built. ${ }^{19}$ Made of 3 long concentric tubes, the probe was supplied with liquid nitrogen from a pressurized source. The inner tube served as a conduit for liquid nitrogen flow to the tip of the probe, while the space between the inner tube and the middle tube provided a path for the return of gaseous nitrogen from the tip of the probe. The space between the outer tube and the middle tube was vacuum insulated and had a radiative shield, allowing the liquid nitrogen to be conducted without heat loss to the tip of the probe.

Between 1961 and 1970, other cryosurgical apparatuses suitable for office based practice were developed using liquid nitrogen and other cryogenic agents, including nitrous oxide, carbon dioxide, argon, ethyl chloride, and fluorinated hydrocarbons. ${ }^{20}$ Douglas Torre, a dermatologist, used Cooper's apparatus for skin diseases, developing a nitrogen spray device that could also be used with cryoprobe tips of various shapes and sizes, converting the conduit line to a closed system in $1965 .{ }^{21}$ Zacarian developed a hand-held device, the Kryospray, in 1967 and popularized the use of this equipment.22-25 Zacarian's spray allowed one-handed operation with trigger type control, and interchangeable tips permitted variations in spray diameter. Zacarian also developed copper probes that allowed tissue-freezing to depths of up to $7 \mathrm{~mm}$. Amoils developed a liquid nitrogen probe that achieved cooling by expansion. ${ }^{26}$ He performed cataract extraction (cryoextraction) successfully but cooling was slow and temperatures were not low enough for the treatment of a tumor. This system is still widely used in gynaecology and ophthalmology.

\section{Cardiac cryosurgery}

Cryoenergy is used by different specialties and was first evaluated for cardiac surgery in 1964 by Lister et al. In this experimental study cryoenergy was applied to the cardiac conduction tissue of two mongrel dogs by suturing a flat coil over the region of the sinoatrial node and a 4-mm " $U$ "-shaped silver tube near the bundle of His. Sinus node function was depressed by cooling with an alcohol and carbon dioxide mixture at -10 to $-20^{\circ} \mathrm{C}$, whereas at the atrioventricular (AV) node, progressive $\mathrm{AV}$ delay occurred through deeper cooling with high-grade $\mathrm{AV}$ block obtained at $-45^{\circ} \mathrm{C}$. When cooling was discontinued $\mathrm{AV}$ conduction almost immediately recovered, demonstrating for the first time its clinical potential for "cryomapping".

In 1977, Harrison et al.27 introduced cryosurgery using handheld bipolar electrode probes with nitrous oxide as a coolant, by targeting the AV node through an open-chest procedure, cryoenergy was applied first in 20 dogs and 
thereafter in 3 patients with intractable supraventricular arrhythmias. Under cardiopulmonary bypass, complete but reversible AV block was achieved in all patients when the temperature of the cryosurgical probe was lowered to $0^{\circ} \mathrm{C}$ at the His bundle site. Following two or more consecutive freeze-thaw cycles at probe temperatures of $-60^{\circ} \mathrm{C}$ for $90-120$ seconds, AV block became permanent. During long-term follow-up ranging up to 37 months was later reported, with permanent AV block was achieved in 17 of 22 patients. ${ }^{28}$ Additional studies reported similar results. ${ }^{29-31}$ Less invasive maneuvers not requiring extracorporeal bypass were later designed. Bredikis described a technique consisting of two atriotomy incisions; one for digital palpation and the second for the cryoprobe. ${ }^{30,} 32$ Positioning of the cryoprobe was guided by digital orientation of anatomic landmarks, recording electrodes, cryomapping, and/or pressureinduced AV block. Using this method, complete AV block was achieved in $85 \%$ of 34 patients $^{30}$ and $92 \%$ of 72 patients. ${ }^{32}$ Louagie et al. ${ }^{33}$ proposed an alternative epicardial approach via the right coronary fossa. After this pioneering work of cryosurgical ablation to permanently damage AV-conductive tissue, more substrates were targeted to treat a variety of arrhythmias. Gallagher and coworkers $^{34}$ reported the first two cases of successful cryosurgical accessory pathway ablation in 1977. One pathway was concealed and paraseptal and the second manifest and left-sided. Several case series followed, either using an epicardial approach were cryoablation was applied after removal of the AV fat pad, $35-39$ or a percutaneous approach were a special designed probe enabled cryoablation via the coronary sinus. ${ }^{40}$ In 1978, Gallagher et al. ${ }^{41}$ cryosurgically ablated a pharmacologically resistant ventricular tachycardia focus in the anterior right ventricular free wall with three 90 -seconds applications at $-60^{\circ} \mathrm{C}$. A second case was reported the following year. ${ }^{42}$ Cryosurgery has since become a recognized treatment for selected patients with refractory ventricular arrhythmias, ${ }^{29}, 43-47$ often as an adjunct to more extensive surgery including aneurysmectomy, subendocardial resection, encircling endocardial ventriculotomy, coronary artery bypass grafting, and valvular replacement. With cryosurgery alone, Caceres et al. ${ }^{48}$ and others ${ }^{49}$ reported a $93 \%$ event-free follow-up in patients with refractory ventricular tachycardia. These results compare favorably to previous studies that used other surgical modalities for ventricular tachycardia. ${ }^{49-51}$ In addition surgical cryoablation has shown to be successful in less common arrhythmias including nodoventricular tachycardia, ${ }^{52}$ sinoatrial reentrant tachycardia, ${ }^{53}$ bidirectional bundle branch reentry tachycardia, ${ }^{54}$ and fetal malignant tachyarrhythmias..$^{55}$ 


\section{Transvenous cryoablation}

Technical advances in equipment and probe design allowed the introduction of transvenous cryodelivery in a closed-chest procedure in 1991. In 5 miniature swine, Gillette et al. reported complete AV block using an 11-French Dacron woven cryocatheter cooled by pressurized nitrous oxide. ${ }^{56}$ Cryothermia was applied for 3 minutes and repeated up to 3 times. Four of the 5 pigs remained in AV block for 1 hour, while 1 recovered partially with 2:1 AV conduction. Similar to previous cryosurgery specimens, ${ }^{57,58}$ histology showed acute lesions that were sharply demarcated. In a chronic study of 8 swine, successive 3 minutes cryoapplications were delivered to the $\mathrm{AV}$ junction at $-60^{\circ} \mathrm{C}$ via 8 or 11 -French cryocatheters. ${ }^{59}$ Long-term AV block was maintained in 5 of 8 animals. At 6 weeks, well-defined dense lesions were noted histologically, free of inflammation or thrombus formation. Although transcatheter cryolesion formation proved to be feasible, the limited success was attributed to lack of steerability and recording electrodes. Cryocatheter placement required the use of a second catheter to record local signals. Five years later, in 1998, the first animal experiment using a steerable cryocatheter with integrated recording and pacing electrodes was reported. ${ }^{60} \mathrm{~A}$ total of 42 cryoapplications were made in the right and left ventricle of 6 dogs using a 9-French catheter with a 4-mm electrode tip. Cryomapping of the $\mathrm{AV}$ node was also evaluated by sequentially applying lower temperatures to the AV nodal junction. Definite lesions, showing a typical, welldelineated spherical shape, occurred at tip temperatures below $-30^{\circ} \mathrm{C}$. This was supported by the rapid resumption of $1: 1 \mathrm{AV}$ conduction and the lack of any identifiable lesion on gross and microscopic histopathology if freezing was performed above this limit. Unfortunately, due to the early stage of catheter development, only $62 \%$ of all applications reached target temperatures. In a later study of cryomapping providing more detailed electrophysiological measurements, reversible AV nodal effects were achieved in 7 of 8 dogs at a mean tip temperature of $-34^{\circ} \mathrm{C} .{ }^{61}$ Parameters including atrial-His interval, His ventricular interval, Wenckebach cycle length, and AV node effective refractory periods, remained stable up to 56 days after cryomapping of the AV node. Chronic cryoablation lesions, created at a mean tip temperature of $-55^{\circ} \mathrm{C}$, were later characterized in 9 mongrel dogs sacrificed 3 and 6 weeks after ablation. ${ }^{61}$ Histologically, well-demarcated ultrastructurally intact lesions without thrombus were observed. Similar results were obtained with 8.5-French cryocatheters in 6 dogs $^{62}$ and 7 pigs, ${ }^{63}$ supporting the ability of transvenous cryoablation to induce permanent lesions irrespective of the heat sink generated by the circulating blood. Further improvements in transvenous cryocatheter systems such as the use of other refrigerants (Halocarbon $502^{60}$ (Freon) to Genetron AZ-2064-66 to the currently used nitrous oxide ${ }^{67}$ ) and computerized pressure regulation of the refrigerant, permitted higher cooling rates and lower freezing temperatures. 
Since 2001, after more than a century of technical developments and evolving knowledge in cryothermic lesion formation catheter-based cryoablation came into clinical practice. ${ }^{64}$ 


\section{References}

1. Arnott J: On the treatment of cancer by the regulated application of an anaesthetic temperature. London: Churchill 1851, pp.

2. Cailletet L: Recherches sur la liquéfaction des gaz. Ann Chemie Physique 1878; 15:132-144.

3. Pictet R: Mémoire sur la liquéfaction de l'oxygène Ann Chemie Physique 1878; 13:145-227.

4. White AC: Liquid air: its application in medicine and surgery. Med Rec 1899; 56:109-112.

5. White AC: Possibilities of liquid air to the physician. JAMA 1901; 36:426-429.

6. Whitehouse H: Liquid air in dermatology: its indications and limitations. JAMA 1907:371-377.

7. Bowen J, Towle H: Liquid air in dermatology. Med Surg J 1907; 157:561.

8. Roller H, Thilorier M: Thilorier and the first solidification of a "permanent" gas (1835). Isis 1952; 43:109-113.

9. Pusey W: The use of carbon dioxide snow in the treatment of naevi and other lesions of the skin. JAMA 1935:1354-1356.

10. Edwards J: The therapeutic effects of carbon dioxide snow: methods of collecting and application. Lancet 1911; ii:87-90.

11. Hall-Edwards J: Carbon dioxide snow: its therapeutic uses. . London: Simpkin, Marshall, Hamilton, Kent, 1913, pp.

12. Cranston-Low R: Carbonic Acid snow as a therapeutic agent in the treatment of disease of the skin. Edinburgh/London: William Green, 1911, pp.

13. Bracco D: The historic development of cryosurgery. Clin Dermatol 190; 8:1-4.

14. Irvine H, Turnacliffe D: Liquid oxygen in dermatology. Arch Dermatol Syphilol 1929; 19:270280.

15. Kile R, Welsh A: Liquid oxygen in dermatologic practice. Arch Dermatol Syph 1948; 57:57-60.

16. Allington HV: Liquid nitrogen in the treatment of skin diseases. Calif Med 1950; 72:153-155.

17. Cooper IS: Cryogenic surgery: a new method of destruction or extirpation of benign or malignant tissues. N Engl J Med 1963; 268:743-749.

18. Grimmett RH: Liquid nitrogen therapy. Histologic observations. Arch Dermatol 1961; 83:563567.

19. Cooper IS, Lee AS: Cryostatic congelation: a system for producing a limited, controlled region of cooling or freezing of biologic tissues. J Nerv Ment Dis 1961; 133:259-263.

20. Torre D: Alternate cryogens for cryosurgery. J Dermatol Surg 1975; 1:56-58.

21. Torre D: Cutaneous cryosurgery. N Y State J Med 1970; 70:2551-2554.

22. Zacarian S: Cryogencis: the cryolesion and the pathogenisis of cryonecrosis. . In Zacarian S, ed: Cryosurgery for skin cancer and cutaneous disorders. St. Louis: Mosby, 1985, pp. 1-30.

23. Zacarian S: Cryosurgery of tumors of skin cancer and cryogenic techniques in dermatology. Springfield, IL: Charles C. Thomas, 1969,

24. Zacarian S: Cryosurgery of tumors of the skin and oral cavity. Springfield, IL: Charles C. Thomas, 1973,

25. Zacarian S: Cryosurgical advances in dermatology and tumors of the head and neck. Springfield, IL: Charles C. Thomas, 1973,

26. Amoils SP: The Joule Thomson cryoprobe. Arch Ophthalmol 1967; 78:201-207.

27. Harrison L, Gallagher JJ, Kasell J, Anderson RH, Mikat E, Hackel DB, Wallace AG: Cryosurgical ablation of the A-V node-His bundle: a new method for producing A-V block. Circulation 1977; 55:463-470.

28. Klein GJ, Sealy WC, Pritchett EL, Harrison L, Hackel DB, Davis D, Kasell J, Wallace AG, Gallagher JJ: Cryosurgical ablation of the atrioventricular node-His bundle: long-term follow-up and properties of the junctional pacemaker. Circulation 1980; 61:8-15.

29. Garratt C, Camm AJ: The role of cryosurgery in the management of cardiac arrhythmias. Clin Cardiol 1991; 14:153-159.

30. Bredikis J: Cryosurgical ablation of atrioventricular junction without extracorporeal circulation. J Thorac Cardiovasc Surg 1985; 90:61-67. 
31. Camm J, Ward DE, Spurrell RA, Rees GM: Cryothermal mapping and cryoablation in the treatment of refractory cardiac arrhythmias. Circulation 1980; 62:67-74.

32. Bredikis JJ, Bredikis AJ: Surgery of tachyarrhythmia: intracardiac closed heart cryoablation. Pacing Clin Electrophysiol 1990; 13:1980-1984.

33. Louagie YA, Guiraudon GM, Klein GJ, Yee R: Closed heart cryoablation of the His bundle using an anterior septal approach. Ann Thorac Surg 1991; 51:616-619.

34. Gallagher JJ, Sealy WC, Anderson RW, Kasell J, Millar R, Campbell RW, Harrison L, Pritchett EL, Wallace AG: Cryosurgical ablation of accessory atrioventricular connections: a method for correction of the pre-excitation syndrome. Circulation 1977; 55:471-479.

35. Guiraudon GM, Klein GJ, Gulamhusein S, Jones DL, Yee R, Perkins DG, Jarvis E: Surgical repair of Wolff-Parkinson-White syndrome: a new closed-heart technique. Ann Thorac Surg 1984; 37:6771.

36. Rowland E, Robinson K, Edmondson S, Krikler DM, Bentall HH: Cryoablation of the accessory pathway in Wolff-Parkinson-White syndrome: initial results and long term follow up. Br Heart J 1988; 59:453-457.

37. Guiraudon GM, Klein GJ, Sharma AD, Milstein S, McLellan DG: Closed-heart technique for WolffParkinson-White syndrome: further experience and potential limitations. Ann Thorac Surg 1986; 42:651-657.

38. Watanabe S, Koyanagi H, Endo M, Yagi Y, Shiikawa A, Kasanuki H: Cryosurgical ablation of accessory atrioventricular pathways without cardiopulmonary bypass: an epicardial approach for Wolff-Parkinson-White syndrome. Ann Thorac Surg 1989; 47:257-264.

39. Lee AW, Crawford FA, Jr., Gillette PC, Roble SM: Cryoablation of septal pathways in patients with supraventricular tachyarrhythmias. Ann Thorac Surg 1989; 47:566-568.

40. Bredikis J, Bredikis A: Cryosurgical ablation of left parietal wall accessory atrioventricular connections through the coronary sinus without the use of extracorporeal circulation. J Thorac Cardiovasc Surg 1985; 90:199-205.

41. Gallagher JJ, Anderson RW, Kasell J, Rice JR, Pritchett EL, Gault HJ, Harrison L, Wallace AG: Cryoablation of drug-resistant ventricular tachycardia in a patient with a variant of scleroderma. Circulation 1978; 57:190-197.

42. Camm J, Ward DE, Cory-Pearce R, Rees GM, Spurrell RA: The successful cryosurgical treatment of paroxysmal ventricular tachycardia. Chest 1979; 75:621-624.

43. Krafchek J, Lawrie GM, Roberts R, Magro SA, Wyndham CR: Surgical ablation of ventricular tachycardia: improved results with a map-directed regional approach. Circulation 1986; 73:1239-1247.

44. Page PL, Cardinal R, Shenasa M, Kaltenbrunner W, Cossette R, Nadeau R: Surgical treatment of ventricular tachycardia. Regional cryoablation guided by computerized epicardial and endocardial mapping. Circulation 1989; 80:I124-134.

45. Ott DA, Garson A, Cooley DA, McNamara DG: Definitive operation for refractory cardiac tachyarrhythmias in children. J Thorac Cardiovasc Surg 1985; 90:681-689.

46. Guiraudon GM, Thakur RK, Klein GJ, Yee R, Guiraudon CM, Sharma A: Encircling endocardial cryoablation for ventricular tachycardia after myocardial infarction: experience with 33 patients. Am Heart J 1994; 128:982-989.

47. Ott DA, Garson A, Jr., Cooley DA, Smith RT, Moak J: Cryoablative techniques in the treatment of cardiac tachyarrhythmias. Ann Thorac Surg 1987; 43:138-143.

48. Caceres J, Werner P, Jazayeri M, Akhtar M, Tchou P: Efficacy of cryosurgery alone for refractory monomorphic sustained ventricular tachycardia due to inferior wall infarction. J Am Coll Cardiol 1988; 11:1254-1259.

49. Hargrove WC, 3rd, Miller JM, Vassallo JA, Josephson ME: Improved results in the operative management of ventricular tachycardia related to inferior wall infarction. Importance of the annular isthmus. J Thorac Cardiovasc Surg 1986; 92:726-732.

50. Miller JM, Marchlinski FE, Harken AH, Hargrove WC, Josephson ME: Subendocardial resection for sustained ventricular tachycardia in the early period after acute myocardial infarction. Am J Cardiol 1985; 55:980-984. 
51. Cox JL: The status of surgery for cardiac arrhythmias. Circulation 1985; 71:413-417.

52. Silka MJ, Kron J, Cutler JE, Wilson RA, Cobanoglu A: Cryoablation of medically refractory nodoventricular tachycardia. Pacing Clin Electrophysiol 1990; 13:908-915.

53. Kerr CR, Klein GG, Guiraudon GM, Webb JG: Surgical therapy for sinoatrial reentrant tachycardia. Pacing Clin Electrophysiol 1988; 11:776-783.

54. Andress JD, Vander Salm TJ, Huang SK: Bidirectional bundle branch reentry tachycardia associated with Ebstein's anomaly: cured by extensive cryoablation of the right bundle branch. Pacing Clin Electrophysiol 1991; 14:1639-1647.

55. Assad RS, Aiello VD, Jatene MB, Costa R, Hanley FL, Jatene AD: Cryosurgical ablation of fetal atrioventricular node: new model to treat fetal malignant tachyarrhythmias. Ann Thorac Surg 1995; 60:S629-632.

56. Gillette PC, Swindle MM, Thompson RP, Case CL: Transvenous cryoablation of the bundle of His. Pacing Clin Electrophysiol 1991; 14:504-510.

57. Wetstein L, Mark R, Kaplan A, Mitamura H, Sauermelch C, Michelson EL: Nonarrhythmogenicity of therapeutic cryothermic lesions of the myocardium. J Surg Res 1985; 39:543-554.

58. Hunt GB, Chard RB, Johnson DC, Ross DL: Comparison of early and late dimensions and arrhythmogenicity of cryolesions in the normothermic canine heart. J Thorac Cardiovasc Surg 1989; 97:313-318.

59. Fujino H, Thompson RP, Germroth PG, Harold ME, Swindle MM, Gillette PC: Histologic study of chronic catheter cryoablation of atrioventricular conduction in swine. Am Heart J 1993; 125:1632-1637.

60. Dubuc M, Talajic M, Roy D, Thibault B, Leung TK, Friedman PL: Feasibility of cardiac cryoablation using a transvenous steerable electrode catheter. J Interv Card Electrophysiol 1998; 2:285292.

61. Dubuc M, Roy D, Thibault B, Ducharme A, Tardif JC, Villemaire C, Leung TK, Talajic M: Transvenous catheter ice mapping and cryoablation of the atrioventricular node in dogs. Pacing Clin Electrophysiol 1999; 22:1488-1498.

62. Rodriguez LM, Leunissen J, Hoekstra A, Korteling BJ, Smeets JL, Timmermans C, Vos M, Daemen M, Wellens HJ: Transvenous cold mapping and cryoablation of the AV node in dogs: observations of chronic lesions and comparison to those obtained using radiofrequency ablation. J Cardiovasc Electrophysiol 1998; 9:1055-1061.

63. Hoekstra A, de Langen CD, Nikkels PG, Korteling BJ, Bel KJ, Crijns HJ: Prediction of lesion size through monitoring the 0 degree $\mathrm{C}$ isothermic period following transcatheter cryoablation. J Interv Card Electrophysiol 1998; 2:383-389.

64. Dubuc M, Khairy P, Rodriguez-Santiago A, Talajic M, Tardif JC, Thibault B, Roy D: Catheter cryoablation of the atrioventricular node in patients with atrial fibrillation: a novel technology for ablation of cardiac arrhythmias. J Cardiovasc Electrophysiol 2001; 12:439-444.

65. Timmermans C, Rodriguez LM, Van Suylen RJ, Leunissen J, Vos M, Ayers GM, Crijns HJ, Wellens HJ: Catheter-based cryoablation produces permanent bidirectional cavotricuspid isthmus conduction block in dogs. J Interv Card Electrophysiol 2002; 7:149-155.

66. Rodriguez LM, Geller JC, Tse HF, Timmermans C, Reek S, Lee KL, Ayers GM, Lau CP, Klein HU, Crijns HJ: Acute results of transvenous cryoablation of supraventricular tachycardia (atrial fibrillation, atrial flutter, Wolff-Parkinson-White syndrome, atrioventricular nodal reentry tachycardia). J Cardiovasc Electrophysiol 2002; 13:1082-1089.

67. Khairy P, Chauvet P, Lehmann J, Lambert J, Macle L, Tanguay JF, Sirois MG, Santoianni D, Dubuc M: Lower incidence of thrombus formation with cryoenergy versus radiofrequency catheter ablation. Circulation 2003; 107:2045-2050. 



\section{Chapter II}

\section{Catheter-based cryoablation permanently cures patients with common atrial flutter}

Randy Manusama, MD; Carl Timmermans, MD, PhD; Froylan Limon, MD;

Suzanne Philippens, RN; Harry JGM Crijns, MD, PhD; Luz-Maria Rodriguez, MD, PhD

Circulation. 2004;109:1636-1639 


\section{Abstract}

Background: Cryoablation (cryo) has a high success rate in the acute treatment of atrial flutter (AFL), but results of chronic efficacy are lacking. The current study reports the long-term effect of cryo of the cavo-tricuspid isthmus (CTI) in patients with common AFL.

Patients and methods: Thirty-five consecutive patients (28 men; mean age 53 years) underwent cryo of the CTI. In thirty-four patients the AFL had a counterclockwise rotation (cycle length: $242 \pm 43 \mathrm{~ms}$ ). Eleven patients had structural heart disease. Cryo was performed using a $10 \mathrm{~F}$ catheter with 6-mm tip electrode (CryoCor ${ }^{\mathrm{TM}}$ ). Applications (3-5 minutes each) were delivered using a point-bypoint technique to create the ablation line. The acute end-point of the procedure was creation of bi-directional isthmus conduction block and non-inducibility of AFL.

Results: A median of 14 (range 4 to 30) applications at 10 sites (range 14 to 19) were given along the CTI with a mean temperature of $-80.0 \pm 5.0^{\circ} \mathrm{C}$. Mean fluoroscopy and procedure time were $40 \pm 26 \mathrm{~min}$ and $3.0 \pm 1.3$ hours respectively. Thirty-four of the 35 patients were acutely successfully ablated (97\%). After a mean follow-up of $17.6 \pm 6.2$ (range 9.6 to 26.1 ) months, 31 patients (89\%) did not have recurrence of AFL. Three of the four patients with a recurrence of AFL had a second successful procedure. One patient had transient ST-elevation in the inferior leads during cryoapplication.

Conclusion: Cryo produces permanent bi-directional isthmus conduction block of the CTI. Acute and chronic success rates are comparable to radiofrequency ablation. 


\section{Introduction}

Currently, radiofrequency ablation is considered first line therapy for the treatment of atrial flutter (AFL) because of its high success rate and significant improvement in quality of life as compared to conventional medical therapy.1, 2 Advances in cryotechnology have allowed the development of transvenous cryoablation (cryo) catheter systems, able to create transmural lesions in regions with high blood flow. Recently, it was shown that the acute success rate and safety obtained with cryo for AFL is comparable to radiofrequency ablation. ${ }^{3}$ Importantly, when ablating the cavotricuspid isthmus (CTI) ${ }^{3}$ patients feel no pain during cryo in contrast to radiofrequency ablation. To evaluate the safety and efficacy of cryo, long-term follow-up is important. This was the purpose of this study.

\section{Patients and methods}

\section{Patients}

Between June 2001 and May 2002, 35 consecutive patients (28 men; mean age of $53 \pm 11$, range 30 to 73 years) were included. All gave written informed consent for the procedure and the study which was approved by the local hospital Ethics Committee. Twenty-eight patients (80\%) also had a history of atrial fibrillation. In eleven of these patients (31\%) atrial fibrillation organised into AFL during treatment with a class $1 \mathrm{C}$ antiarrhythmic drug $(\mathrm{n}=9)$ or amiodarone $(\mathrm{n}=2)$. Of the 35 patients, 11 (31\%) had structural heart disease, which was either hypertensive $(n=7)$, congestive $(n=1)$, or congenital $(n=3)$. The latter consisted of two atrial septal defects, one of which was surgically corrected, and a ventricular septal defect, which had closed spontaneously by the time of study. One patient was suffering from persistent $\mathrm{AF}$ and developed a tachycardia induced cardiomyopathy. A His-bundle ablation, following a pacemaker implantation was performed in this patient. Left ventricular ejection fraction and left atrial size were measured before the procedure using two-dimensional echocardiography. The mean left ventricular ejection fraction and mean left atrial size were $60.1 \pm 7.94$ (range 33 to 69 ) $\%$ and $4.7 \pm 0.7$ (range 3.8 to 6.2 ) $\mathrm{cm}$ respectively. Three patients had previously failed a radiofrequency ablation procedure. Demographic characteristics of all patients are shown in table 1. 


\section{CHAPTER II}

Table 1 Patient characteristics

\begin{tabular}{lc}
\hline No patients & 35 \\
Age (years) & $53 \pm 11$ \\
Sex (M/F) & $28 / 7$ \\
Structural heart disease & 11 \\
$\quad$ Hypertensive & 7 \\
$\quad$ Dilated & 1 \\
$\quad$ Congenital & 3 \\
Mean left ventricular ejection fraction (\%) & $60.1 \pm 7.9$ \\
Mean left atrial size (cm) & $4.7 \pm 0.7$ \\
Concomitant atrial fibrillation & 24 \\
Patients with implanted pacemaker & 4 \\
Patients with previous RF-attempts & 3 \\
IC AFL & 9 \\
Class III AAD (amiodaron/sotalol/both) & $10 / 8 / 1$ \\
Other (metroprolol/dysopyramide/digitalis) & 13 \\
\hline
\end{tabular}

Abbreviations: $\mathrm{AAD}=$ antiarrhythmic drug, $\mathrm{IC}$ AFL = organisation of atrial fibrillation to atrial flutter during treatment of IC antiarrhythmic drugs, $\mathrm{RF}=$ radiofrequency ablation

Table 2 Electrophysiologic characteristics

\begin{tabular}{lc}
\hline AFL: CCW/CW & $34 / 1$ \\
1C AFL & 11 \\
Cycle length (ms) & $242 \pm 43$ \\
Cardioversion (pts) & 5 \\
$\quad$ Flecainide & 2 \\
$\quad$ External & 1 \\
$\quad$ Internal & 2 \\
Number of freezes & $15 \pm 4$ \\
Number of sites (median) & 10 \\
Temperature ( ${ }^{\circ}$ Celsius) & $-80 \pm 5.0$ \\
Fluoroscopy time (min) & $40 \pm 26$ \\
Procedure time (hours) & $3.2 \pm 1.3$ \\
Acute success & $34(97 \%)$ \\
Recurrence AFL (total) & $4(11 \%)$ \\
AF post-ablation & $15(43 \%)$ \\
$\quad$ New & 0 \\
Recurrent & 15 \\
1C AFL & 6 \\
\hline
\end{tabular}

Abbreviations: $\mathrm{AFL}=$ atrial flutter, $\mathrm{IC} \mathrm{AFL}=$ organisation of atrial fibrillation to atrial flutter during treatment of class IC antiarrhythmic drugs, $\mathrm{AF}=$ atrial fibrillation, pts= patients.

\section{Follow up}

Patients living in the region of Maastricht (the majority of the patients) were followed-up at our outpatient clinic at 1- and, thereafter, every 3 months. For patients, from outside this region, follow-up was obtained by their own referring Cardiologist. In case of documentation of AFL, the patient was again re- 
ferred to our hospital for further evaluation and re-ablation. In patients with antiarrhythmic drug-induced AFL, antiarrhythmic drugs were continued after the ablation procedure. A 24-hour Holter monitor was given immediately after the procedure until hospital discharge and thereafter, if symptoms suggested an arrhythmia recurrence. Patients were instructed to contact our center if they had any symptoms (e.g. palpitations, chest discomfort) which could indicate a recurrence.

\section{Ablation procedure}

All ablation procedures were performed using a similar protocol as used in our center for radiofrequency ablation.2, 4-6 Three multipolar catheters were advanced in the right atrium through insertion of the right femoral vein. One 20pole electrode catheter (2-mm interelectrode spacing, Halo catheter, Biosense Webster, Diamond Bar, CA, USA) was positioned around the tricuspid annulus for sequential activation mapping. A quadripolar catheter and a decapolar catheter were placed at the His-bundle and in the coronary sinus respectively. Cryo was performed using the CryoCor $^{\mathrm{TM}}$ Cardiac Cryoablation System, described previously. ${ }^{7}$ A steerable 10-French bipolar catheter with a 6-mm tip was used in combination with a long venous sheath (St Jude Medical, SL2; 12F; Daig Co, Minnetonka, MN, USA) for mapping and ablation of the CTI.

Entrainment to confirm the isthmus dependence of the AFL circuit, ${ }^{8}$ was performed in patients with only AFL and in patients with AFL and a few episodes of atrial fibrillation. In patients with AFL and frequent atrial fibrillation episodes, entrainment was not performed to avoid induction of atrial fibrillation.

Both catheter-tip temperature and system pressure were monitored throughout the procedure to ensure consistent catheter-tip energy delivery. Linear lesions were created using a point-by-point technique with gradual pullback of the cryocatheter in a ventriculo-atrial fashion. The first application was delivered at the ventricular insertion of the isthmus and applications were continued during 3-5 minutes. In patients where ablation of the posterior isthmus proved insufficient to suppress AFL, an attempt was made to ablate the septal isthmus. After documentation of bi-directional isthmus conduction block, the atrial pacing (from the proximal coronary sinus) protocol (up to three atrial extrastimuli at three pacing cycle lengths and incremental atrial pacing) was performed without and under isoproterenol infusion (1 to $3 \mu \mathrm{g} / \mathrm{min}$ ). ${ }^{9}$ In case of reinduction of AFL or resumption of isthmus conduction, further cryoapplications were delivered.

To determine the presence or absence of a potential learning curve associated with cryoablation, patients were subdivided in two near-equal groups: the first 17 patients treated over the initial ten months, and the 18 patients treated 
thereafter. The fluoroscopy time, number of applications, number of ablation sites and total procedure time were compared for both patient groups.

\section{Statistical analysis}

Values of procedural results are expressed in mean \pm SD. Mann-Whitney nonparametric test was used to signify a learning curve by comparing the first half of the study population with the last one. All values were considered significant at $\mathrm{P}<0.05$.

\section{Results}

In 34 patients (97\%), acute procedural success was achieved. In the remaining patient unidirectional isthmus block and non-inducibility of AFL was demonstrated. This patient had an atrial septal defect with restrictive cardiomyopathy.

All patients had a documented common AFL; thirty-four counterclockwise and one clockwise rotation of the AFL circuit. The median number of freezes needed to obtain the procedure endpoints was 14 , with a median number of 10 (range 4 to 30 ) sites. The average temperature was $-80.0 \pm 5.0$ (range -57 to 90) ${ }^{\circ} \mathrm{C}$ and the mean nadir temperature was $-82.0 \pm 4.6$ (range -64 to $-92^{\circ} \mathrm{C}$. Conversion of atrial fibrillation was undertaken in five patients. Sinus rhythm was obtained by internal cardioversion $(n=2)$, intravenous administration of flecainide $(n=2)$, or flecainide followed by external cardioversion $(n=1)$. Mean fluoroscopy and procedure time were $40 \pm 26$ (range 12 to 152) $\min$ and $3.2 \pm$ 1.3 (range 1 to 6.5 ) hours respectively. Two patients (6\%) needed additional septal ablation to obtain complete isthmus conduction block. Comparing the first group of patients treated (17 pts) to the second group (18 pts), no significant differences were observed as to the number of applications, number of ablation sites and fluoroscopy time $(p>0.05)$. However, the procedure time was significant longer for the first group $(\mathrm{p}<0.001)$ (Figure 1).

\section{Complications}

One patient had anginal complaints with ST-segment elevation in the inferior leads during one cryoapplication in the area of the septal isthmus. The patient fully recovered after stopping the application and the administration of nitroglycerine. Subsequent coronary angiography revealed wall irregularities in the right coronary artery, without significant stenosis. No patients had in-hospital recurrences of their AFL. No thromboembolic complications occurred. There were no major adverse events after the ablation procedure and throughout the follow-up period. 
Procedure time of study population

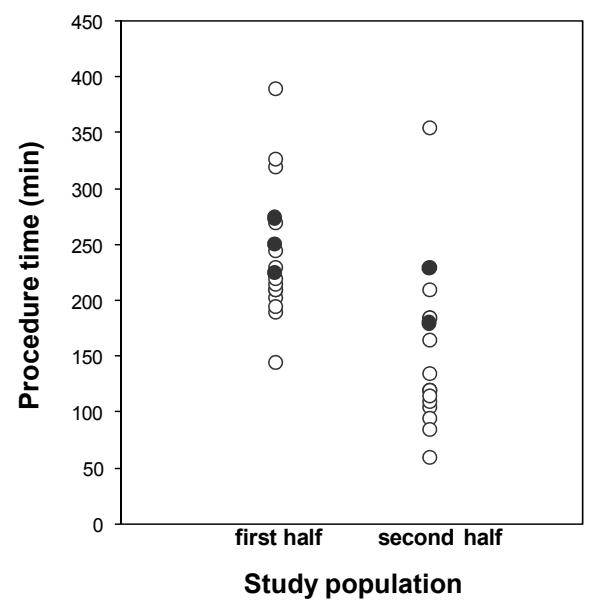

Figure 1 Scatter plot of procedure time of the first 17 (group 1) and the last 18 patients (group 2). There is a clear difference in procedure time with the majority of patients in group 1 treated in $220 \mathrm{~min}$. versus 100 min. in group 2. Black dots represent patients in whom additional cardioversion was performed because of atrial fibrillation at the time of the procedure.

\section{Follow-up}

After a mean follow-up of $17.0 \pm 6.2$ (range 9.6 to 26.1 ) months, 31 patients $(89 \%)$ had no recurrence of AFL. Four patients had a recurrence of AFL after 5, 7,9 , and 14 months respectively and three patients underwent a second ablation. One of them had a failed radiofrequency ablation procedure in the past. After 11, 6 and 5 months respectively, these patients have not shown recurrences of AFL. The remaining patient is awaiting a second cryoablation procedure.

Of the 28 patients with atrial fibrillation prior to the procedure, 15 patients (54\%) continued to have atrial fibrillation episodes after cryoablation of the CTI. In two of these patients the clinical course was complicated by an amiodarone induced hyperthyroidism. No new onset of atrial fibrillation has been reported. Chronic complications were not observed.

\section{Discussion}

The present study supports for the first time, the long-term safety and efficacy of cryo for the treatment of isthmus dependent AFL. Both acute and chronic efficacy was comparable to radiofrequency ablation. Importantly, cryo causes no or minimal pain perception ${ }^{3}$ which is of value during application in the inferior vena cava region when attempting to ablate the posterior isthmus. This is in contrast to radiofrequency ablation, which can be very painful in this region. 3, 10

In our study the long-term results were comparable to those obtained after radiofrequency ablation reporting up to $15 \%$ of AFL recurrences after assess- 
ment of acute bi-directional isthmus conduction block. ${ }^{4-6,11}$ Resumption of AFL mostly occurred in the first months after radiofrequency ablation. ${ }^{9}, 12,13$ In our study $11 \%$ of the study population showed recurrence of AFL despite initial demonstration of bi-directional isthmus conduction block. One patient reported a recurrence of AFL after 14 months. In this patient, previous radiofrequency ablation procedures using an 8-mm catheter and a thermocool catheter were also unsuccessful.

Antiarrhythmic drugs were not withdrawn before the procedure, which could have compromised reliable interpretation of definite bi-directional isthmus conduction block. Class I and III agents are known to depress conduction velocity of myocardial tissue. Temporary block or a critical conduction delay along the CTI at the time of ablation could facilitate re-entry when drug concentration is altered and slow conduction is regained. We previously studied the effect of isoproterenol in the evaluation of bi-directional isthmus conduction block in patients treated with radiofrequency ablation 9 . Despite continuation of antiarrhythmic drugs, isoproterenol was able to identify residual isthmus conduction with subsequently a low AFL recurrence rate.

Lastly, the number of sites needed to obtain bi-directional isthmus conduction block with cryo are comparable to the number required during radiofrequency procedures using an 8-mm catheter tip and the point-by-point technique. ${ }^{9}, 14,15$ Recurrences of AFL in those studies were comparable to those of the current study using cryo, suggesting a similar lesion size.

\section{Procedural considerations}

When the fluoroscopy and the procedure time were compared using cryoablation versus radiofrequency ablation, no differences were observed in fluoroscopy time. If radiofrequency ablation is used with a bi-directional isthmus conduction block as an endpoint, fluoroscopy times vary between 36 and $46 \mathrm{~min},{ }^{9}$, 14,15 which are similar to our results using cryo. In contrast to the fluoroscopy time the total procedure time was long. This may be explained on one hand to the nature of this technology (cryo requires longer ablation times ${ }^{16,17}$ ), and on the other hand to a learning curve in the use of this new technology. This learning curve was demonstrated by a significant decrease in procedure time between the first and the second half of the study population. In addition a good relationship was observed between fluoroscopy and procedure time. Thus increasing experience with the current technique and optimisation in the number of applications required to obtain chronic bi-directional isthmus conduction block may shorten the fluoroscopy and procedure time. 


\section{Complications}

One patient showed temporary ST elevation in the inferior leads, which presumably was caused by coronary spasm considering the angiographic absence of a significant stenosis. Although intramural haemorrhages in the right coronary artery adjacent to the site of lesion along with intraluminal narrowing have been described during radiofrequency ablation ${ }^{18-20}$ the clinical impact of this finding with respect to cryotechnology remains unclear. This patient only had complains during the procedure and remained asymptomatic thereafter.

\section{Study limitations}

As in most of the studies reporting on the long-term outcome after ablation of AFL, a late control electrophysiological study to confirm permanent bidirectional CTI block was not done. Like in our study, follow-up was mainly based on symptom recurrence.

It was beyond the scope and the design of this study to evaluate in detail recurrences of atrial fibrillation after the ablation procedure. While improvement in atrial fibrillation recurrences has been reported after treatment with radiofrequency ablation especially in $1 \mathrm{C}-\mathrm{AFL},{ }^{14}$ the effect of cryo can only be evaluated if frequency and severity of atrial fibrillation recurrences are carefully monitored. Every attempt was made to evaluate a recurrence of AFL. Most of the analysis was dependent on the patient's ability to recognize the arrhythmia, which in some cases was difficult due to concomitant atrial fibrillation or lack of symptoms.

\section{Conclusion}

Cryo produces permanent bi-directional isthmus conduction block of the CTI. Acute and chronic success rates are comparable to radiofrequency ablation. The safety and the chronic results obtained in this study together with the low pain perception $^{3}$ in the CTI might reinforce the clinical use of cryothermia for the treatment of other arrhythmias, especially those originating in regions like the coronary sinus and the atria. 


\section{References}

1. Wellens HJ: Contemporary management of atrial flutter. Circulation 2002; 106:649-652.

2. Natale A, Newby KH, Pisano E, Leonelli F, Fanelli R, Potenza D, Beheiry S, Tomassoni G: Prospective randomized comparison of antiarrhythmic therapy versus first-line radiofrequency ablation in patients with atrial flutter. J Am Coll Cardiol 2000; 35:1898-1904.

3. Timmermans C, Ayers GM, Crijns HJ, Rodriguez LM: Randomized study comparing radiofrequency ablation with cryoablation for the treatment of atrial flutter with emphasis on pain perception. Circulation 2003; 107:1250-1252.

4. Nakagawa H, Lazzara R, Khastgir T, Beckman KJ, McClelland JH, Imai S, Pitha JV, Becker AE, Arruda M, Gonzalez MD, Widman LE, Rome M, Neuhauser J, Wang X, Calame JD, Goudeau MD, Jackman WM: Role of the tricuspid annulus and the eustachian valve/ridge on atrial flutter. Relevance to catheter ablation of the septal isthmus and a new technique for rapid identification of ablation success. Circulation 1996; 94:407-424.

5. Poty H, Saoudi N, Nair M, Anselme F, Letac B: Radiofrequency catheter ablation of atrial flutter. Further insights into the various types of isthmus block: application to ablation during sinus rhythm. Circulation 1996; 94:3204-3213.

6. Hsieh MH, Tai CT, Chiang CE, Tsai CF, Yu WC, Chen YJ, Ding YA, Chen SA: Recurrent atrial flutter and atrial fibrillation after catheter ablation of the cavotricuspid isthmus: a very long-term follow-up of 333 patients. J Interv Card Electrophysiol 2002; 7:225-231.

7. Rodriguez LM, Geller JC, Tse HF, Timmermans C, Reek S, Lee KL, Ayers GM, Lau CP, Klein HU, Crijns HJ: Acute results of transvenous cryoablation of supraventricular tachycardia (atrial fibrillation, atrial flutter, Wolff-Parkinson-White syndrome, atrioventricular nodal reentry tachycardia). J Cardiovasc Electrophysiol 2002; 13:1082-1089.

8. Cosio FG, Lopez Gil M, Arribas F, Palacios J, Goicolea A, Nunez A: Mechanisms of entrainment of human common flutter studied with multiple endocardial recordings. Circulation 1994; 89:2117-2125.

9. Nabar A, Rodriguez LM, Timmermans C, Smeets JL, Wellens HJ: Isoproterenol to evaluate resumption of conduction after right atrial isthmus ablation in type I atrial flutter. Circulation 1999; 99:3286-3291.

10. Cosio FG: Atrial flutter update. Card Electrophysiol Rev 2002; 6:356-364.

11. Anselme F, Saoudi N, Poty H, Douillet R, Cribier A: Radiofrequency catheter ablation of common atrial flutter: significance of palpitations and quality-of-life evaluation in patients with proven isthmus block. Circulation 1999; 99:534-540.

12. Schumacher B, Pfeiffer D, Tebbenjohanns J, Lewalter T, Jung W, Luderitz B: Acute and long-term effects of consecutive radiofrequency applications on conduction properties of the subeustachian isthmus in type I atrial flutter. J Cardiovasc Electrophysiol 1998; 9:152-163.

13. Tai CT, Chen SA, Chiang CE, Lee SH, Wen ZC, Huang JL, Chen YJ, Yu WC, Feng AN, Lin YJ, Ding YA, Chang MS: Long-term outcome of radiofrequency catheter ablation for typical atrial flutter: risk prediction of recurrent arrhythmias. J Cardiovasc Electrophysiol 1998; 9:115-121.

14. Nabar A, Rodriguez LM, Timmermans C, van den Dool A, Smeets JL, Wellens HJ: Effect of right atrial isthmus ablation on the occurrence of atrial fibrillation: observations in four patient groups having type I atrial flutter with or without associated atrial fibrillation. Circulation 1999; 99:1441-1445.

15. Rodriguez LM, Nabar A, Timmermans C, Wellens HJ: Comparison of results of an 8-mm split-tip versus a 4-mm tip ablation catheter to perform radiofrequency ablation of type I atrial flutter. Am J Cardiol 2000; 85:109-112, A109.

16. Rodriguez LM, Leunissen J, Hoekstra A, Korteling BJ, Smeets JL, Timmermans C, Vos M, Daemen M, Wellens HJ: Transvenous cold mapping and cryoablation of the AV node in dogs: observations of chronic lesions and comparison to those obtained using radiofrequency ablation. J Cardiovasc Electrophysiol 1998; 9:1055-1061. 
17. Timmermans C, Rodriguez LM, Van Suylen RJ, Leunissen J, Vos M, Ayers GM, Crijns HJ, Wellens HJ: Catheter-based cryoablation produces permanent bidirectional cavotricuspid isthmus conduction block in dogs. J Interv Card Electrophysiol 2002; 7:149-155.

18. Weiss C, Becker J, Hoffmann M, Willems S: Can radiofrequency current isthmus ablation damage the right coronary artery? Histopathological findings following the use of a long $(8 \mathrm{~mm})$ tip electrode. Pacing Clin Electrophysiol 2002; 25:860-862.

19. Ouali S, Anselme F, Savoure A, Cribier A: Acute coronary occlusion during radiofrequency catheter ablation of typical atrial flutter. J Cardiovasc Electrophysiol 2002; 13:1047-1049.

20. Paul T, Bokenkamp R, Mahnert B, Trappe HJ: Coronary artery involvement early and late after radiofrequency current application in young pigs. Am Heart J 1997; 133:436-440. 



\section{Chapter III}

\section{Single cryothermia applications of less than five minutes produce permanent cavotricuspid isthmus block in humans}

Randy Manusama, MD; Carl Timmermans, MD, PhD; Suzanne Philippens, RN; Harry J.G.M. Crijns, MD, PhD; Gregory M. Ayers, MD;

Luz-Maria Rodriguez, MD, PhD

Heart Rhythm. 2004 Nov;1(5):594-9. 


\section{Abstract}

Objectives: The aim of this study was to compare single-3-minutes (Single-3) with double-3-minutes (Double-3) cryothermia applications for the treatment of atrial flutter (AFL).

Background: Previous animal studies have indicated the need for a double 5minute cryothermal application in order to create large and permanent lesions.

Methods: Forty patients ( $56 \pm 13$ years old) with common AFL (cycle length $229 \pm 35 \mathrm{~ms})$ were randomised to Single-3 $(\mathrm{n}=20)$ or Double-3 $(\mathrm{n}=20)$ cryothermia applications at each site along the cavotricuspid isthmus. Cryoablation was performed with the CryoCor ${ }^{\mathrm{TM}}$ Cryoablation System. A successful procedure was defined as non-inducibility of AFL with the concomitant presence of bidirectional isthmus conduction block under isoproterenol infusion.

Results: All but one patient (95\%) of the Single-3 group and all patients (100\%) of the Double-3 group were successfully ablated. The number of sites needed to create isthmus conduction block was $9 \pm 4$ (Single-3) and $8 \pm 2$ (Double-3) (NS). Fluoroscopy time did not differ between both groups (Single-3: $31 \pm 13$ and Double-3: $36 \pm 17 \mathrm{~min}, \mathrm{NS}$ ). The procedure time of the Single-3 group was significantly shorter compared to the procedure time of the Double-3 group (mean procedure duration $132 \pm 64$ versus $159 \pm 50 \mathrm{~min}, \mathrm{p}<0.04$ ). After a mean follow-up of $10.7 \pm 4.7$ months, two recurrences of AFL occurred in the Double-3 group.

Conclusion: Single cryothermia applications of 3 minutes produce permanent cavotricuspid isthmus conduction block in patients with common AFL and significantly reduce the duration of the procedure. 


\section{Introduction}

Radiofrequency catheter ablation has shown to be highly effective in the treatment of atrial flutter (AFL). ${ }^{1}$ By creating a continuous line of block at the cavotricuspid isthmus, the AFL circuit is interrupted, preventing arrhythmia reoccurrence. ${ }^{1}$ An incomplete ablation line due to regression or insufficient coalescence of successive lesions correlates with a high recurrence rate. ${ }^{2}$ To warrant a stable line of block, several techniques have been investigated, primarily because of their ability to induce large and permanent lesions. ${ }^{3-5}$

Catheter-based cryoablation has been shown to be equally effective to radiofrequency ablation in the treatment of AFL.6, 7 Reports also indicate that cryoablation has several advantages. This includes a low thrombogenicity, ${ }^{8,9} \mathrm{a}$ firm stability of the catheter-tip to the underlying tissue during cryoablation (cryoadherence), ${ }^{10}$ the absence of pain during an application, ${ }^{6,11}$ and the formation of homogeneous, well-delineated lesions. ${ }^{10,12-14}$ However compared to radiofrequency ablation, cryoablation has been associated with long procedure times. ${ }^{15}$

In order to produce large focal lesions, several authors have created lesions by applying cryothermia using double freezes of 5 minutes duration..$^{15,16}$ On the other hand, stable ice ball formation during cryodelivery appears to occur at 3 minutes, ${ }^{14}, 16,17$ and correlates with the maximum amount of tissue injury. ${ }^{14}$ Moreover, histological data have confirmed permanent lesions after single cryothermal applications of 3 minutes. ${ }^{14}$ Such a reduction in number and duration of cryothermal applications could be expected to reduce procedure times while maintaining the high efficacy rate of cryoablation. Therefore, the purpose of our study was to evaluate the effect of a single application of 3 minutes duration versus double applications of 3 minutes when using a point-by-point method to create cavotricuspid isthmus block for the treatment of common AFL and to evaluate the impact of the two schemes on the overall procedure time.

\section{Methods}

\section{Patients}

Forty consecutive patients were referred to our center for ablation of common AFL. The patients were randomly assigned to one of two groups. The first group was to undergo cavotricuspid isthmus cryoablation using single-3-minutes applications (Single-3 group) while the second group was to undergo the same procedure using double-3-minutes applications per site (Double-3 group). Cryoablation was applied in both groups in a point-by-point manner. The hospital ethics committee approved the study, and patients provided informed consent. 
Eighteen patients (90\%) in the Single-3 group and $13(65 \%)$ in the Double-3 group had concomitant atrial fibrillation, including 5 patients who had AFL as the result of atrial fibrillation treatment with class IC or III antiarrhythmic drugs ( $\mathrm{n}=3$ (Single-3) and $\mathrm{n}=2$ (Double-3) patients). Patient characteristics are shown in Table 1 . There were no significant differences with respect to these clinical variables for the two treatment groups.

Table 1 Patient characteristics

\begin{tabular}{|c|c|c|c|}
\hline & Single-3 group & Double-3 group & P-value \\
\hline Patients & 20 & 20 & NS \\
\hline Age & $58 \pm 13(36-83)$ & $56 \pm 14(35-80)$ & NS \\
\hline Men/women & $18 / 2$ & $15 / 5$ & NS \\
\hline Structural heart disease, $\mathrm{n}(\%)$ & $10(50)$ & $11(55)$ & NS \\
\hline Ischemic & 3 & 1 & \\
\hline Hypertensive & 6 & 7 & \\
\hline Valvular & 1 & 1 & \\
\hline Dilated & 2 & 0 & \\
\hline Congenital & 1 & 3 & \\
\hline Left ventricular ejection fraction, $\%$ & $60.6 \pm 7.6(40-75)$ & $60.0 \pm 6.5(46-68)$ & NS \\
\hline Left atrial size, $\mathrm{cm}$ & $4.6 \pm 0.5(38-60)$ & $4.4 \pm 0.5(38-58)$ & NS \\
\hline Concomitant atrial fibrillation, n (\%) & $18(90)$ & $13(65)$ & NS \\
\hline AAD-AFL, n (\%) & $6(30)$ & $3(15)$ & NS \\
\hline Patients with implanted pacemaker, n (\%) & $2(10)$ & $1(5)$ & NS \\
\hline \multicolumn{4}{|l|}{ AAD, $n$} \\
\hline IC AAD & 11 & 7 & NS \\
\hline Class III AAD (amiodaron/sotalol) & $6 / 6$ & $7 / 6$ & NS \\
\hline Other AAD & 1 & 0 & NS \\
\hline
\end{tabular}

Abbreviations: $\mathrm{AAD}=$ antiarrhythmic drugs; $\mathrm{AAD}-\mathrm{AFL}=$ conversion of atrial fibrillation to atrial flutter during treatment of class IC or III antiarrhythmic drugs;

\section{Electrophysiological study and ablation procedure}

The electrophysiological study was performed according to a technique previously defined. ${ }^{18}$ Antiarrhythmic drugs were not discontinued before the procedure. A quadripolar, decapolar and duodecapolar catheter was positioned at the His-bundle, coronary sinus and tricuspid valve annulus, respectively. Isthmus dependency of the flutter circuit was confirmed by entrainment mapping in those patients with lone AFL and in patients with non-dominant atrial fibrillation. In patients with frequent episodes of atrial fibrillation, entrainment was not performed to avoid induction of atrial fibrillation. Cryothermia was delivered with the CryoCor Cryoablation System (CryoCor, Inc), which consists of a console and a 10-French, $6.5-\mathrm{mm}$ tip catheter. The cryocatheter was used in combination with a long venous sheath for stable mapping and ablation performance. Individual applications were given at successive sites along the cavotricuspid isthmus, starting from the tricuspid annulus bringing the line towards the inferior vena caval orifice. Cryothermia was applied for 3 minutes 
once (Single-3 group) or twice (Double-3 group) at every site, allowing recovery of temperature to approximately body temperature between each application in the Double-3 group. Procedural success was evaluated by assessment of bidirectional cavotricuspid isthmus conduction block and non-inducibility of AFL under isoproterenol infusion. ${ }^{1}$ Additional cryoapplications were delivered after reinduction of AFL or resumption of isthmus conduction. Procedure time was defined as the time interval between the first femoral vein puncture for catheter insertion and the last cryoapplication.

\section{Follow-up}

Follow-up was conducted in our outpatient clinic at 1 month and thereafter every 3 months. For those patients living outside the region of Maastricht, the 3monthly follow-up was obtained from the referring cardiologist after the first visit at 1 month. A 24-hour Holter-recording was made immediately after the procedure and thereafter if symptoms were suggestive for arrhythmia recurrence. Every patient was instructed to contact our center or the nearest hospital in case of a suspected arrhythmia recurrence. In case of ECG documented recurrence of AFL, the patient was referred for a second procedure. Antiarrhythmic drugs were continued only in patients with antiarrhythmic drug-induced AFL and concomitant atrial fibrillation.

\section{Statistical analysis}

Results are expressed in mean \pm SD. Statistical analysis was performed using the Student $t$-test for unpaired data. Dichotomous variables were compared using chi-square test with Yates' correction. To compare fluoroscopy and procedure time between both treatment groups, Mann-Whitney non-parametric test was used. All values were considered significant at $p<0.05$.

\section{Results}

Common AFL was documented in every patient; counterclockwise AFL in all patients of the Single-3 group and in all but one patient of the Double-3 group. Table 2 summarizes the electrophysiological characteristics and ablation parameters of the 40 patients. In the majority of the patients (18 patients in the Single-3 group and 20 patients in the Double-3 group), ablation was performed during coronary sinus pacing. Nineteen patients (95\%) of the Single-3 group and all patients of the Double- 3 group achieved the acute endpoints and were considered successfully ablated. The unsuccessfully ablated patient had atrial fibrillation treated with a class IC antiarrhythmic drug that caused the development of AFL. During the electrophysiological study, this patient was unable to 
maintain sinus rhythm after several attempts to electrically and chemically convert atrial fibrillation. Therefore, the procedure was prematurely terminated. The mean number of applications needed to obtain the procedural endpoints was $9 \pm 4$ in the Single- 3 group and $16 \pm 3(\mathrm{p}<0.001)$ in the Double- 3 group at 9 \pm 4 and $8 \pm 2$ (NS) sites, respectively. During the electrophysiological study atrial fibrillation was induced in 7 patients of the Single- 3 group and 4 patients of the Double-3 group (NS), all having a history of concomitant atrial fibrillation. Cardioversion was required in 10 patients; 6 of the Single- 3 group and 4 of the Double-3 group (NS). All cardioversions resulted in sinus rhythm using only internal cardioversion ( $n=1$; Single-3 group: 1 ), only flecainide infusion $(n=6$; Single-3 group: 3 ) or a combination ( $n=3$; Single-3 group: 2 ). Fluoroscopy time was $30.6 \pm 14 \mathrm{~min}$ in the Single- 3 and $36.2 \pm 17 \mathrm{~min}$ in the Double-3 group (NS). Total procedure time was $132 \pm 64 \mathrm{~min}$ in the Single- 3 group and $159 \pm 50 \mathrm{~min}$ in the Double-3 group ( $\mathrm{p}<0.04)$. The cumulative procedure time of the individual patients in both treatment groups is depicted in Figure 1. No complications were observed during the procedure.

Table 2 Electrophysiological characteristics and ablation parameters

\begin{tabular}{lccc}
\hline & Single-3 group & Double-3 group & P-value \\
\hline AFL, CCW/CW & $20 / 1$ & $20 / 0$ & NS \\
Cycle length, ms & $222 \pm 30(150-280)$ & $236 \pm 40(180-360)$ & NS \\
Cardioversion, $\mathrm{n}(\%)$ & $6(30)$ & $4(20)$ & $\mathrm{NS}$ \\
$\quad$ Flecainide & 3 & 3 & $\mathrm{NS}$ \\
$\quad$ Internal & 1 & 0 & $\mathrm{NS}$ \\
$\quad$ Both & 2 & 1 & $\mathrm{NS}$ \\
Number of freezes & $9 \pm 4(4-19)$ & $16 \pm 3(10-22)$ & $\mathrm{NS}$ \\
Number of sites, median & $9 \pm 4(4-19)$ & $8 \pm 2(5-11)$ & $P<0.001$ \\
Temperature, ${ }^{\circ}$ Celcius & $-79 \pm 6.0(73-87)$ & $-80 \pm 4.0(70-88)$ & $\mathrm{NS}$ \\
Fluoroscopy time, min & $30 \pm 28(12-57)$ & $36 \pm 17(12-68)$ & $\mathrm{NS}$ \\
Procedure time, min & $132 \pm 64(60-365)$ & $159 \pm 50(75-240)$ & $\mathrm{NS}$ \\
Acute success, $\mathrm{n}(\%)$ & $19(95)$ & $20(100)$ & $P<0.04$ \\
Recurrence AFL, $\mathrm{n}(\%)$ & 0 & $2(10)$ & $\mathrm{NS}$ \\
Follow-up (months) & $11 \pm 4.7(3-17)$ & $11 \pm 4.8(3-18)$ & $\mathrm{NS}$ \\
Atrial fibrillation post-ablation, $\mathrm{n}(\%)$ & $9(45)$ & $8(40)$ & $\mathrm{NS}$ \\
$\quad$ New onset & 0 & 2 & $\mathrm{NS}$ \\
$\quad$ Recurrent, $\mathrm{n}$ & 9 & 6 & $\mathrm{NS}$ \\
AAD-AFL, $\mathrm{n}$ & 4 & 2 & \\
\hline
\end{tabular}

Abbreviations: $\mathrm{AFL}=$ atrial flutter; $\mathrm{AAD}-\mathrm{AFL}=$ conversion of atrial fibrillation to atrial flutter during treatment of class IC or III antiarrhythmic drugs; CCW = counterclockwise; $\mathrm{CW}=$ clockwise

\section{Follow-up}

After a mean follow-up of $10.7 \pm 4.7$ (range $3.3-18.0$ ) months, two patients of the Double-3 group had a recurrence of AFL 5 and 8 months post-ablation, respectively. The second patient has only recently undergone a repeat procedure for which there exists inadequate follow-up to comment on arrhythmia cure. 
One of the two patients underwent a second ablation procedure and has been arrhythmia free through 9 months of follow-up. During repeat electrophysiologic study, both patients showed gaps at the atrioventricular junction that required 1 and 3 applications, respectively, to again meet acute procedural endpoints. Nine patients (45\%) in Single-3 group and 8 patients (40\%) in Double-3 group (40\%) had recurrent atrial fibrillation postablation. No complications, either procedural or AFL related, were observed during the follow-up period.

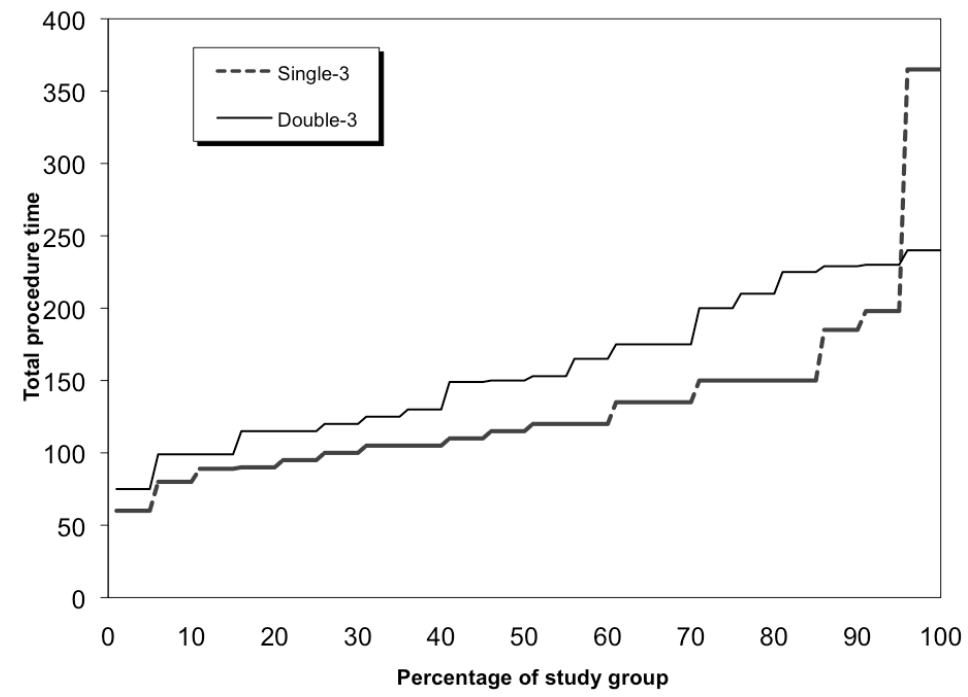

Figure 1 Procedure time with cumulative percentage of total number of patients in Single-3 group (dotted line) versus Double group (solid line). Note that $40 \%$ of patients in Single 3-group and 10\% of Double-3 group are treated within approximately 100 minutes.

\section{Discussion}

The main findings of our study are that single cryoapplications to create bidirectional cavotricuspid isthmus block using a point-by-point technique, prevent recurrences of AFL and are as effective as when double applications are delivered to each site. Furthermore, the duration of each cryoapplication could be reduced to 3 minutes without affecting the (acute and chronic) ablation outcome as compared to the 5 minutes applications reported in the literature..$^{15}$ This resulted in a significant reduction of the duration of a cryoablation procedure for the treatment of isthmus dependent AFL.

Cryothermia has shown to be an effective therapy in arrhythmia treatment.19-21 The creation of large and transmural lesions that persist over time is desirable during ablation therapy. Viable myocardial tissue within a lesion or at 
deeper myocardial layers form a substrate for reentrant arrhythmias by means of anisotropic conduction ${ }^{22}$. Cryoablation has shown to induce well-delineated and homogeneous lesions that lack arrhythmogenicity and are transmural. ${ }^{10,12 \text {, }}$ 14, 23, 24 However, reports in the literature indicate that cryoablation procedures are longer in duration as compared to corresponding procedures completed with radiofrequency energy. Two variables of energy delivery during catheter based cryoablation, application duration and number, are likely to be the cause of this difference.

Early transthoracic surgery showed a close relationship between cryolesions and probe size, ${ }^{14}$ low cooling temperatures ${ }^{25}$ and more importantly the temperature of the underlying tissue. ${ }^{26}$ Thermal conduction during cryodelivery was facilitated if the target tissue was precooled either by systemic cooling during cardioplegia ${ }^{26}$ or a preceding application at the same site. ${ }^{25,}{ }^{27}$ Repetition of cryoablation in the operation room has been shown to create larger lesions compared to single applications. This may be because previously damaged cell structures acting as a syncititium enhance thermal conductivity of the following cold front. ${ }^{25}$ However, in the current study, single applications of 3 minutes were sufficient to establish bidirectional cavotricuspid isthmus conduction block. The high efficacy supported by the absence of AFL recurrences indicates that a stable ablation line has formed with adequate coalescence between individual cryolesions. Post-mortem studies have shown that in human hearts, the average size of the cavotricuspid isthmus region measures $34 \mathrm{~mm}$ in length and $6 \mathrm{~mm}$ in depth. ${ }^{28}$ It is possible in the study reported herein, that the combination of low temperatures along with a larger catheter tip size resulted in deeper lesions than previously have been reported, hence allowing for shorter duration, fewer in number, applications with the same end result of complete cavotricuspid isthmus block.

A study in dogs, where single 4 minutes applications were delivered at mean temperatures of $-45^{\circ} \mathrm{C}$ in combination with a $4-\mathrm{mm}$ catheter tip, showed variable lesion depth (1.3 to $6.6 \mathrm{~mm}$ ) in the right and left ventricle. ${ }^{29}$ The largest lesions were created at temperatures below $-50^{\circ} \mathrm{C}$. Another recent study reported similar lesion depth when comparing single cryoapplications delivered from a 7-French catheter with repeated cryoapplications from a 9-French catheter in 22 mongrel dogs. ${ }^{9}$ Temperatures of -60 during 4 minutes of cryodelivery were able to induce deep lesions that on average penetrated approximately 5 $\mathrm{mm}$ of myocardial tissue. ${ }^{9}$ Cooling temperatures beyond $-50^{\circ} \mathrm{C}$ are known to cause cell death by irreversible damage of intracellular organelles. These changes occur irrespective of the ablation protocol used. ${ }^{30}$ Ablation temperatures lower than $-50^{\circ} \mathrm{C}$ may enhance passive conduction to deeper myocardial layers and increase the duration of thawing. Massive dilation of hyperpermeable microvasculature in response to slow thawing, creates a hypo-osmotic state of extracellular compartments. ${ }^{30,} 31$ These events may set off a higher degree of inwards fluid shift, causing more cellular membranes to disrupt by intracellular 
swelling. Intralesional cell death is further enhanced by the contraction of surrounding (micro) vessels during freezing, followed by intraluminal swelling and protrusion of endothelial cells after thawing. ${ }^{31}$ In the current study cryoapplications were delivered using a $6.5-\mathrm{mm}, 10$-French catheter tip at $-80^{\circ} \mathrm{C}$ which may account for the ability to shorten the duration of applications and deliver one instead of two applications per site.

The number of sites was not significantly different between the treatment groups while efficacy remained unaffected. In the cavotricuspid isthmus the cumulative effect of a repeated cryoapplication appears to be minimal and is overcome by partial overlap between sequential applications, exposing cells to a double freeze-thaw cycle in the single application group.

Patients treated with single cryoapplications showed a significant reduction in procedure time compared to repeated cryodelivery. Initial studies using double cryoapplications for 4 to 5 minutes, resulted in procedures for the treatment of typical AFL with average procedure times lasting more than 4 hours. ${ }^{15}$ Increasing operator experience in addition to the decrease in application duration likely resulted in the shorter procedure times observed in the present study. Importantly due to these aspects cryoablation requires procedure times similar to those reported in previous studies of conventional radiofrequency ablation of common AFL (procedure times varying between 160 and 200 minutes). ${ }^{1,5}, 18$ In fact there is a decrease of 30 minutes in procedure time when single instead of repeated applications are used, with nearly $40 \%$ of patients treated within approximately 100 minutes.

\section{Study limitation}

Although the majority of the study population remained free from AFL recurrences, permanent cavotricuspid isthmus conduction block indicating continuous transmural lesions was not confirmed by a repeated electrophysiological study.

\section{Conclusion}

This study demonstrated that single cryoapplications of 3 minutes are sufficient to create permanent cavotricuspid isthmus block. These modifications (fewer applications per site and 3-minutes application times) in the cryoablation protocol showed a significant reduction in total procedure time as compared to multiple cryoapplications delivered at each site. With these protocol modifications, cryoablation of isthmus dependent AFL can be completed in a procedure of comparable duration as those reported with radiofrequency ablation. 


\section{References}

1. Nabar A, Rodriguez LM, Timmermans C, Smeets JL, Wellens HJ: Isoproterenol to evaluate resumption of conduction after right atrial isthmus ablation in type I atrial flutter. Circulation 1999; 99:3286-3291.

2. Schumacher B, Pfeiffer D, Tebbenjohanns J, Lewalter T, Jung W, Luderitz B: Acute and long-term effects of consecutive radiofrequency applications on conduction properties of the subeustachian isthmus in type I atrial flutter. J Cardiovasc Electrophysiol 1998; 9:152-163.

3. Marrouche NF, Schweikert R, Saliba W, Pavia SV, Martin DO, Dresing T, Cole C, Balaban K, Saad E, Perez-Lugones A, Bash D, Tchou P, Natale A: Use of different catheter ablation technologies for treatment of typical atrial flutter: acute results and long-term follow-up. Pacing Clin Electrophysiol 2003; 26:743-746.

4. Rodriguez LM, Nabar A, Timmermans C, Wellens HJ: Comparison of results of an 8-mm split-tip versus a 4-mm tip ablation catheter to perform radiofrequency ablation of type I atrial flutter. Am J Cardiol 2000; 85:109-112, A109.

5. Jais P, Haissaguerre M, Shah DC, Takahashi A, Hocini M, Lavergne T, Lafitte S, Le Mouroux A, Fischer B, Clementy J: Successful irrigated-tip catheter ablation of atrial flutter resistant to conventional radiofrequency ablation. Circulation 1998; 98:835-838.

6. Timmermans C, Ayers GM, Crijns HJ, Rodriguez LM: Randomized study comparing radiofrequency ablation with cryoablation for the treatment of atrial flutter with emphasis on pain perception. Circulation 2003; 107:1250-1252.

7. Manusama R, Timmermans C, Limon F, Philippens S, Crijns HJ, Rodriguez LM: Catheter-based cryoablation permanently cures patients with common atrial flutter. Circulation 2004; 109:1636-1639.

8. van Oeveren W, Crijns HJ, Korteling BJ, Wegereef EW, Haan J, Tigchelaar I, Hoekstra A: Blood damage, platelet and clotting activation during application of radiofrequency or cryoablation catheters: a comparative in vitro study. J Med Eng Technol 1999; 23:20-25.

9. Khairy P, Chauvet P, Lehmann J, Lambert J, Macle L, Tanguay JF, Sirois MG, Santoianni D, Dubuc $\mathrm{M}$ : Lower incidence of thrombus formation with cryoenergy versus radiofrequency catheter ablation. Circulation 2003; 107:2045-2050.

10. Timmermans C, Rodriguez LM, Van Suylen RJ, Leunissen J, Vos M, Ayers GM, Crijns HJ, Wellens HJ: Catheter-based cryoablation produces permanent bidirectional cavotricuspid isthmus conduction block in dogs. J Interv Card Electrophysiol 2002; 7:149-155.

11. Skanes AC, Yee R, Krahn AD, Klein GJ: Cryoablation of atrial arrhythmias. Card Electrophysiol Rev 2002; 6:383-388.

12. Rodriguez LM, Leunissen J, Hoekstra A, Korteling BJ, Smeets JL, Timmermans C, Vos M, Daemen M, Wellens HJ: Transvenous cold mapping and cryoablation of the AV node in dogs: observations of chronic lesions and comparison to those obtained using radiofrequency ablation. J Cardiovasc Electrophysiol 1998; 9:1055-1061.

13. Klein GJ, Sealy WC, Pritchett EL, Harrison L, Hackel DB, Davis D, Kasell J, Wallace AG, Gallagher JJ: Cryosurgical ablation of the atrioventricular node-His bundle: long-term follow-up and properties of the junctional pacemaker. Circulation 1980; 61:8-15.

14. Hunt GB, Chard RB, Johnson DC, Ross DL: Comparison of early and late dimensions and arrhythmogenicity of cryolesions in the normothermic canine heart. J Thorac Cardiovasc Surg 1989; 97:313-318.

15. Rodriguez LM, Geller JC, Tse HF, Timmermans C, Reek S, Lee KL, Ayers GM, Lau CP, Klein HU, Crijns HJ: Acute results of transvenous cryoablation of supraventricular tachycardia (atrial fibrillation, atrial flutter, Wolff-Parkinson-White syndrome, atrioventricular nodal reentry tachycardia). J Cardiovasc Electrophysiol 2002; 13:1082-1089.

16. Skanes AC, Dubuc M, Klein GJ, Thibault B, Krahn AD, Yee R, Roy D, Guerra P, Talajic M: Cryothermal ablation of the slow pathway for the elimination of atrioventricular nodal reentrant tachycardia. Circulation 2000; 102:2856-2860. 
17. Dubuc M, Roy D, Thibault B, Ducharme A, Tardif JC, Villemaire C, Leung TK, Talajic M: Transvenous catheter ice mapping and cryoablation of the atrioventricular node in dogs. Pacing Clin Electrophysiol 1999; 22:1488-1498.

18. Nabar A, Rodriguez LM, Timmermans C, van den Dool A, Smeets JL, Wellens HJ: Effect of right atrial isthmus ablation on the occurrence of atrial fibrillation: observations in four patient groups having type I atrial flutter with or without associated atrial fibrillation. Circulation 1999; 99:1441-1445.

19. Holman WL, Ikeshita M, Douglas JM, Jr., Smith PK, Lofland GK, Cox JL: Ventricular cryosurgery: short-term effects on intramural electrophysiology. Ann Thorac Surg 1983; 35:386-393.

20. Gallagher JJ, Anderson RW, Kasell J, Rice JR, Pritchett EL, Gault HJ, Harrison L, Wallace AG: Cryoablation of drug-resistant ventricular tachycardia in a patient with a variant of scleroderma. Circulation 1978; 57:190-197.

21. Camm J, Ward DE, Spurrell RA, Rees GM: Cryothermal mapping and cryoablation in the treatment of refractory cardiac arrhythmias. Circulation 1980; 62:67-74.

22. Spach MS, Josephson ME: Initiating reentry: the role of nonuniform anisotropy in small circuits. J Cardiovasc Electrophysiol 1994; 5:182-209.

23. Wetstein L, Mark R, Kaplan A, Mitamura H, Sauermelch C, Michelson EL: Nonarrhythmogenicity of therapeutic cryothermic lesions of the myocardium. J Surg Res 1985; 39:543-554.

24. Wadhwa MK, Rahme MM, Dobak J, Li H, Wolf P, Chen P, Feld GK: Transcatheter cryoablation of ventricular myocardium in dogs. J Interv Card Electrophysiol 2000; 4:537-545.

25. Gill W, Fraser J, Carter DC: Repeated freeze-thaw cycles in cryosurgery. Nature 1968; 219:410413.

26. Markovitz LJ, Frame LH, Josephson ME, Hargrove WC, 3rd: Cardiac cryolesions: factors affecting their size and a means of monitoring their formation. Ann Thorac Surg 1988; 46:531-535.

27. Ohkawa S, Hackel DB, Mikat EM, Gallagher JJ, Cox JL, Sealy WC: Anatomic effects of cryoablation of the atrioventricular conduction system. Circulation 1982; 65:1155-1162.

28. Cabrera JA, Sanchez-Quintana D, Ho SY, Medina A, Anderson RH: The architecture of the atrial musculature between the orifice of the inferior caval vein and the tricuspid valve: the anatomy of the isthmus. J Cardiovasc Electrophysiol 1998; 9:1186-1195.

29. Dubuc M, Talajic M, Roy D, Thibault B, Leung TK, Friedman PL: Feasibility of cardiac cryoablation using a transvenous steerable electrode catheter. J Interv Card Electrophysiol 1998; 2:285292.

30. Gage AA, Baust J: Mechanisms of tissue injury in cryosurgery. Cryobiology 1998; 37:171-186.

31. Lustgarten DL, Keane D, Ruskin J: Cryothermal ablation: mechanism of tissue injury and current experience in the treatment of tachyarrhythmias. Prog Cardiovasc Dis 1999; 41:481-498. 



\section{Chapter IV}

\section{Typical atrial flutter can effectively be treated using single one-minute cryoapplications: results from a repeat electrophysiological study}

Randy Manusama, MD; Carl Timmermans, MD, PhD; Laurent Pison, MD;

Suzanne Philippens RN; David Perez MD and Luz-Maria Rodriguez, MD, PhD

J Interv Card Electrophysiol. 2009 Oct;26(1):65-72. 


\section{Abstract}

Purpose: Catheter-based cryoablation (cryo) has proven to be as effective as radiofrequency energy (RF) ablation for the treatment of arrhythmias. Nevertheless, the duration of cryo applications has been reported as being significantly longer than RF applications.

Methods: Thirty-seven consecutive patients (28 men; mean age $59 \pm 14$ years) with typical atrial flutter (AFL) underwent cryo of the cavotricuspid isthmus (CTI). Applications of 1 minute were delivered with a 10-French, 10-mm tipped catheter (CryoCor ${ }^{\mathrm{TM}}$ ). If bidirectional CTI block was not obtained after 12 oneminute applications, applications of 3 minutes were selectively delivered to areas of conduction breakthrough. The endpoint of the procedure was creation of bidirectional CTI block and non-inducibility of AFL.

Results: A median of 7 (range 3 to 12) one-minute applications were given along the CTI with a mean temperature of $-88.6 \pm 2.3^{\circ} \mathrm{C}$. Mean fluoroscopy and procedure time were $27 \pm 14 \mathrm{~min}$ and $110 \pm 28 \mathrm{~min}$ respectively. Five patients required additional three-minutes applications; in 1 patient an overextended ablation catheter prevented the completion of the index-procedure. The acute success rate of the index-procedure was 97\%. In 12/24 patients, 2 with AFL recurrence, resumption of CTI conduction was found 4 months post-ablation. In all patients bidirectional CTI block was re-obtained after a median of 1 oneminute application. No additional AFL recurrences occurred, after a mean follow-up of $37 \pm 3$ (range 30 to 44 ) months.

Conclusions: Cryo of AFL can successfully be performed using the same application duration as used for RF ablation. Both acute and long-term results are comparable to RF ablation. AFL recurrences occurred in only a minority of patients with resumption of CTI conduction. 


\section{Introduction}

Catheter-based cryoablation (cryo) has proven to be an effective, safe and versatile tool for arrhythmia treatment. Despite several advantages, it still requires relatively long procedure times compared to radiofrequency energy (RF) catheter ablation. Historically, lesion formation during cryo is subject to several factors including cooling temperature, ${ }^{1}$ application duration, repetition of an application $^{2}$ and convective heating, 3,4 the combination of which can considerably prolong procedure time. We have shown that a high efficacy can be maintained when single instead of repeated freeze thaw cycles are used, which results in a significant reduction of the procedure time..$^{5}$ Other studies have shown that typical atrial flutter (AFL) can be effectively treated when the duration of a cryoapplication is reduced from 5 to 2 minutes. ${ }^{6-9}$ However, it is unknown if procedural and long-term efficacy remain unaffected if short cryoapplication times (similar to RF) are used. Biomedical engineering has enabled deeper cooling temperatures and catheter refinements that allow for a reduction of the application duration. Other factors like contact pressure, catheter-tip orientation and tip-size also play an important role in cryo. ${ }^{10,11}$ These developments in cryotechnology may have rendered short application times effective. The purpose of the current study was to prospectively evaluate the acute and long-term efficacy of cryo for AFL using single one-minute applications.

\section{Patients and methods}

\section{Patients}

Thirty-seven consecutive patients ( 28 men; mean age of $59 \pm 14$, range 18 to 78 years) were included. In 23 patients the AFL burden could be assessed. This burden of clinical AFL was documented for a median of 8 months, ranging from 1 to 105 months. Ten patients required two or more cardioversions at the emergency department. In the remaining 14 patients total AFL burden could not be determined.

The study was approved by the hospital ethics committee and informed consent was obtained from all patients for both the index-procedure and a repeat electrophysiological study scheduled 4 months after the index-procedure. The demographic characteristics of the patients are shown in table 1. Twentyfour patients (65\%) also had a history of atrial fibrillation. In four of these patients $(17 \%)$ atrial fibrillation organised into AFL during treatment with class $1 \mathrm{C}$ anti-arrhythmic drugs (AAD). 
Table 1 Demographics

\begin{tabular}{lc}
\hline Patients & 37 \\
Age, years & $59 \pm 14$ \\
Sex, M/F & $28 / 9$ \\
Structural heart disease, $\mathrm{n}$ & 24 \\
$\quad$ Hypertensive & 10 \\
$\quad$ Ischemic & 4 \\
$\quad$ Dilated & 3 \\
Valvular & 1 \\
$\quad$ Hypertensive/ischemic & 3 \\
$\quad$ Hypertensive/Dilated & 2 \\
$\quad$ Hypertensive/Valvular & 1 \\
Mean left ventricular ejection fraction, \% & $54 \pm 15$ \\
Mean left atrial size, mm & $45 \pm 7$ \\
Concomitant atrial fibrillation, $n$ & 24 \\
Pacemaker/ICD, $\mathrm{n}$ & $4 / 2$ \\
IC AFL, $\mathrm{n}$ & 4 \\
Class III AAD (amiodaron/sotalol/both), n & $6 / 10 / 1$ \\
Other AAD, n & 16 \\
\hline
\end{tabular}

Abbreviations: $\mathrm{n}=$ number of patients; $\mathrm{AAD}=$ anti-arrhythmic drugs; $\mathrm{IC}$ AFL = organisation of atrial fibrillation to atrial flutter during treatment of IC antiarrhythmic drugs; ICD = intracardiac defibrillator

\section{Ablation procedure}

The ablation procedure was performed according to a technique previously defined ${ }^{7}$. AAD were not discontinued before the procedure. All patients were studied in the fasting state under local anaesthesia. Intravenous heparin was given as a $100 \mathrm{IU} / \mathrm{kg}$ bolus dose directly after insertion of the venous sheath, and the activated clotting time was kept at 300-350 seconds by additional heparin bolus throughout the remainder of the procedure.

Three multipolar catheters were advanced in the right atrium through insertion of a femoral vein. One 20-pole electrode catheter (2-mm interelectrode spacing, Halo catheter, Biosense Webster, Diamond Bar, CA, USA) was positioned around the tricuspid annulus for sequential activation mapping. A quadripolar catheter and a decapolar catheter were placed at the His-bundle and in the coronary sinus respectively. Cryo was performed using the CryoCor ${ }^{\mathrm{TM}} \mathrm{Car}-$ diac Cryoablation System. ${ }^{7}$ A steerable 10-French bipolar catheter with a 10-mm tip was used in combination with a long venous sheath (St Jude Medical, SL2; 12-F; Daig Co, Minnetonka, MN, USA) for mapping and ablation of the cavotricuspid isthmus (CTI). After initial fluoroscopic positioning of the ablation catheter at the CTI, all subsequent repositioning was done with the aid of anatomic (fluoroscopic) and electrophysiological guidance. The 12-lead ECG and intracardiac electrograms were recorded and stored by the BARD Labsystem Pro. Electrograms were analyzed at a gain setting of 0.1 to $0.2 \mathrm{mV} / \mathrm{cm}$ and at a sweep speed of 100 to $200 \mathrm{~mm} / \mathrm{s}$. Entrainment to confirm isthmus dependency of the 
AFL circuit was performed in patients with only AFL and in patients with AFL and a few episodes of atrial fibrillation. In patients with AFL and frequent atrial fibrillation episodes, entrainment was not performed to avoid induction of atrial fibrillation. If atrial fibrillation was present an attempt was made to regain sinus rhythm by means of flecainide infusion and/or internal or external cardioversion. Both catheter-tip temperature and system pressure were monitored throughout the procedure to ensure consistent catheter-tip energy delivery. Linear lesions were created at a target temperature of $-90^{\circ} \mathrm{C}$, using single oneminute cryoapplications in a ventriculo-atrial fashion, starting at the tricuspid annulus edge. If a complete line of block was not achieved within 12 one-minute applications, additional three-minutes applications were used. This cut-off value was used based on our previous experience with an 8-mm tipped RF catheter where a mean of 12 applications were necessary to obtain CTI block. ${ }^{12}$ After documentation of bidirectional isthmus conduction block, incremental atrial pacing from the proximal coronary sinus was performed without and with isoproterenol infusion ( 1 to $3 \mu \mathrm{g} / \mathrm{min}$ ) to induce AFL. Thirty minutes were taken to monitor CTI reconduction after CTI block was obtained. On the resumption of CTI conduction, further cryoapplications were delivered until complete block was obtained again, whereafter another 30-minutes observation was used to confirm CTI block. As stated above, a maximum of 12 one-minute applications (including all applications prior to isoproterenol infusion) were allowed to meet procedural endpoints. Thereafter, three-minutes applications were used.

Procedural endpoints were the assessment of bidirectional CTI block and non-inducibility of AFL. Procedure time was defined as the time interval between the first femoral vein puncture for catheter insertion and the last cryoapplication.

\section{Post-ablation management}

A 24-hour Holter monitor was given immediately after the procedure until hospital discharge and thereafter, if symptoms suggested an arrhythmia recurrence. Only in patients with pre-existing atrial fibrillation, AAD were continued after the ablation procedure. Oral anticoagulation was started the day of the ablation. After 3 months the necessity for long-term anticoagulation was reassessed by the number of AFL/atrial fibrillation recurrences and the presence of risk factors for thromboembolic complications. Patients living in the region of Maastricht were followed-up at our outpatient clinic at 1- and, thereafter, every 3 months. For patients, from outside this region, follow-up was obtained by the referring Cardiologist. In case of documentation of AFL, the patient was again referred to our hospital for further evaluation and re-ablation. All patients were instructed to contact our center or the nearest hospital if they had any symptoms (e.g. palpitations, chest discomfort), which could indicate a recurrence. Electrophysiological re-evaluation was performed either after 4 months and/or 
if there was a recurrence of AFL. In case of resumption of isthmus conduction a second ablation was performed using one-minute applications at areas of conduction breakthrough in an attempt to regain complete bidirectional CTI block. The electrograms were observed from the ablation catheter-tip just before the delivery of energy. The amplitude of the atrial and ventricular component was used for gap localization along the CTI (ventricle, atrioventricular groove, atrium and atrium-inferior vena cava transition). Conduction times measured during the electrophysiological re-evaluation were not compared directly to those obtained during the index-procedure, since identical electrode positions could not be guaranteed.

\section{Statistical analysis}

All data are expressed in mean \pm SD or median and range. To compare baseline characteristics between patients with persistent CTI block and those with CTI reconduction an unpaired $t$-test was used for continuous variables and the chisquare (or Fisher's exact) test for categorical variables. When normality and equal variance analyses failed, a Mann-Whitney rank sum test was used instead of an unpaired $t$-test. For differences between patients with persistent CTI block, CTI reconduction and undetermined CTI conduction (no repeat electrophysiological study) a Kruskal-Wallis test was used for continuous variables and the chi-square test for categorical variables. The significance level was set at $\mathrm{p}<0.05$.

\section{Results}

Details of the electrophysiological study and cryo procedure are summarized in Table 2. All patients had a documented typical AFL. In one patient an overextended cryoablation catheter necessitated the use of RF ablation to complete the procedure. This patient was excluded from further analysis. In another patient an abnormal atrial anatomy prevented adequate cannulation of the coronary sinus prolonging fluoroscopy time. In this patient 11 one-minute applications were delivered to observe isthmus conduction delay before the procedure was prematurely terminated. This patient did not show any AFL recurrence during 40 months of follow-up.

The median number of one-minute freezes needed to obtain the procedural endpoints was 7 (range 3-12). Five patient (14\%) required additional threeminutes applications (median 2, range 2-5). The average temperature during one-minute cryodelivery was $-88.6 \pm 2.3$ (range -83 to -93 ) ${ }^{\circ} \mathrm{C}$ and the mean nadir temperature was $-89.0 \pm 2.3$ (rang -85 to -93 ) ${ }^{\circ} \mathrm{C}$. Isoproterenol infusion was used in all but three patients, in whom repeated bouts of atrial fibrillation already occurred during atrial pacing. Nine patients $(25 \%)$ showed recovery of 
isthmus conduction during isoproterenol infusion. In all patients bidirectional CTI block could be re-established after a median of 2 one-minute applications (range 1-3; 8 patients), and 2 three-minute applications. No additional applications were required during a second observation period.

Table 2 Electrophysiological characteristics of the index-procedure

\begin{tabular}{lc}
\hline AFL, CCW/CW & $34 / 3$ \\
Cycle length, ms & $252 \pm 44$ \\
Patients requiring cardioversion, & 8 \\
$\quad$ Chemical, and & 3 \\
$\quad$ Electrical & 8 \\
Successful 1-minute-application, $\mathrm{n}$ & $31 / 36(86 \%)$ \\
Number of 1-minute-applications & $7 \pm 2$ \\
Temperature, ${ }^{\circ} \mathrm{C}$ & $-88 \pm 2$ \\
Fluoroscopy time, min & $27 \pm 14$ \\
Procedure time, min & $110 \pm 28$ \\
Acute success, n & $35 / 36(97 \%)$ \\
Recurrence AFL, $\mathrm{n}$ & $2 / 36(6 \%)$ \\
\hline
\end{tabular}

Abbreviations: $\mathrm{AFL}=$ atrial flutter; $\mathrm{CCW}=$ counterclockwise, $\mathrm{CW}=$ clockwise; $\mathrm{n}=$ number of patients

Cardioversion of atrial fibrillation was performed in 8 patients. Sinus rhythm was obtained by internal cardioversion $(n=2)$, external cardioversion $(n=3)$, or intravenous administration of flecainide followed by external cardioversion $(\mathrm{n}=3)$. Mean fluoroscopy and procedure time were $27 \pm 14$ (range 8 to 58) and $110 \pm 28$ (range 61 to 180 ) minutes respectively.

\section{Follow-up}

After a mean follow-up of $37 \pm 3$ (range 30 to 44 ) months, a recurrence of AFL was registered in only 2 patients (6\%), 2 and 3 months after the indexprocedure respectively. Eleven patients declined a repeated electrophysiological study, despite previous informed consent and one patient died of a non-cardiac cause 2 months after the index-procedure. A total of 24 patients underwent a repeated electrophysiological study including both patients with AFL recurrence. In these two patients, the arrhythmia terminated after 1 and 2 oneminute cryoapplications at the atrioventricular groove. Complete bidirectional CTI block was seen in 12 patients (50\%) even though significant fewer cryoapplications were used at the index-procedure compared to those patients that showed resumption of CTI conduction ( $\mathrm{P}=0.004$; table 3$)$. Furthermore, no three-minutes applications had been required during the index-procedure for those patients who underwent a repeat electrophysiological study.

In the majority of patients in whom isthmus reconduction was observed, gaps were found at the atrioventricular groove (58\%). Details concerning their 
second ablation procedure are depicted in table 4. AFL occurred in four patients: in two patients AFL recurred (as mentioned above) and in the other two patients AFL was induced with incremental atrial pacing. Procedural endpoints were met in all patients after a median of 1 one-minute application (range 1-3) without the need of additional applications after isoproterenol infusion. The patient did not report any discomfort during cryodelivery. ${ }^{13}$ No complications were seen, including groin hematomas or pseudo-aneurysm formation despite the large diameter of the sheath used.

Of the 24 patients with atrial fibrillation prior to the procedure, 6 patients $(25 \%)$ underwent additional pulmonary vein isolation during follow-up because of recurrent symptomatic episodes.

Table 3 Baseline characteristics of CTI conduction properties

\begin{tabular}{lccc}
\hline & \multicolumn{2}{c}{ Repeat EPS } & No repeat EPS \\
& CTI block & CTI conduction & Undetermined \\
\hline Patients & 12 & 12 & 12 \\
Age, years & $56 \pm 18(18-78)$ & $63 \pm 10(51-77)$ & $57 \pm 12(25-71)$ \\
Concomitant AF, $\mathrm{n}$ & 7 & 10 & 7 \\
LA size, mm & $45 \pm 10(29-63)$ & $43 \pm 3(38-47)$ & $46 \pm 9(30-58)$ \\
AFL, CCW/CW & $10 / 2$ & $12 / 0$ & $11 / 1$ \\
AFL cycle length, ms & $261 \pm 54(190-328)$ & $251 \pm 59(180-360)$ & $245 \pm 30(200-300)$ \\
Successful 1-minute applications, $\mathrm{n}$ & $6 \pm 2(3-8)^{*} \ddagger$ & $8 \pm 2(5-12)$ & $8 \pm 4(4-12)$ \\
Additional 3-minutes applications, $\mathrm{n}$ & $0 \ddagger$ & 0 & 5 \\
Reconduction during isoprotenerol & $6 \neq$ & 2 & 1 \\
Temperature, $\mathrm{o} C$ & $-86 \pm 2(-81--90)$ & $-87 \pm 3(-83--94)$ & $-87 \pm 1(-85--88)$ \\
Fluoroscopy time, min & $21 \pm 12(8-54)^{*} \ddagger$ & $26 \pm 6(16-43)$ & $39 \pm 20(11-78)$ \\
Procedure time, min & $99 \pm 22(67-134)$ & $110 \pm 24(73-145)$ & $119 \pm 42(61-180)$ \\
Acute success, $\mathrm{n}(\%)$ & $12(100)$ & $12(100)$ & $11(92)$ \\
Recurrence AFL, $\mathrm{n}(\%)$ & $0 \ddagger$ & $2(17)$ & 0 \\
Follow-up, months & $38 \pm 4(30-41)$ & $38 \pm 5(31-47)$ & $36 \pm 4(30-41)$ \\
\hline
\end{tabular}

EPS = electrophysiological study; $\mathrm{AF}=$ atrial fibrillation; $\mathrm{n}=$ number of patients; $\mathrm{LA}=$ left atrium; $\mathrm{AFL}=$ atrial flutter; $\mathrm{CCW}=$ counterclockwise; $\mathrm{CW}=$ clockwise

* $\mathrm{P}<0.05$ compared to patients with CTI conduction

$\ddagger \mathrm{P}<0.05$ compared to patients with or undetermined CTI conduction

\section{Discussion}

\section{Major findings}

The present study demonstrates that a reduction in application duration as low as 1 minute is feasible during cryo of AFL, resulting in shorter procedure times compared to previous cryoablation protocols, ${ }^{5-8}$ while maintaining similar clinical efficacy. Although a substantial number of patients revealed resumption of CTI conduction 4 months after cryo, AFL recurred in only 2 patients (6\%). 


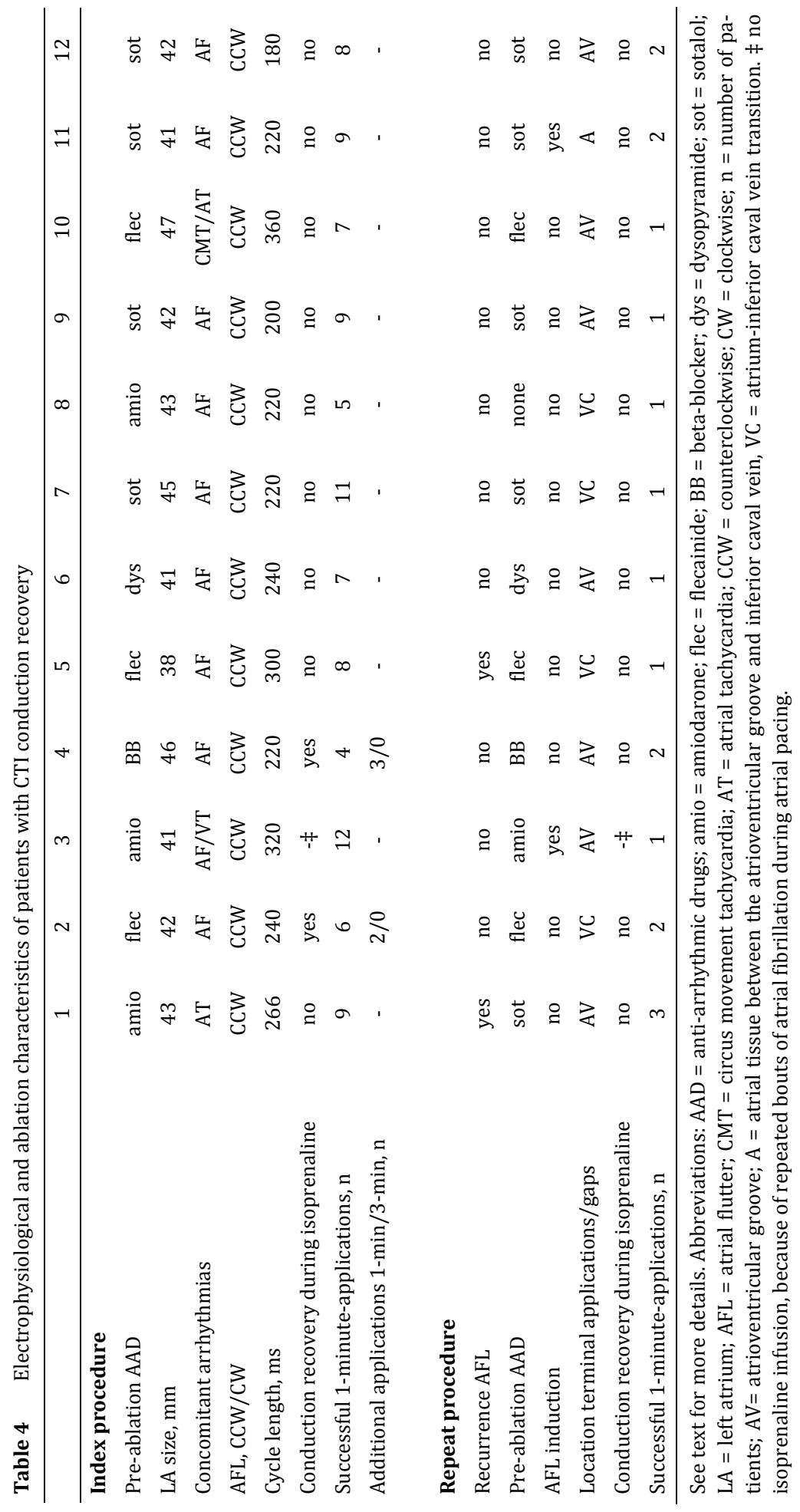




\section{Refinements in cryothermia: cryo vs. cryo}

As opposed to early catheter development using smaller catheter-tips and higher nadir temperatures, 6, 8, 9, 14 current equipment presented herein enables large lesion formation reflected by stable CTI conduction block at the minimum duration of cryodelivery. Applications were delivered using a 10-F, 10-mm catheter-tip at a mean temperature of $-88.6^{\circ} \mathrm{C}$ the combination of which allowed a decrease in the duration of cryodelivery as low as 1 minute per application per site. Lesion formation during cryothermia is a complex process involving the synergetic effects of the initiated expanding cold front during freezing and its anticipated thawing. As a result shifts in membrane permeability and osmotic state inflict irreversible cell damage by massive intracellular swelling ultimately leading to membrane disruption and loss of cell integrity. Ablation temperatures beyond $-50^{\circ} \mathrm{C}$ are known to cause irreversible tissue damage ${ }^{15}$ and may enhance passive conduction to deeper myocardial layers. Deep cooling temperatures may also delay total thaw duration augmenting the deleterious effects of affected frozen cells. In addition, contraction of surrounding (micro) vessels as tissue temperature decreases may further add to cell decay. ${ }^{15}$ Cryo at mean tiptemperatures of $-88.6^{\circ} \mathrm{C}$ obtained in our study have not been previously reported and may have an advantage regarding the abovementioned cumulative effects.

The repetition of a cryoapplication supported by evidence from cryosurgery $^{2}, 16$ has long been advocated for percutaneous applications, since it is known to enhance tissue injury. This may be because previously damaged cell structures act as a synctitium to facilitate thermal conductivity of the following cold front thereby allowing deep penetration and subsequently more tissue loss. $^{2}$ In conjunction with recent reports, ${ }^{6,8,14}$ our study supports the reduction in number of applications per site during transvenous cryodelivery either being the result of site specific cryoredundancy or differences in biophysics compared to its extra-luminal counterpart.

Contrary to 1 minute of single cryodelivery used in this study, ablation protocols from previous studies used at least 2 minutes per application and allowed an increase in application time up to 5 minutes to obtain acute and long-lasting success.6,8,9,14 Furthermore, the number of applications necessary to maintain CTI block used in these studies was similar compared to our study indicating equal lesion formation. Counterintuitively, in our study patients with stable CTI block required significant fewer applications compared to patients that showed conduction recovery, suggesting that other factors like CTI anatomy (e.g. pouchlike configuration $)^{17}$ and catheter-tip orientation may also be important. In an experimental model, Tse et al. ${ }^{18}$ favoured the use of long application times, repetition of applications and horizontal positioning of the catheter-tip in order to gain maximal tissue injury. Even at maximum target temperatures of approximately $-78^{\circ} \mathrm{C}$ obtained by single 2.5 -minutes applications in combination with a 6.5-mm catheter-tip, lesion geometry could be sufficient to override CTI dimen- 
sions $^{19}$ thus prohibiting excess cryodelivery and its attendant delay in procedure time.

\section{CTI conduction recovery}

In the current study, a large proportion of patients showed isthmus reconduction, without a recurrence of AFL. Resumption of CTI conduction is not infrequently seen, but only a few studies systematically re-evaluated CTI conduction. While complete CTI block is associated with a high long-term success, most studies have focussed on AFL recurrences, withholding possible conduction recovery incapable of AFL re-initiation. Anselme et al. ${ }^{20}$ reported conduction recovery in up to $45 \%$ of patients (18/40) treated with RF 1 month after the index-procedure. The recurrence of AFL was low, though might have been obscured at early re-evaluation where wound healing may still be in progress. Schumacher et al. ${ }^{21}$ performed a repeat electrophysiological study in 38/41 patients one year after RF ablation. The authors used non-inducibility of AFL regardless of CTI block as the primary endpoint. Only 2/22 patients experienced AFL recurrence after previous confirmation of bidirectional CTI block, contrary to the $7 / 13$ and $6 / 6$ patients with either unidirectional block or only $\geq 10 \mathrm{~ms}$ CTI delay respectively. This high incidence of AFL recurrence may be due to differences in primary endpoints and the lack of isoproterenol infusion ${ }^{22}$ during the observation period, which proved effective in $25 \%$ of our patients. Montenero et al. ${ }^{14}$ reported a CTI recovery rate of $31 \%, 3$ months after treatment with cryo. While the authors considered this as a possible reservoir for AFL reinitiation, no AFL recurrence was reported during 9 months of follow-up. These data confirm that CTI conduction recovery does not necessarily imply AFL recurrence and that CTI block after 3 months likely precludes future recovery. In our study population, 2 patients without recurrent AFL were susceptible to AFL induction, suggesting a higher recurrence rate than we described. One cannot exclude the possibility that the high CTI reconduction rate was due to the short cryoapplication time. Moreover, early re-ablation could in part have prevented future AFL from re-occurring, thereby masquerading a higher AFL recurrence rate. On the other hand, no resumption of AFL was found during substantial long-term follow-up even though $30 \%$ of patients declined re-evaluation. This may indicate either stable CTI block or sufficient CTI delay to prevent maintenance of a reentry circuit in the right atrium. Deprived blood supply and differences in cell-to-cell (mal) orientation ${ }^{23}$ may have altered conduction properties of the remaining viable cells and subsequently their critical coupling necessary for the development of AFL. The abovementioned effects may have also increased the action potential duration of embedded viable cells thereby influencing their susceptibility and dose-response to AAD. ${ }^{24,}{ }^{25}$ In addition, one may hypothesize that some patients with sufficient CTI delay may have had at least in 
part AF secondary to degeneration of AFL, thereby decreasing the amount of reinitiated AFL. ${ }^{26}$

Gaps were mainly found at the level of the tricuspid valve ridge emphasizing the need for adequate catheter alignment to the underlying tissue to obtain maximum lesion size. Although cryoadherence facilitates catheter stability during freezing initial positioning prior to delivery remains vital. The pouch-like configuration of the isthmus may hamper an optimal tip-tissue interface necessary to attain sufficient injury of deeper myocardial layers. Possibly longer applications or repeated ones are required in this region to prevent future recurrences.

\section{Cryoablation vs. RF ablation}

By lowering single freeze duration in conjunction with a $10-\mathrm{mm}$ catheter-tip, the procedure time was comparable to the procedure time obtained by conventional RF ablation using 4- or 8-mm catheter-tips. ${ }^{12,}$ 13, 27 Shorter RF ablation times have been reported when using a maximal voltage-guided approach. One has to consider that procedure time is not always adequately defined and a 30minute waiting period is not uniformly included.

In addition, the mean number of applications necessary to obtain bidirectional CTI block was not different from that required during conventional RF delivery. ${ }^{21}$ Fluoroscopy time was also comparable to RF, suggesting a similar time span for catheter handling27 More importantly, these parameters could be adjusted to RF standards without compromising acute (97\%) and long-term (94\%) efficacy.

\section{Study limitations}

The current study was conducted in a small group of patients. Only two-thirds of the study population agreed to undergo re-evaluation, which may have biased the observed CTI conduction recovery and its relation to AFL recurrences. As in most studies reporting on long-term efficacy of AFL, follow-up was mainly based on symptoms. Therefore, we cannot exclude a higher recurrence rate due to asymptomatic episodes of AFL.

\section{Conclusions}

Cryo of AFL can successfully be performed with one-minute applications, using a $10-\mathrm{mm}$ catheter-tip, resulting in short procedure times. Both acute and longterm results are comparable to RF ablation. A high CTI reconduction rate was observed at follow-up but was not associated with a similar degree of AFL re- 
currences. The clinical relevance of this finding could not be answered by this study.

\section{References}

1. Holman WL, Ikeshita M, Douglas JM, Jr., Smith PK, Cox JL: Cardiac cryosurgery: effects of myocardial temperature on cryolesion size. Surgery 1983; 93:268-272.

2. Gill W, Fraser J, Carter DC: Repeated freeze-thaw cycles in cryosurgery. Nature 1968; 219:410413.

3. Dubuc M, Talajic M, Roy D, Thibault B, Leung TK, Friedman PL: Feasibility of cardiac cryoablation using a transvenous steerable electrode catheter. J Interv Card Electrophysiol 1998; 2:285292.

4. Pilcher TA, Saul JP, Hlavacek AM, Haemmerich D: Contrasting effects of convective flow on catheter ablation lesion size: cryo versus radiofrequency energy. Pacing Clin Electrophysiol 2008; 31:300-307.

5. Manusama R, Timmermans C, Philippens S, Crijns HJ, Ayers GM, Rodriguez LM: Single cryothermia applications of less than five minutes produce permanent cavotricuspid isthmus block in humans. Heart Rhythm 2004; 1:594-599.

6. Feld GK, Daubert JP, Weiss R, Miles WM, Pelkey W: Acute and long-term efficacy and safety of catheter cryoablation of the cavotricuspid isthmus for treatment of type 1 atrial flutter. Heart Rhythm 2008; 5:1009-1014.

7. Manusama R, Timmermans C, Limon F, Philippens S, Crijns HJ, Rodriguez LM: Catheter-based cryoablation permanently cures patients with common atrial flutter. Circulation 2004; 109:1636-1639.

8. Kuniss M, Kurzidim K, Greiss H, Berkowitsch A, Sperzel J, Hamm C, Pitschner HF: Acute success and persistence of bidirectional conduction block in the cavotricuspid isthmus one month post cryocatheter ablation of common atrial flutter. Pacing Clin Electrophysiol 2006; 29:146-152.

9. Thornton AS, Janse P, Alings M, Scholten MF, Mekel JM, Miltenburg M, Jessurun E, Jordaens L: Acute success and short-term follow-up of catheter ablation of isthmus-dependent atrial flutter; a comparison of $8 \mathrm{~mm}$ tip radiofrequency and cryothermy catheters. J Interv Card Electrophysiol 2008; 21:241-248.

10. Tse HF, Ripley KL, Lee KL, Siu CW, Van Vleet JF, Pelkey WL, Lau CP: Effects of temporal application parameters on lesion dimensions during transvenous catheter cryoablation. J Cardiovasc Electrophysiol 2005; 16:201-204.

11. Montenero AS, Bruno N, Antonelli A, Mangiameli D, Barbieri L, Andrew P, Zumbo F: Comparison between a 7 French $6 \mathrm{~mm}$ tip cryothermal catheter and a 9 French $8 \mathrm{~mm}$ tip cryothermal catheter for cryoablation treatment of common atrial flutter. J Interv Card Electrophysiol 2005; 13:59-69.

12. Rodriguez LM, Nabar A, Timmermans C, Wellens HJ: Comparison of results of an 8-mm split-tip versus a 4-mm tip ablation catheter to perform radiofrequency ablation of type I atrial flutter. Am J Cardiol 2000; 85:109-112, A109.

13. Timmermans C, Ayers GM, Crijns HJ, Rodriguez LM: Randomized study comparing radiofrequency ablation with cryoablation for the treatment of atrial flutter with emphasis on pain perception. Circulation 2003; 107:1250-1252.

14. Montenero AS, Bruno N, Antonelli A, Mangiameli D, Barbieri L, Andrew P, Murphy O, O'Connor S, Zumbo F: Long-term efficacy of cryo catheter ablation for the treatment of atrial flutter: results from a repeat electrophysiologic study. J Am Coll Cardiol 2005; 45:573-580.

15. Gage AA, Baust J: Mechanisms of tissue injury in cryosurgery. Cryobiology 1998; 37:171-186.

16. Ohkawa S, Hackel DB, Mikat EM, Gallagher JJ, Cox JL, Sealy WC: Anatomic effects of cryoablation of the atrioventricular conduction system. Circulation 1982; 65:1155-1162. 
17. Okumura Y, Watanabe I, Ashino S, Kofune M, Yamada T, Takagi Y, Kawauchi K, Okubo K, Hashimoto K, Shindo A, Sugimura H, Nakai T, Saito S: Anatomical characteristics of the cavotricuspid isthmus in patients with and without typical atrial flutter: Analysis with two- and threedimensional intracardiac echocardiography. J Interv Card Electrophysiol 2006; 17:11-19.

18. Tse HF, Lau CP: Impact of duration of cryothermal application on clinical efficacy of pulmonary vein isolation using transvenous cryoablation. Pacing Clin Electrophysiol 2005; 28:839-843.

19. Cabrera JA, Sanchez-Quintana D, Ho SY, Medina A, Anderson RH: The architecture of the atrial musculature between the orifice of the inferior caval vein and the tricuspid valve: the anatomy of the isthmus. J Cardiovasc Electrophysiol 1998; 9:1186-1195.

20. Anselme F, Frederiks J, Papageorgiou P, Monahan KM, Epstein LM, Spach MS, Josephson ME: Nonuniform anisotropy is responsible for age-related slowing of atrioventricular nodal reentrant tachycardia. J Cardiovasc Electrophysiol 1996; 7:1145-1153.

21. Schumacher B, Pfeiffer D, Tebbenjohanns J, Lewalter T, Jung W, Luderitz B: Acute and long-term effects of consecutive radiofrequency applications on conduction properties of the subeustachian isthmus in type I atrial flutter. J Cardiovasc Electrophysiol 1998; 9:152-163.

22. Nabar A, Rodriguez LM, Timmermans C, Smeets JL, Wellens HJ: Isoproterenol to evaluate resumption of conduction after right atrial isthmus ablation in type I atrial flutter. Circulation 1999; 99:3286-3291.

23. Spach MS: The role of cell-to-cell coupling in cardiac conduction disturbances. Adv Exp Med Biol 1983; 161:61-77.

24. Perez FJ, Wood MA, Schubert CM: Effects of gap geometry on conduction through discontinuous radiofrequency lesions. Circulation 2006; 113:1723-1729.

25. Kenigsberg DN, Khanal S, Kowalski M, Krishnan SC: Prolongation of the QTc interval is seen uniformly during early transmural ischemia. J Am Coll Cardiol 2007; 49:1299-1305.

26. Roithinger FX, Karch MR, Steiner PR, SippensGroenewegen A, Lesh MD: Relationship between atrial fibrillation and typical atrial flutter in humans: activation sequence changes during spontaneous conversion. Circulation 1997; 96:3484-3491.

27. Schwartzman D, Callans DJ, Gottlieb CD, Dillon SM, Movsowitz C, Marchlinski FE: Conduction block in the inferior vena caval-tricuspid valve isthmus: association with outcome of radiofrequency ablation of type I atrial flutter. J Am Coll Cardiol 1996; 28:1519-1531. 


\section{Chapter V \\ Comparison of a $6.5-\mathrm{mm}, 10-\mathrm{mm}$ and 15-mm cryoablation catheter-tip for the treatment of common atrial flutter}

Randy Manusama, MD; Carl Timmermans, MD, PhD; Maud van der Schoot, MD;

Suzanne Philippens, RN; Jillian Allen, BS; Luz-Maria Rodriguez, MD, PhD

Submitted for publication 


\section{Abstract}

Purpose: Radiofrequency catheter ablation using a large catheter-tip has proven to have superior procedural efficacy compared to a conventional small catheter-tip. For catheter-based cryoablation (cryo) only a few studies have investigated the effect of large tip-sizes. This study evaluates the safety and efficacy of cryo of the cavotricuspid isthmus (CTI) using a 6.5-mm, a 10-mm and a novel 15-mm tip for the treatment of typical atrial flutter (AFL).

Methods: Forty-five consecutive patients (age $60 \pm 13$, range 21 - 86 years) with common AFL underwent cryo of the CTI. Single applications of 3 minutes were delivered at each site along the CTI. The first 15 patients were treated using a $6.5-\mathrm{mm}$ catheter-tip, the next 15 patients received cryo using a $10-\mathrm{mm}$ catheter-tip and the last 15 patients were treated using a 15 -mm catheter-tip.

Results: Baseline characteristics of the 3 groups were comparable. The overall acute success rate was $89 \%$ and there was no difference with respect to the tipelectrode size $(\mathrm{p}>0.05)$. Fewer applications were required for a $10-\mathrm{mm}(6 \pm 2$, range 3 - 7) and a 15 -mm ( $6 \pm 1$, range $4-8)$, compared to a 6.5 -mm catheter-tip $(8 \pm 3$, range $4-14 ; p<0.05)$. Procedure time was significantly shorter with the largest tip electrode ( $89 \pm 26 \mathrm{~min}$., versus $132 \pm 28 \mathrm{~min}$ ( 6.5 -mm tip), $\mathrm{p}<0.05$ ). No complications occurred. After a mean follow-up of $51 \pm 5$ months, 43 patients (96\%) were without recurrence of AFL.

Conclusions: Large cryo tip-electrodes require fewer applications to create bidirectional CTI block, without compromising safety and efficacy. Compared to a conventional $6.5-\mathrm{mm}$ tip, a significant decrease in fluoroscopy and procedure time was obtained by using a $15-\mathrm{mm}$ electrode tip, which may encourage its future implementation. 


\section{Introduction}

From its first introduction till its current performance, the use of cryothermia in invasive arrhythmia treatment has made enormous strides. Initially considered as a versatile tool to treat cardiac arrhythmias during cardiosurgery, ${ }^{1,2}$ the ongoing biomedical engineering brought about endocardial cryodelivery using percutaneuous catheters. ${ }^{3}$ Although cryothermia has several advantages over radiofrequency energy (RF), while maintaining equal clinical efficacy, the procedure time of catheter-based cryoablation (cryo) has been reported to be relatively long. Early experimental studies showed that for cryoablation to be effective, long application times, ${ }^{4}$ repeated cryodelivery ${ }^{4}$ and deep cooling temperatures using larger probes ${ }^{5,6}$ are warranted, all of which considerably may prolong the procedure time. Recently, it has been shown that cryo of atrial flutter (AFL) can be successfully performed using single 1-minute cryoapplications which results in short procedure times. ${ }^{7}$ Furthermore, a number of studies with different sizes of RF catheter-tips have proven that larger catheter-tips have superior procedural efficacy compared to conventional 4- or 5-mm cathetertips.-10 A recent experimental study has shown that larger cryocatheter electrode-tips produce larger lesions of similar depth.11 We hypothesised that by using large tip sizes, fewer freezes are required to treat AFL. This may shorten the procedure time. In order to investigate these advantages we prospectively evaluated the safety and efficacy of cryo of the cavotricuspid isthmus (CTI) for the treatment of AFL using a $6.5-\mathrm{mm}$, a $10-\mathrm{mm}$ and a $15-\mathrm{mm}$ tip.

\section{Patients and methods}

\section{Patients}

Forty-five consecutive patients ( 35 men; mean age of $60 \pm 11$, range 21 to 86 years) with symptomatic common AFL were enrolled to undergo cryo. All patients gave written informed consent for the procedure and the study was approved by the local hospital Ethics Committee. The first 15 patients were treated with a 6.5-mm catheter-tip (group 1), the next 15 patients with a $10-\mathrm{mm}$ catheter-tip (group 2) and the last 15 patients with a 15-mm catheter-tip (group 3). The demographic characteristics of the patients are shown in Table 1. 
Table 1 Patient characteristics

\begin{tabular}{lcccc}
\hline & group 1 & group 2 & group 3 & $P$ \\
\hline Age, years & $60 \pm 12(38-84)$ & $59 \pm 15(21-75)$ & $60 \pm 13(43-86)$ & NS \\
Sex, M/F & $13 / 2$ & $12 / 3$ & $10 / 5$ & NS \\
Structural heart disease, $\mathrm{n}$ & 8 & 7 & 8 & NS \\
Mean left ventricular ejection fraction, $\%$ & $54 \pm 14(21-65)$ & $53 \pm 12(23-70)$ & $61 \pm 9(35-73)$ & NS \\
Mean left atrial size, mm & $43 \pm 7(34-53)$ & $43 \pm 6(33-53)$ & $43 \pm 6(32-55)$ & NS \\
Concomitant atrial fibrillation, $n$ & 13 & 12 & 10 & NS \\
AAD-AFL, & 5 & 2 & 2 & NS \\
AAD, n & & & & \\
$\quad$ Class IC & 2 & 4 & 4 & NS \\
Class III & 9 & 6 & 8 & NS \\
Other & 2 & 4 & 3 & NS \\
\hline
\end{tabular}

Abbreviations: $\mathrm{M}=$ male $\mathrm{F}=$ female, $\mathrm{AAD}=$ antiarrhythmic drug, $\mathrm{AAD}-\mathrm{AFL}=$ organisation of atrial fibrillation to atrial flutter during treatment with class Ic or class III anti-arrhythmic drugs, $\mathrm{n}=$ number of patients

\section{Electrophysiological study and ablation procedure}

The ablation procedure was performed according to a technique previously described.12 Three multipolar catheters were advanced in the right atrium through insertion of a femoral vein. A duodecapolar catheter (Biosense Webster, Diamond Bar, CA, USA) was positioned around the tricuspid annulus for sequential activation mapping. A quadripolar and a decapolar catheter were placed at the His-bundle and in the coronary sinus respectively. Cryo was performed using the CryoCor Cardiac Cryoablation System ${ }^{\mathrm{TM}}$ (CryoCor Inc., San Diego, CA, USA). A steerable 10-F bipolar catheter either with a 6.5-mm tip (group I), a 10$\mathrm{mm}$ tip (group 2) or a 15-mm tip (group 3) was used in combination with a long venous sheath (DAIG, St Jude Medical Inc., St Paul, MN, USA) for mapping and ablation of the CTI. No difference between the design or assembly procedure other than the length was present between the 3 different tip sizes. Both the small and large tips operated using the same algorithms, software and console to warrant equal tip pressures.

Entrainment to confirm the isthmus dependence of the AFL circuit was performed in patients with only AFL and in patients with AFL and a few episodes of atrial fibrillation. In patients with AFL and frequent atrial fibrillation episodes, entrainment was not performed to avoid induction of atrial fibrillation.

Both catheter-tip temperature and system pressure were monitored throughout the procedure to ensure consistent catheter-tip energy delivery. Linear lesions were created using single 3-minutes applications in a ventriculoatrial fashion, starting at the tricuspid annular edge. If within $30 \mathrm{sec}$, no additional CTI conduction delay or termination of AFL was observed, the application was stopped and the ablation catheter was repositioned. These incomplete applications were classified as ineffective applications. Procedural endpoints were the assessment of bidirectional CTI block and the non-inducibility of AFL. After 
documentation of bi-directional isthmus conduction block, the atrial pacing (from the proximal coronary sinus) protocol (up to 3 atrial extrastimuli at 3 pacing cycle lengths and incremental atrial pacing) was performed without and during isoproterenol infusion ( 1 to $3 \mu \mathrm{g} / \mathrm{min}$ ). In case of reinduction of AFL or resumption of isthmus conduction, further cryoapplications were delivered. Procedure time was defined as the time interval between the first femoral vein puncture for catheter insertion and the removal of the sheaths.

The number of (in-) effective applications, the ablation temperatures, the fluoroscopy time, the procedure time, and the (acute and longterm) outcome were compared for the 3 groups.

\section{Follow-up}

Patients living in the region of Maastricht were followed-up at our out patient clinic at 1 month and every 3 months thereafter. For patients from outside this region, follow-up was obtained by their referring cardiologist. In case of documentation of $\mathrm{AFL}$, the patient was again referred to our hospital for further evaluation and re-ablation. Only in patients with lone AFL, anti-arrhythmic drugs were discontinued after the ablation procedure. A 24-hour Holter monitor was given immediately after the procedure until hospital discharge and thereafter, if symptoms suggested an arrhythmia recurrence. Patients were instructed to contact our center or the nearest hospital if they had any symptoms (e.g. palpitations, chest discomfort) that could indicate a recurrence.

\section{Statistical analysis}

Results are expressed as mean \pm SD and range. Patient characteristics and treatment effects of the different groups were compared with the chi-square test for categorical variables; for continues variables ANOVA with post-hoc Bonferroni adjustment for pairwise comparisons was used. All values were considered significant at $\mathrm{p}<0.05$.

\section{Results}

\section{Ablation characteristics}

The demographic characteristics of the 3 patient groups were comparable (Table 1). Table 2 summarizes the electrophysiological and ablation characteristics of the 45 patients. There was no difference between the 3 groups in the number of patients that required cardioversion for atrial fibrillation during the procedure (NS). Acute procedural success was achieved in 40 patients (89\%) and 
there was no difference with respect to the tip-electrode size (NS). In the remaining 5 patients ( 2 patients of group 1 and 3 patient of group 2) only noninducibility of AFL and CTI conduction delay could be achieved. No failure was observed during treatment with a $15-\mathrm{mm}$ catheter-tip. Fewer effective applications were required for the $10-\mathrm{mm}(6 \pm 2$, range $3-7)$ and $15-\mathrm{mm}(6 \pm 1$, range 4 - 8)) compared to the 6.5 -mm catheter-tip $(8 \pm 3$, range $4-14) ; \mathrm{p}<0.05)$. The number of ineffective applications did not differ between the 3 groups (NS). The average temperature decreased significantly when larger catheter-tips were used $(\mathrm{p}<0.001)$, although no difference was observed between the $10-\mathrm{mm}$ and $15-\mathrm{mm}$ catheter-tip. A persistent decrease in fluoroscopy time and procedure duration was noted, though proved only significant between the $6.5-\mathrm{mm}$ and the $15-\mathrm{mm}$ catheter-tip. No procedure related complications occurred in either patient group.

Table 2 Electrophysiological and ablation characteristics

\begin{tabular}{|c|c|c|c|c|}
\hline & group 1 & group 2 & group 3 & $P$ \\
\hline AFL: CCW/CW, n & $14 / 1$ & $14 / 1$ & $14 / 1$ & NS \\
\hline AFL cycle length, ms & $237 \pm 52(196-384)$ & $249 \pm 38(220-330)$ & $233 \pm 33(200-300)$ & NS \\
\hline Cardioversion, $\mathrm{n}$ & 5 & 6 & 3 & NS \\
\hline Flecainide & 2 & 4 & 3 & \\
\hline External & 2 & 1 & 0 & \\
\hline Internal & 1 & 1 & 0 & \\
\hline Number of effective applications & $8 \pm 3(4-14) *$ & $6 \pm 2(3-7)$ & $6 \pm 1(4-8) \dagger$ & 0.005 \\
\hline Number of ineffective applications & $9 \pm 9(0-22)$ & $8 \pm 10(0-21)$ & $3 \pm 5(0-7)$ & NS \\
\hline Temperature, ${ }^{\circ} \mathrm{C}$ & $-81 \pm 3(-80--88)^{*}$ & $-85 \pm 2(-84--91)$ & $-86 \pm 4(-84--92) \dagger$ & 0.001 \\
\hline Fluoroscopy time, min & $38 \pm 22(12-81)$ & $32 \pm 16(12-54)$ & $22 \pm 11(8-47) \dagger$ & 0.048 \\
\hline Procedure time, min & $132 \pm 28(61-230)$ & $119 \pm 41(75-180)$ & $89 \pm 26(47-110) \dagger$ & 0.016 \\
\hline Acute success, n (\%) & $13(87)$ & $12(80)$ & $15(100)$ & NS \\
\hline Recurrence AFL, n (\%) & $2(13)$ & 0 & 0 & \\
\hline
\end{tabular}

Abbreviations: $\mathrm{AFL}=$ atrial flutter, $\mathrm{CCW}=$ counter clockwise, $\mathrm{CW}=$ clockwise, $\mathrm{n}=$ number of patients Data presented as mean \pm SD. p value listed for the overall ANOVA, or chi-square analysis of all three groups. Items flagged with the following symbols indicate that the specified pairwise comparisons were statistically significant at the Bonferroni-adjusted $\mathrm{p}<0.05 . * 6.5-\mathrm{mm}$ tip versus $10-\mathrm{mm}$ tip, † 6.5-mm tip versus $15-\mathrm{mm}$ tip

\section{Follow-up}

After a mean follow-up of $51 \pm 5$ (range 44 to 60 ) months, only 2 patients (96\%) both treated with a $6.5-\mathrm{mm}$ tip and previously judged to have bidirectional CTI block, had recurrence of AFL, 1 and 3 months post-ablation, respectively. One of 
them was successfully re-ablated with 1 application directed at the tricuspid valve ridge. The remaining patient required 2 additional sessions ultimately targeting the septal isthmus to meet procedural endpoints. Chronic complications were not observed.

\section{Discussion}

To the best of our knowledge, the current study is the first to compare the safety and efficacy of cryo for the treatment of typical AFL using different catheter-tips, including a novel $15-\mathrm{mm}$ tip-electrode. There was a high acute $(89 \%)$ and chronic (96\%) success rate without difference between the tip sizes. No procedure related complications occurred. Compared to a $6.5-\mathrm{mm}$ tip, the number of effective cryoapplications at the CTI region could significantly be reduced with the use of a $10-\mathrm{mm}$ and $15-\mathrm{mm}$ tip. Cryo with a $15-\mathrm{mm}$ tip resulted in the shortest fluoroscopy and procedure time, which was significantly shorter in comparison with the conventional 6.5-mm tip electrode.

The current study shows that by using larger tip sizes, fewer applications can be delivered, without compromising efficacy which is in accordance with early cryosurgery where larger probes induced larger lesions. ${ }^{4}$ However, unlike epicardial ablation, lesion formation during percutaneous catheter ablation is also dependant on electrode-tip orientation and superfusate flow which from RF experience may reduce any beneficial effect of a larger tip size. ${ }^{13}$ In experimental models, lesion dimension was greatly enhanced by horizontal positioning of the catheter-tip due to a larger contact area and less convective heating. ${ }^{14,15}$ The relative low requirement of cryoenergy using a $10-\mathrm{mm}$ and $15-\mathrm{mm}$ tip may be due to a larger surface area when adequately oriented and a greater reserve to adhere to a more proximal site if anatomic derangements like the trabeculated CTI prohibit parallel alignment or optimal tissue contact. The decrease in ablation temperatures, when using a $10-\mathrm{mm}$ or a $15-\mathrm{mm}$ tip supports a larger ice ball formation, enabling stable, low core temperatures to be measured at the catheter-tip. However, the variation seen in catheter (internal) tip temperatures from the 3 tip sizes may also be attributed to typical manufacturing variation in the location of the thermocouple and its proximity to the inside surface of the tip. ${ }^{16}$ In several studies, the electrode temperature has shown to be a poor surrogate for tissue temperature as it proved heavily dependent on electrode orientation, convective warming and characteristics of the catheter (tip size/diameter, refrigerant flow rate). ${ }^{16,17}$ Since all 3 tip sizes have similar console operating parameters, it is not very likely that the clinical outcome would vary due to this temperature differential.

Fluoroscopy time and ineffective cryodelivery mainly reflecting catheter manipulation showed a persistent decrease with a clear trend to significance as tip size increased. The shortest fluoroscopy and procedure time was observed 
during cryo with a 15-mm tip electrode, showing a significant decrease compared to a 6.5-mm tip. The decline in fluoroscopy and procedure time did not reach a significant level between a $6.5-\mathrm{mm}$ and $10-\mathrm{mm}$ tip electrode, which may be due to the small sample size. A meta-analysis of the clinical efficacy of 8-mm tip and cooled tip RF catheters showed a variable fluoroscopy and procedure time ranging from 11 to 33 minutes and 41 to 159 minutes respectively, which seems comparable to our results from a $10-\mathrm{mm}$ and $15-\mathrm{mm}$ tip. ${ }^{18}$ Also the high acute and long-term efficacy obtained from a 15-mm tip was similar to those obtained by RF either using 8-mm, 10-mm or irrigated tips. ${ }^{8,10,13,19}$

Only a few studies investigated the clinical effects of large cryocatheters, exceeding a 6.5-mm tip length for the treatment of AFL. Malmborg et al. compared an 8-mm cryo electrode-tip with an 8-mm RF tip, but showed a high degree of cryo-to-RF crossovers (40\%) defined as acute cryofailures and a $10 \%$ recurrence rate during 15 months of observation. ${ }^{20}$ The lower efficacy even in the presence of a large tip size may be related to differences in catheter steerability and higher cryoablation temperatures. The procedure time was comparable to that obtained by a $6.5-\mathrm{mm}$ tip, which may be the result of redundant cryodelivery, as they used 4 minutes per effective and 2 minutes per ineffective application. Thornton et al. also used an 8-mm electrode-tip with 4 minutes per effective application to evaluate the acute effects of typical AFL ablation. ${ }^{21}$ In contrast to our study, 18 applications and 150 minutes of procedure time were necessary to meet procedural endpoints. The acute efficacy was similar to our study though clinical follow up was only limited to 3 months. We recently reported a comparable clinical efficacy using a 10-mm tip electrode in conjunction with one minute of cryodelivery. ${ }^{7}$ Considering the shorter procedure time of 110 minutes of the latter study and our present observations, a further decrease in procedure time may be expected if the application duration is reduced to 1 minute using either a $10-\mathrm{mm}$ or $15-\mathrm{mm}$ tip electrode.

\section{Limitations}

Inherent to the study design, allocation to the different tip sizes was conducted in a non-randomized manner. This may have obscured the recurrence rate in patients treated with the 15-mm tip. However, follow-up exceeded 4 years, which is comparable to most studies reporting on long-term efficacy. Another limitation is the small sample size, which was mainly due to the limited availability of a 15-mm tip electrode. Larger trials are necessary to confirm the current results. 


\section{Conclusion}

Large cryoablation catheter-tips, like a 10 - and $15-\mathrm{mm}$ tip, require significantly fewer applications for the treatment of AFL compared to conventional 6.5-mm tip cryoablation catheters. Fluoroscopy and procedure time are comparable to $\mathrm{RF}$ ablation and show an improvement over recent cryostudies. Considering the persistent decrease in procedure time while preserving overall safety and efficacy, the use of larger tip sizes during cryo of the CTI should encourage its future implementation. 


\section{References}

1. Holman WL, Ikeshita M, Ungerleider RM, Smith PK, Ideker RE, Cox JL: Cryosurgery for cardiac arrhythmias: acute and chronic effects on coronary arteries. Am J Cardiol 1983; 51:149-155.

2. Holman WL, Ikeshita M, Douglas JM, Jr., Smith PK, Lofland GK, Cox JL: Ventricular cryosurgery: short-term effects on intramural electrophysiology. Ann Thorac Surg 1983; 35:386-393.

3. Dubuc M, Talajic M, Roy D, Thibault B, Leung TK, Friedman PL: Feasibility of cardiac cryoablation using a transvenous steerable electrode catheter. J Interv Card Electrophysiol 1998; 2:285292.

4. Holman WL, Kirklin JK, Anderson PG, Pacifico AD: Variation in cryolesion penetration due to probe size and tissue thermal conductivity. Ann Thorac Surg 1992; 53:123-126.

5. Holman WL, Ikeshita M, Douglas JM, Jr., Smith PK, Cox JL: Cardiac cryosurgery: effects of myocardial temperature on cryolesion size. Surgery 1983; 93:268-272.

6. Gill W, Fraser J, Carter DC: Repeated freeze-thaw cycles in cryosurgery. Nature 1968; 219:410413.

7. Manusama R, Timmermans C, Pison L, Philippens S, Perez D, Rodriguez LM: Typical atrial flutter can effectively be treated using single one-minute cryoapplications: results from a repeat electrophysiological study. J Interv Card Electrophysiol 2009; 26:65-72.

8. Feld G, Wharton M, Plumb V, Daoud E, Friehling T, Epstein L: Radiofrequency catheter ablation of type 1 atrial flutter using large-tip 8- or 10-mm electrode catheters and a high-output radiofrequency energy generator: results of a multicenter safety and efficacy study. J Am Coll Cardiol 2004; 43:1466-1472.

9. Tsai CF, Tai CT, Yu WC, Chen YJ, Hsieh MH, Chiang CE, Ding YA, Chang MS, Chen SA: Is 8-mm more effective than 4-mm tip electrode catheter for ablation of typical atrial flutter? Circulation 1999; 100:768-771.

10. Rodriguez LM, Nabar A, Timmermans C, Wellens HJ: Comparison of results of an 8-mm split-tip versus a 4-mm tip ablation catheter to perform radiofrequency ablation of type I atrial flutter. Am J Cardiol 2000; 85:109-112, A109.

11. Khairy P, Rivard L, Guerra PG, Tanguay JF, Mawad W, Roy D, Talajic M, Thibault B, Macle L, Dubuc M: Morphometric ablation lesion characteristics comparing 4, 6, and $8 \mathrm{~mm}$ electrode-tip cryocatheters. J Cardiovasc Electrophysiol 2008; 19:1203-1207.

12. Manusama R, Timmermans C, Limon F, Philippens S, Crijns HJ, Rodriguez LM: Catheter-based cryoablation permanently cures patients with common atrial flutter. Circulation 2004; 109:1636-1639.

13. Kasai A, Anselme F, Teo WS, Cribier A, Saoudi N: Comparison of effectiveness of an 8-mm versus a 4-mm tip electrode catheter for radiofrequency ablation of typical atrial flutter. Am J Cardiol 2000; 86:1029-1032, A1010.

14. Parvez B, Pathak V, Schubert CM, Wood M: Comparison of lesion sizes produced by cryoablation and open irrigation radiofrequency ablation catheters. J Cardiovasc Electrophysiol 2008; 19:528-534.

15. Tse HF, Ripley KL, Lee KL, Siu CW, Van Vleet JF, Pelkey WL, Lau CP: Effects of temporal application parameters on lesion dimensions during transvenous catheter cryoablation. J Cardiovasc Electrophysiol 2005; 16:201-204.

16. Wood MA, Parvez B, Ellenbogen AL, Shaffer KM, Goldberg SM, Gaspar MP, Arief I, Schubert CM: Determinants of lesion sizes and tissue temperatures during catheter cryoablation. Pacing Clin Electrophysiol 2007; 30:644-654.

17. Reek S, Geller JC, Schildhaus HU, Ripley KL, Klein HU: Feasibility of catheter cryoablation in normal ventricular myocardium and healed myocardial infarction. Pacing Clin Electrophysiol 2004; 27:1530-1539.

18. Da Costa A, Cucherat M, Pichon N, Messier M, Laporte S, Romeyer-Bouchard C, Mismetti P, Lopez $\mathrm{M}$, Isaaz K: Comparison of the efficacy of cooled-tip and 8-mm-tip catheters for radiofrequency catheter ablation of the cavotricuspid isthmus: a meta-analysis. Pacing Clin Electrophysiol 2005; 28:1081-1087. 
19. Scavee C, Jais P, Hsu LF, Sanders P, Hocini M, Weerasooriya R, Macle L, Raybaud F, Clementy J, Haissaguerre M: Prospective randomised comparison of irrigated-tip and large-tip catheter ablation of cavotricuspid isthmus-dependent atrial flutter. Eur Heart J 2004; 25:963-969.

20. Malmborg $\mathrm{H}$, Lonnerholm S, Lundqvist CB: A prospective randomised comparison of large-tip cryoablation and 8-mm-tip radiofrequency catheter ablation of atrial flutter. J Interv Card Electrophysiol 2009; 24:127-131.

21. Thornton AS, Janse P, Alings M, Scholten MF, Mekel JM, Miltenburg M, Jessurun E, Jordaens L: Acute success and short-term follow-up of catheter ablation of isthmus-dependent atrial flutter; a comparison of $8 \mathrm{~mm}$ tip radiofrequency and cryothermy catheters. J Interv Card Electrophysiol 2008; 21:241-248. 



\section{Chapter VI \\ Long-term follow-up after cryothermic ostial pulmonary vein isolation in paroxysmal atrial fibrillation}

Wendel Moreira, MD;* Randy Manusama, MD;* Carl Timmermans, MD, PHD; Benoit Ghaye, MD; Suzanne Philippens, RN; Hein J. J. Wellens, MD, PHD; LuzMaria Rodriguez, MD, PHD

*Moreira and Manusama contributed equally to this study

J Am Coll Cardiol 2008 Feb;51:850-5 


\section{Abstract}

Objectives: This study was designed to evaluate the long-term effect of segmental pulmonary vein (PV) cryoablation in patients with recent-onset paroxysmal atrial fibrillation (PAF).

Background: Patients with PAF have more triggers to initiate and less substrate to sustain atrial fibrillation (AF). Elimination of the potential initiators alone may be sufficient to abolish the arrhythmia.

Methods: Patients with PAF were prospectively recruited from July 2001 to July 2005. If the triggers for AF were identified, PV cryoisolation of the arrhythmogenic vein(s) was performed. Otherwise, all PVs were isolated.

Results: Seventy patients with minimal or no heart disease (54 men; age $40 \pm$ 10 years) were enrolled. The duration of AF was $4 \pm 1$ year. The left ventricular ejection fraction and left atrial size were $59 \pm 8 \%$ and $41 \pm 5 \mathrm{~mm}$, respectively. An arrhythmogenic PV was found in 10 patients (14\%). Complications occurred in 3 patients (4\%). No PV stenosis or esophageal injury was detected during a mean follow-up of $33 \pm 15$ months. Thirty-four patients (49\%) achieved complete success (no AF and no antiarrhythmic drugs [AAD]); 15 patients (22\%) had no recurrences with AAD; and 8 patients $(11 \%)$, still with sporadic bursts of AF, improved $>50 \%$ with AAD. Overall, $82 \%$ of the patients benefited from the procedure. Patients in whom the arrhythmogenic PV was identified and isolated had no recurrences.

Conclusions: Pulmonary vein cryoisolation is effective in $82 \%$ of patients with recent-onset PAF during a mean follow-up of $33 \pm 15$ (range 15 to 60 ) months. If the arrhythmogenic PV is identified and isolated, the long-term outcome is excellent, indicating no need to isolate all PVs. 


\section{Introduction}

Atrial fibrillation (AF) is a disease with different stages. In early stages, paroxysmal and nonsustained episodes are the rule. ${ }^{1,2}$ In this stage, the triggers, mostly located in the pulmonary veins (PV), are the main culprit of $\mathrm{AF}^{3}$ Over time, atrial remodeling starts to occur, and more substrate becomes available to sustain longer episodes. ${ }^{4}$ Therefore, self-perpetuation of AF (AF begets AF) leads to the idea that a treatment strategy employed early in the disease would be more likely to succeed. The actual ablative techniques are intended to eliminate the triggers (ostial PV isolation 1 by 1 or 2 by 2) and/or to modify the substrate. A technique that modifies the substrate consists of the creation of multiple lines in both atria. ${ }^{5}$ Adding extensive left atrial linear ablation, although reported to improve overall success rates in a group of patients with more advanced stages of $\mathrm{AF}$, has increased morbidity and mortality (including iatrogenic left atrial flutter, phrenic nerve paralysis, and left atrial-to-esophageal fistula, which is almost universally fatal). ${ }^{6-8}$ Many patients with AF and structurally normal hearts are now frequently referred for ablation. In this group, empiric extensive left atrial ablation may not be the best approach because the longterm risk of such extensive lesions is unknown.

Cryothermy has been shown to have some inherent advantages over radiofrequency (RF) ablation. The absence of pulmonary vein stenosis is one advantage..$^{9}$ But despite cryothermy's benefits, the great majority of AF ablation is done using RF. ${ }^{10}$ Our study, OPIPAF (Ostial Pulmonary vein Isolation in Paroxysmal Atrial Fibrillation), was designed to evaluate the effect of a more localized ablation strategy using cryothermy in patients with PAF in the early stages of the disease.

\section{Methods}

Seventy patients with drug-refractory, symptomatic PAF were enrolled prospectively from July 2001 to July 2006.

The screening protocol consisted of a review of Holter-recordings, daily transtelephonic telemetry (TTM), the number of failed antiarrhythmic drugs (AAD), functional capacity, type of AF, and imaging studies to exclude silent myocardial ischemia. Inclusion criteria required the following: 1) symptomatic $\mathrm{PAF}$; 2) duration of PAF $\leq 5$ years; 3 ) age $\leq 65$ years; 4 ) lone AF or minimal heart disease; and 5) left atrial size $\leq 40 \mathrm{~mm}$ and no exposure to amiodarone.

All subjects were given a transtelephonic event recorder and instructed to use it daily (preferably at the same time) and when they had symptoms. This monitoring started 30 days before and continued up to day 180 after pulmonary 
vein isolation (PVI). From then on, a Holter-monitor was used during clinic visits $(1,3,6,9$, and 12 months $)$ or when patients had symptoms.

A baseline contrast-enhanced spiral computed tomography (CT) scan of the thorax with 3-dimensional reconstruction of the heart was performed within 1 month before the ablation procedure and evaluated blindly by the same radiologist who performed the follow-up study (B.G.).

All the patients in the study signed a written consent form that was approved by the local ethics committee. Before PVI, all patients were orally anticoagulated to a therapeutic international normalized ratio of 2 to 3 for at least 3 weeks and up to 3 months after ablation. All AAD were stopped 5 days before PVI and restarted immediately thereafter. Transesophageal echocardiogram (TEE) was performed during the procedure to exclude left atrial thrombus and to aid in the transeptal puncture.

PV cryoisolation. All patients were studied in the fasting state without sedation, except if external cardioversion was needed (when small doses of midazolam were used). Internal cardioversions were done without sedation. Those patients presenting in AF while in the catheterization room were converted to sinus rhythm by internal or external cardioversion.

During the procedure (but after the transseptal punctures), intravenous heparin was given as a 100-IU/kg bolus dose followed by boluses of 5,000 IU every $1.5 \mathrm{~h}$ if needed to keep an activated clotting time $\geq 300 \mathrm{~s}$. A decapolar catheter was positioned in the distal coronary sinus and a quadripolar catheter in the His bundle region via the femoral route. Double transseptal catheterization was performed under fluoroscopic and transesophageal guidance.

Left atrial angiography was performed after adenosine administration ${ }^{11}$ to visualize the ostia of the pulmonary veins. Together with the left atrial angiography, we used the NavX system (Endocardial Solutions, St. Jude Medical Inc., St. Paul, Minnesota) for virtual reconstruction of the ostia of the veins in the last 20 patients. A deflectable, circumferential decapolar mapping catheter (LASSO, Biosense-Webster Inc., Baldwin Park, California) was advanced into the left atrium and positioned at the ostium of each PV. A deflectable, 10-F (6.5-mm tip) cryoablation catheter (CryoCor Inc., San Diego, California) was inserted into the left atrium through a 12-F, 65-cm long sheath (DAIG, St. Jude Medical Inc., St. Paul, Minnesota; or Cook Inc., Bloomington, Indiana).

Segmental isolation of PV guided by the recording of their potentials with the LASSO catheter was performed using the CryoCor cryoablation system as described previously. ${ }^{12}$ Efforts were made to identify the arrhythmogenic PV (culprit PV) using adenosine (24 to $40 \mathrm{mg}$ ) (Fig. 1) or isoproterenol (1 to $5 \mu \mathrm{g}$ ). If the culprit PV(s) were not identified, all veins with potentials recorded at their ostium were targeted for ablation. 


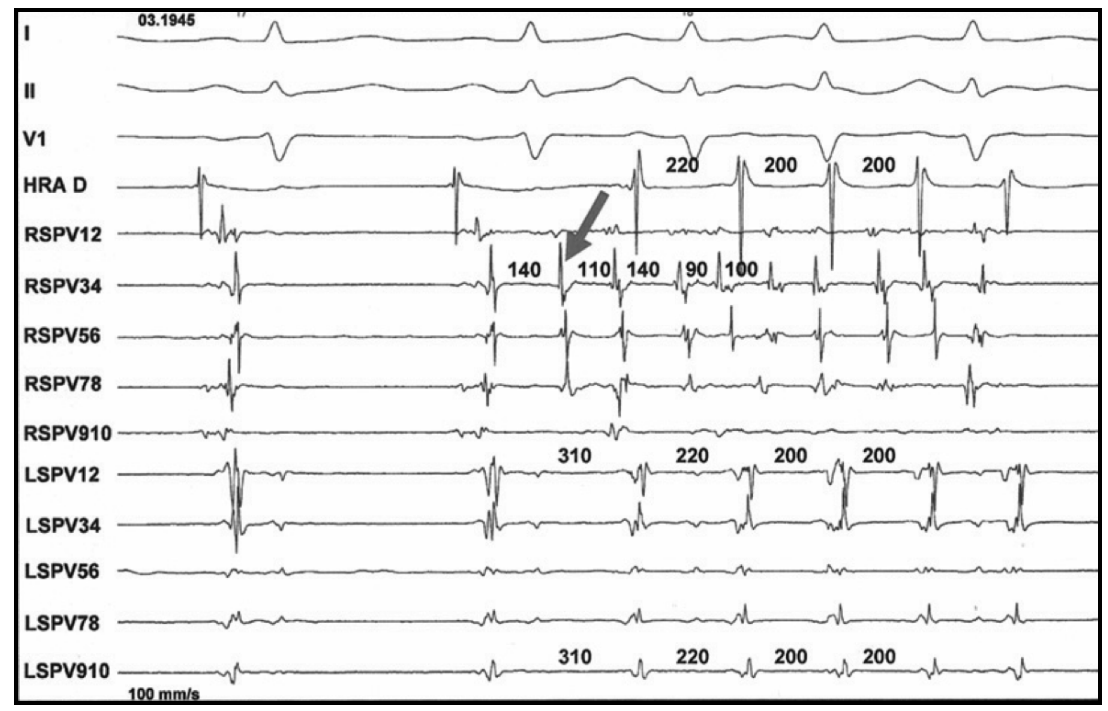

Figure 1. AF initiated by trigger in the RSPV An example of adenosine-induced atrial fibrillation (AF). HRA D = high right atrium distal; LSPV = left superior pulmonary vein; RSPV = right superior pulmonary vein

Isolation of the PV was performed during sinus rhythm or coronary sinus pacing by delivering cryoablation at ostial sites that had the earliest bipolar potential. Systematic pacing in the right superior PV region was performed before application to access phrenic nerve capture.

At each effective target site, defined by the abolishment of a PV potential or a change in the PV potential activation sequence during cryothermal application, 3 min of cryoablation was delivered. If no changes in the electrogram were observed after $20 \mathrm{~s}$, despite a catheter-tip temperature of $-90^{\circ} \mathrm{C}$, the application was stopped and the catheter repositioned. The early procedural end point was complete electrical isolation of PV based on abolition of all ostial PV potentials or complete entrance conduction block into the PV.

After-ablation management. Every patient was monitored in the hospital for 24 hour and oral anticoagulation was restarted the same day as the ablation. The same AAD were continued for at least 3 months after the procedure. After this period, the need for chronic anticoagulation was assessed by the amount of recurrences of $\mathrm{AF}$ and the presence of risk factors for thromboembolic events.

All patients had a Holter-recording at discharge and during each clinic visit $(1,3,6,9$, and 12 months) or earlier if they had symptoms. They were instructed to keep a diary of events associated with their transtelephonic monitors. A visual analog scale ranging from zero (indicating no improvement at all) to 100 (asymptomatic and AF free after PVI) was used during the clinic visits.

Because of the logistics of the Maastricht area and the presence of a dedicated research nurse (S.P.) who was available to address patients' concerns and 
questions at any time, we were able to follow every patient on an individual basis and achieve a $90 \%$ compliance rate with daily TTM at the end of 180 days.

To assess the presence of PV stenosis, serial CT scans of the heart were performed at 3, 6 (63 patients), and 12 months (12 patients). In 7 patients, a repeated CT scan was not performed on follow-up because of an allergic reaction to the contrast agent on their baseline scan $(n=3)$ and patient refusal $(n=4)$. A TEE was performed in those individuals showing no increase in Doppler flow velocities suggestive of $\mathrm{PV}$ stenosis.

The same radiologist (B.G.) reviewed all before- and after-cryoablation images in a blinded manner. The diameter of the ostia of the PV was determined for each patient in a pairwise manner to maintain consistency in the measurements.

Definitions. Arrhythmogenic veins were considered those that, during AF, had a tachycardia cycle length shorter than the one recorded in the coronary sinus catheter. Induction of AF was attempted first by manipulation of the LASSO catheter inside the vein (mechanical contact); if that did not result in arrhythmias, administrations of adenosine and isoproterenol infusion were used.

According to the 2007 Heart Rhythm Society/European Heart Rhythm Association/European Cardiac Arrhythmia Society expert consensus statement on catheter ablation of $\mathrm{AF}^{13}$ an episode of $\mathrm{AF}$ detected by monitoring was considered a recurrence if it had a duration of $30 \mathrm{~s}$ or more.

Statistical analysis. Continuous variables are presented as mean $\pm \mathrm{SD}$, where appropriate. In cases of a non-Gaussian distribution, medians and quartiles are given. Categorical variables are expressed as numbers and percentages of patients.

A Kaplan-Meier analysis was used to determine the percentage of patients either free from $\mathrm{AF}$ (with or without AAD) or with $\geq 50 \%$ improvement after the index PVI.

\section{Results}

Our cohort consisted of 70 patients (54 men and 16 women) with PAF who fulfilled the described recruitment criteria of the OPIPAF study.

The mean age was $40 \pm 10$ years (range 21 to 65 years). The mean duration of AF was $4 \pm 1$ year. Patients had failed 1 to $2 \mathrm{AAD}$ before PVI, and most of them had no ( $\mathrm{n}=54$ patients) or minimal heart disease $(\mathrm{n}=16$ patients; 11 had arterial hypertension and 5 had a history of coronary artery disease). There was no history of amiodarone use.

The mean left atrial dimension was $38 \pm 2$ (range 33 to 40 ) $\mathrm{mm}$, with a mean left ventricular ejection fraction of $59 \pm 8 \%$. All targeted PV were successfully isolated (mean of $3 \pm 1$ [range 1 to 4] PV per patient). The following veins had 
potentials and were isolated: left superior in 63 patients, left inferior in 52 patients, right superior in 57 patients, and right inferior in 16 patients. The right inferior PV was mapped in 32 patients: one-half of them (16 patients) did not have any potentials in this vessel, whereas the other 16 patients had PV potentials that were ablated. A total of 881 complete cryoapplications were given in 188 veins. A mean of 5 (range 1 to 13) applications were given per PV and 13 (range 3 to 23) applications per patient. No PV stenosis (accessed by serial spiral CT in 63 patients and TEE Doppler velocities in 7 patients) or esophageal injury was detected during a mean follow-up of $33 \pm 15$ (15 to 60) months.

Total procedure time averaged $331 \mathrm{~min}$ and fluoroscopy time $88 \mathrm{~min}$. Our long procedure times during PVI are in part due to extensive pacing/pharmacologic maneuvers and other interventions that we used while trying to induce arrhythmias and access end points.

Thirty-four patients (49\%) had no AF recurrences without AAD, 15 patients $(22 \%)$ had no AF recurrences with $\mathrm{AAD}$, and 8 patients $(11 \%)$ with sporadic $\mathrm{AF}$ bursts reported an improvement of $\geq 50 \%$ with AAD after the ablation. Overall, $82 \%$ of patients benefited from the procedure after the index PVI (Fig. 2). Of the 13 patients who did not improve, 10 had a second PVI 6 months after the first procedure. Of those patients, 6 had much improvement in their symptoms. Three patients remained with symptomatic AF and opted for rate control. In 1 patient, a third procedure was needed to ablate a focal tachycardia coming from the left inferior PV. He became asymptomatic. In only 10 patients (14\%), the arrhythmogenic PV(s) could be identified using the criterion of a higher AF rate in the PV than in the coronary sinus or adenosine administration (Fig. 1). When compared with the rest of the cohort, we found no statistically significant differences in their clinical characteristics using $t$-tests or chi-square tests. The characteristics were distributed as follows: one patient had 3 different arrhythmogenic veins, 7 patients had 2 arrhythmogenic veins, and 2 patients had only 1 arrhythmogenic vein. In those patients, no recurrences were observed during long-term follow-up.

Complications. Complications were seen in 3 patients (4\%). One of our first patients had a cerebral ischemic event with left-sided hemiplegia occurring at the end of the procedure. Factors other than the energy source could have played a role in this event (such as problems with anticoagulation, several exchanges of the sheaths, or long procedure time) Subsequently, this patient recovered all his baseline function.

A second patient developed a pulmonary embolism 2 months after the ablation (when he was also found to be inadequately anticoagulated). Although we cannot directly associate this event with the cryoablation, we decided to count it as an adverse effect during our follow-up.

The third patient had transient phrenic nerve paralysis during the application in the right superior PV. However, the diaphragmatic movement recovered immediately after stopping the cryoapplication. 


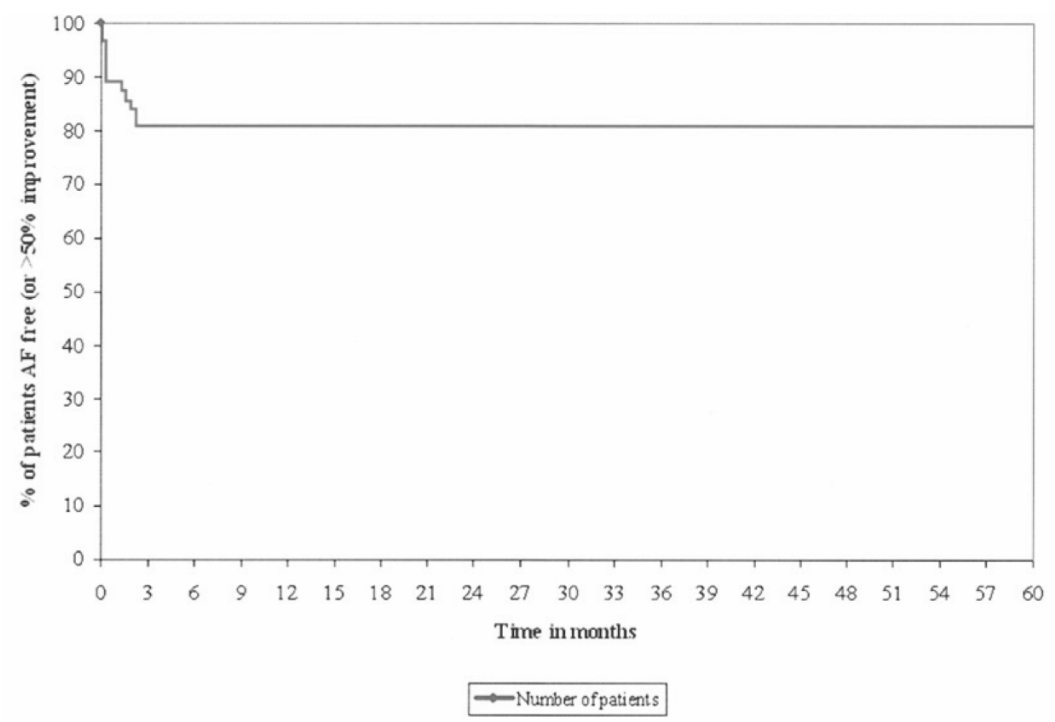

\begin{tabular}{ccccccccccccccc}
$\begin{array}{c}\text { Follow-up in } \\
\text { months }\end{array}$ & 3 & 6 & 9 & $\begin{array}{c}12- \\
24\end{array}$ & 27 & $\begin{array}{c}30- \\
33\end{array}$ & 36 & 39 & 42 & $45-$ & 51 & 54 & 57 & 60 \\
\hline Events & 13 & 0 & 0 & 0 & 0 & 0 & 0 & 0 & 0 & 0 & 0 & 0 & 0 & 0 \\
\hline $\begin{array}{c}\text { Number of } \\
\text { patients at } \\
\text { risk }\end{array}$ & 70 & 57 & 57 & 57 & 45 & 33 & 21 & 15 & 14 & 10 & 9 & 8 & 7 & 7 \\
\hline
\end{tabular}

Figure 2. Kaplan-Meier Curve Showing the Outcomes of Pulmonary Vein Cryoisolation After a mean follow-up of $33 \pm 15$ months, pulmonary vein cryoisolation was effective in $82 \%$ of patients. An event was considered a patient who, at any time, reported $>50 \%$ improvement. The table shows the number of events compared with patients at risk over time. $\mathrm{AF}=$ atrial fibrillation.

\section{Discussion}

Main findings. Our study shows that a more localized ablation strategy using cryothermy is effective in $82 \%$ of patients with PAF: $49 \%$ without AF recurrences without $\mathrm{AAD}, 22 \%$ without $\mathrm{AF}$ while receiving $\mathrm{AAD}$, and $11 \%$ improved $50 \%$ with AAD (sporadic bursts of AF) during a mean follow-up of $33 \pm 15$ (range 15 to 60) months. The acute complications seen (stroke and transient phrenic nerve paralysis) were within the acceptable range for the procedure and did not result in long-term limitations for the patients. 
In those patients in whom the arrhythmogenic PV could be identified and isolated, no recurrences were observed. Cryothermy is effective as an energy source in AF ablation. Our study shows that $82 \%$ of patients with PAF benefited from pulmonary vein cryoisolation during long-term follow-up (Fig. 2). Those results are similar to those obtained with RF. ${ }^{14-19}$ However, in comparison to RF, cryothermy may have some advantages.

Cryoenergy causes adherence of the catheter-tip to the underlying tissue during energy delivery, ensuring accurate lesion creation. ${ }^{20-22}$ This might be important in avoiding catheter dislocation to areas where complications could occur (such as the posterior left atrium or inside the PV).

Cryoenergy also has the ability to create reversible loss of function, allowing the prediction of the effectiveness and safety of a lesion. ${ }^{23,}{ }^{24}$ It does not require conscious sedation or anesthesia, as it is painless. ${ }^{25}$ This not only means more comfort for the patients but also decreases the low but real complications of anesthesia.

Cryothermal ablation preserves the extracellular matrix and endothelial integrity. As a result, it had not been associated with PV stenosis, esophageal perforation, or thromboembolic events during the treatment of AF. ${ }^{26,} 27$ Although the rate of thromboembolic complications during RF ablation of AF is small, such consequences could be dreadful in a relatively young and healthy population.

Focal approach versus large lesions in the treatment of $A F$. All patients in whom we were able to identify which PV was the trigger were cured. Our relatively healthy population (no or minimal structural heart disease, normal left atrial dimension, or PAF) could represent the early stages of AF. At this time, ablation of potential triggers instead of isolation of all PV should be preferred.

A study by Nanthakumar et al. ${ }^{28}$ showed that adolescents (without structural heart disease) referred for ablative therapy because of lone AF have an excellent outcome with the focal ablation of distinct foci (most located in the $\mathrm{PV}$ ). Owing to their age, this population could really represent the first stages of $\mathrm{AF}$, and the success in their treatment corroborates our findings of a more localized approach in a healthier population.

Gerstenfeld et al. ${ }^{29}$ have shown a good long-term (18 months) outcome in patients younger than 50 years with PAF undergoing targeted ablation of $\leq 2 \mathrm{PV}$ with triggered atrial premature beats or AF. Also, a recent report by Oral et al. ${ }^{30}$ using a tailored approach to catheter ablation of AF has shown an $80 \%$ success rate despite having $40 \%$ of patients with evidence of structural heart disease. Although one could say that the group's study population had already passed the first stages of AF, their results again ratify the success of limited electrophysiologically guided lesions in the percutaneous treatment of arrhythmias.

Study limitations. Our daily TTM recorded only fractions of the day and do not represent cardiac rhythm during a 24 -h period. Continuous rhythm monitoring would be preferable, but it would be hard to justify implanting a device in 
this healthy population. After 180 days, we returned to a symptom-guided recording method, which despite being widely used has some disadvantages (poor correlation between symptoms and arrhythmias was shown consistently in 2 studies). ${ }^{31,32}$

Despite being around for a long time in the surgical field, catheter-based cryoablation is still a relatively new technology compared to RF. Also, efficiency is highly dependent on the duration of application and pressure against the myocardial tissues. ${ }^{33}, 34$ This could lead to the concept of longer procedure times when comparing cryoablation to RF. But if we consider total time in the electrophysiology laboratory (including time devoted to anesthesia), cryothermy and RF procedures are not that different.

Also the identification of an arrhythmogenic PV was not very frequent. In our population, it was identified in only 10 patients (14\%). Unfortunately, this represents the reality of most patients with PAF submitted to PVI.29, 30

\section{Conclusions}

In patients with recent-onset PAF and no (or minimal) structural heart disease, PV cryoisolation is effective in $82 \%$ of patients: $49 \%$ with complete success (no AF and no AAD) and an additional 33\% with improvement (22\% AF-free with $\mathrm{AAD}$ and $11 \%$, still with sporadic bursts of $\mathrm{AF}$, reporting $>50 \%$ improvement compared to before ablation) during long term follow-up (mean of $33 \pm 15$ months). When the arrhythmogenic PV is identified and isolated, the long-term outcome is excellent (100\% freedom from AF), indicating no need to isolate all PV. Pulmonary vein isolation alone should be performed in patients early in the process of the disease. 


\section{References}

1. Blomstrom-Lundqvist C, Scheinman MM, Aliot EM, Alpert JS, Calkins H, Camm AJ, Campbell WB, Haines DE, Kuck KH, Lerman BB, Miller DD, Shaeffer CW, Stevenson WG, Tomaselli GF, Antman EM, Smith SC, Jr., Faxon DP, Fuster V, Gibbons RJ, Gregoratos G, Hiratzka LF, Hunt SA, Jacobs AK, Russell RO, Jr., Priori SG, Blanc JJ, Budaj A, Burgos EF, Cowie M, Deckers JW, Garcia MA, Klein WW, Lekakis J, Lindahl B, Mazzotta G, Morais JC, Oto A, Smiseth O, Trappe HJ: ACC/AHA/ESC guidelines for the management of patients with supraventricular arrhythmias--executive summary. a report of the American college of cardiology/American heart association task force on practice guidelines and the European society of cardiology committee for practice guidelines (writing committee to develop guidelines for the management of patients with supraventricular arrhythmias) developed in collaboration with NASPE-Heart Rhythm Society. J Am Coll Cardiol 2003; 42:1493-1531.

2. Camm AJ, Obel OA: Epidemiology and mechanism of atrial fibrillation and atrial flutter. Am J Cardiol 1996; 78:3-11.

3. Haissaguerre M, Jais P, Shah DC, Takahashi A, Hocini M, Quiniou G, Garrigue S, Le Mouroux A, Le Metayer P, Clementy J: Spontaneous initiation of atrial fibrillation by ectopic beats originating in the pulmonary veins. N Engl J Med 1998; 339:659-666.

4. Goette A, Honeycutt C, Langberg JJ: Electrical remodeling in atrial fibrillation. Time course and mechanisms. Circulation 1996; 94:2968-2974.

5. Pappone C, Augello G, Santinelli V: Atrial fibrillation ablation. Ital Heart J 2005; 6:190-199.

6. Deisenhofer I, Estner H, Zrenner B, Schreieck J, Weyerbrock S, Hessling G, Scharf K, Karch MR, Schmitt C: Left atrial tachycardia after circumferential pulmonary vein ablation for atrial fibrillation: incidence, electrophysiological characteristics, and results of radiofrequency ablation. Europace 2006; 8:573-582.

7. Pappone C, Oral H, Santinelli V, Vicedomini G, Lang CC, Manguso F, Torracca L, Benussi S, Alfieri O, Hong R, Lau W, Hirata K, Shikuma N, Hall B, Morady F: Atrio-esophageal fistula as a complication of percutaneous transcatheter ablation of atrial fibrillation. Circulation 2004; 109:27242726.

8. Sacher F, Monahan KH, Thomas SP, Davidson N, Adragao P, Sanders P, Hocini M, Takahashi Y, Rotter M, Rostock T, Hsu LF, Clementy J, Haissaguerre M, Ross DL, Packer DL, Jais P: Phrenic nerve injury after atrial fibrillation catheter ablation: characterization and outcome in a multicenter study. J Am Coll Cardiol 2006; 47:2498-2503.

9. Tse HF, Reek S, Timmermans C, Lee KL, Geller JC, Rodriguez LM, Ghaye B, Ayers GM, Crijns HJ, Klein HU, Lau CP: Pulmonary vein isolation using transvenous catheter cryoablation for treatment of atrial fibrillation without risk of pulmonary vein stenosis. J Am Coll Cardiol 2003; 42:752-758.

10. Cappato R, Calkins H, Chen SA, Davies W, Iesaka Y, Kalman J, Kim YH, Klein G, Packer D, Skanes A: Worldwide survey on the methods, efficacy, and safety of catheter ablation for human atrial fibrillation. Circulation 2005; 111:1100-1105.

11. Tse HF, Lee KL, Lau CP: Adenosine triphosphate enhanced contrast pulmonary venogram to facilitate pulmonary vein ablation. J Cardiovasc Electrophysiol 2002; 13:300.

12. Rodriguez LM, Timmermans C: Transvenous cryoablation of cardiac arrhythmias. Technol Cancer Res Treat 2004; 3:515-524. 
13. Calkins H, Brugada J, Packer DL, Cappato R, Chen SA, Crijns HJ, Damiano RJ, Jr., Davies DW, Haines DE, Haissaguerre M, Iesaka Y, Jackman W, Jais P, Kottkamp H, Kuck KH, Lindsay BD, Marchlinski FE, McCarthy PM, Mont JL, Morady F, Nademanee K, Natale A, Pappone C, Prystowsky E, Raviele A, Ruskin JN, Shemin RJ: HRS/EHRA/ECAS expert consensus statement on catheter and surgical ablation of atrial fibrillation: recommendations for personnel, policy, procedures and follow-up. A report of the Heart Rhythm Society (HRS) Task Force on Catheter and Surgical Ablation of Atrial Fibrillation developed in partnership with the European Heart Rhythm Association (EHRA) and the European Cardiac Arrhythmia Society (ECAS); in collaboration with the American College of Cardiology (ACC), American Heart Association (AHA), and the Society of Thoracic Surgeons (STS). Endorsed and approved by the governing bodies of the American College of Cardiology, the American Heart Association, the European Cardiac Arrhythmia Society, the European Heart Rhythm Association, the Society of Thoracic Surgeons, and the Heart Rhythm Society. Europace 2007; 9:335-379.

14. Cheema A, Dong J, Dalal D, Vasamreddy CR, Marine JE, Henrikson CA, Spragg D, Cheng A, Nazarian S, Sinha S, Halperin H, Berger R, Calkins H: Long-term safety and efficacy of circumferential ablation with pulmonary vein isolation. J Cardiovasc Electrophysiol 2006; 17:1080-1085.

15. Domanski M, Waldo AL: Catheter ablation of atrial fibrillation: a treatment frontier. J Interv Card Electrophysiol 2006; 15:141-143.

16. Haissaguerre M, Hocini M, Sanders P, Sacher F, Rotter M, Takahashi Y, Rostock T, Hsu LF, Bordachar P, Reuter S, Roudaut R, Clementy J, Jais P: Catheter ablation of long-lasting persistent atrial fibrillation: clinical outcome and mechanisms of subsequent arrhythmias. J Cardiovasc Electrophysiol 2005; 16:1138-1147.

17. Jais P, Hocini M, Sanders P, Hsu LF, Takahashi Y, Rotter M, Rostock T, Sacher F, Clementy J, Haissaguerre M: Long-term evaluation of atrial fibrillation ablation guided by noninducibility. Heart Rhythm 2006; 3:140-145.

18. Pappone C, Santinelli V: Atrial fibrillation ablation: state of the art. Am J Cardiol 2005; 96:59L64L.

19. Rostock T, Weiss C, Ventura R, Willems S: Pulmonary vein isolation during atrial fibrillation using a circumferential cryoablation catheter. Pacing Clin Electrophysiol 2004; 27:1024-1025.

20. Siu CW, Tse HF, Lau CP: Avoidance of electromagnetic interference to implantable cardiovertordefibrillator during atrioventricular node ablation for atrial fibrillation using transvenous cryoablation. Pacing Clin Electrophysiol 2006; 29:914-916.

21. Skanes AC, Klein G, Krahn A, Yee R: Cryoablation: potentials and pitfalls. J Cardiovasc Electrophysiol 2004; 15:S28-34.

22. Tuzcu V, Gonzalez MB, Schranz D: Cryoablation: better catheter stability compared to RF ablation. Anadolu Kardiyol Derg 2006; 6:182-184.

23. Skanes AC, Dubuc M, Klein GJ, Thibault B, Krahn AD, Yee R, Roy D, Guerra P, Talajic M: Cryothermal ablation of the slow pathway for the elimination of atrioventricular nodal reentrant tachycardia. Circulation 2000; 102:2856-2860.

24. Skanes AC, Jones DL, Teefy P, Guiraudon C, Yee R, Krahn AD, Klein GJ: Safety and feasibility of cryothermal ablation within the mid- and distal coronary sinus. J Cardiovasc Electrophysiol 2004; 15:1319-1323.

25. Timmermans C, Ayers GM, Crijns HJ, Rodriguez LM: Randomized study comparing radiofrequency ablation with cryoablation for the treatment of atrial flutter with emphasis on pain perception. Circulation 2003; 107:1250-1252.

26. Khairy P, Chauvet P, Lehmann J, Lambert J, Macle L, Tanguay JF, Sirois MG, Santoianni D, Dubuc M: Lower incidence of thrombus formation with cryoenergy versus radiofrequency catheter ablation. Circulation 2003; 107:2045-2050.

27. Tse HF, Kwong YL, Lau CP: Transvenous cryoablation reduces platelet activation during pulmonary vein ablation compared with radiofrequency energy in patients with atrial fibrillation. J Cardiovasc Electrophysiol 2005; 16:1064-1070. 
28. Nanthakumar K, Lau YR, Plumb VJ, Epstein AE, Kay GN: Electrophysiological findings in adolescents with atrial fibrillation who have structurally normal hearts. Circulation 2004; 110:117123.

29. Gerstenfeld EP, Sauer W, Callans DJ, Dixit S, Lin D, Russo AM, Beldner S, McKernan M, Marchlinski FE: Predictors of success after selective pulmonary vein isolation of arrhythmogenic pulmonary veins for treatment of atrial fibrillation. Heart Rhythm 2006; 3:165-170.

30. Oral H, Chugh A, Good E, Sankaran S, Reich SS, Igic P, Elmouchi D, Tschopp D, Crawford T, Dey S, Wimmer A, Lemola K, Jongnarangsin K, Bogun F, Pelosi F, Jr., Morady F: A tailored approach to catheter ablation of paroxysmal atrial fibrillation. Circulation 2006; 113:1824-1831.

31. Hindricks G, Piorkowski C, Tanner H, Kobza R, Gerds-Li JH, Carbucicchio C, Kottkamp H: Perception of atrial fibrillation before and after radiofrequency catheter ablation: relevance of asymptomatic arrhythmia recurrence. Circulation 2005; 112:307-313.

32. Neumann T, Erdogan A, Dill T, Greiss H, Berkowitsch A, Sperzel J, Kuniss M, Kurzidim K, Hamm CW, Pitschner HF: Asymptomatic recurrences of atrial fibrillation after pulmonary vein isolation. Europace 2006; 8:495-498.

33. Lustgarten DL, Keane D, Ruskin J: Cryothermal ablation: mechanism of tissue injury and current experience in the treatment of tachyarrhythmias. Prog Cardiovasc Dis 1999; 41:481-498.

34. Tse HF, Lau CP: Impact of duration of cryothermal application on clinical efficacy of pulmonary vein isolation using transvenous cryoablation. Pacing Clin Electrophysiol 2005; 28:839-843. 



\section{Chapter VII}

\section{Catheter-based cryoablation of postinfarction and idiopathic ventricular tachycardia: initial experience in a selected population}

Carl Timmermans, MD, Ph.D; Randy Manusama, MD, Becker Alzand, MD, and Luz-Maria Rodriguez, MD, Ph.D.

J Cardiovasc Electrophysiol. 2010 Mar;21(3):255-61. 


\section{Abstract}

Introduction: Transvenous cryoablation has proven to be safe and effective for the treatment of supraventricular arrhythmias. The aim of this prospective study was to report the feasibility and safety of catheter-based cryoablation for the treatment of postinfarction and idiopathic ventricular tachycardia (VT).

Methods and Results: Catheter-based cryoablation was performed in 17 patients (15 men, $58 \pm 18$ years). VT occurred after a prior myocardial infarction in 10 and was idiopathic in 7 patients. Cryoablation was performed with a 10-F, 6.5-mm tipped catheter. The ablation site was selected using entrainment mapping techniques for postinfarction VT. The site of the earliest activation time with optimal pace mapping was used for ablation of idiopathic VT. All targeted VTs (12 postinfarction and 7 idiopathic) were acute successfully ablated after a median number of 2 applications of 5 minutes with an average temperature of $-82 \pm 4^{\circ} \mathrm{C}$. Mean procedure and fluoroscopy times were $204 \pm 52$ and $52 \pm 20$ min for postinfarction VT and $203 \pm 24$ and $38 \pm 15$ min for idiopathic VT. No cryocatheter or cryoenergy complications were observed. After a follow-up of 6 months, 4 of the 10 patients with postinfarction VT had a recurrence. In one of the 7 patients with idiopathic VT the index arrhythmia recurred.

Conclusion: In this small patient population, catheter-based cryoablation of VT was safe and effective. Future studies are needed to evaluate the effect of cryothermy in a larger group of patients, especially those with postinfarction VT. 


\section{Introduction}

In recent years, catheter-based cryoablation has proven to be safe and effective for the treatment of various supraventricular arrhythmias. ${ }^{1} \mathrm{~A}$ number of unique properties of cryothermia provided several advantages over radiofrequency (RF) energy. Cryothermy does not require conscious sedation or anesthesia as it is painless. ${ }^{2}$ It has the ability to create reversible loss of function allowing the prediction of the effectiveness and safety of a lesion. Cryoenergy causes adherence of the catheter-tip to the underlying tissue during energy delivery assuring accurate lesion creation. ${ }^{3}$ Cryothermal ablation preserves the extracellular matrix and endothelial integrity. As a result, cryoablation has not been associated with pulmonary vein stenosis during the treatment of atrial fibrillation nor thromboembolic events. ${ }^{4,5}$ Finally, the lesions from cryoablation are large, transmural and homogeneous with a well-demarcated border zone. ${ }^{6-8}$ While a study showed that ventricular premature beats or nonsustained ventricular tachycardia (VT) from the right ventricular outflow tract (RVOT) can be successfully treated using cryocatheter ablation, no study has evaluated the use of cryoablation for the treatment of left-sided VT, either postinfarction or idiopathic in origin. ${ }^{9}$ The evaluation of the feasibility and safety of catheter-based cryoablation for the treatment of sustained monomorphic, right- or left-sided, postinfarction and idiopathic VT was the aim of our prospective study.

\section{Methods}

\section{Study population}

Twenty-five consecutive patients with postinfarction or idiopathic VT were enrolled. Patients with postinfarction VT were eligible for inclusion if they presented with a sustained monomorphic VT after a remote myocardial infarction so catheter mapping of the re-entry circuit could be performed. The inclusion criteria specified the need for the VT to be documented on a 12-lead ECG. Patients were excluded if they had any of the following: 1) older than 80 years, 2) active angina or cardiac ischemia on exercise thallium scan, 3) a left ventricular thrombus, 4) untreated or uncompensated congestive heart failure, or New York Heart Association functional class IV, 5) left main coronary artery disease, 6) an implanted artificial heart valve, 7) clinically significant aortic stenosis, 8) myocardial revascularisation within 6 months of the procedure, or 9) severe electrolyte abnormalities at the time of ablation. In patients with idiopathic VT, a 12lead ECG with a sustained or repetitive, monomorphic VT was required. The diagnosis of idiopathic VT was made after an extensive workup as previously 
described. ${ }^{10}$ The study was performed under the hospital ethics committee approval.

\section{Electrophysiological study and ablation procedure}

After obtaining written informed consent, all patients were studied in the fasting state without sedation. Except in patients with postinfarction VT, all antiarrhythmic drugs were discontinued for at least 5 times the drug's half-life before the electrophysiological study. Under local anesthesia, quadripolar catheters were positioned via the femoral route into the His bundle region and right ventricular apex. Programmed electrical stimulation was performed in the right ventricular apex using up to 3 extrastimuli. In patients with idiopathic VT, an additional quadripolar catheter for programmed electrical stimulation was positioned in the right atrium and, when VT could not be induced, the atrial and ventricular stimulation protocol was repeated under isoproterenol infusion at a rate of 1 to $3 \mu \mathrm{g} / \mathrm{min}$. Also in patients with idiopathic VT, rapid ventricular pacing was performed using cycle lengths of 430, 400, 350, and 300 ms given 10, 20, 35, and 50 stimuli. All 12 surface electrocardiographic leads and the bipolar intracardiac electrograms were recorded and stored by BARD Labsystem PRO. During the procedure, intravenous heparin was given as a $100-\mathrm{IU} / \mathrm{kg}$ bolus dose followed by boluses of 5000 IU every 1.5 hour if needed to keep an activated clotting time $\geq 300 \mathrm{~s}$. Protamine was administered routinely as a reversal agent before removing the sheaths.

After reproducible induction of the clinical VT during the baseline study, a $10-\mathrm{F}$, deflectable, bipolar cryoablation catheter with a $6.5-\mathrm{mm}$ tip electrode (CryoCor Inc., San Diego, California) was introduced into the ventricle. The cryoablation catheter was inserted through a 12-F, 62-cm-long sheath (DAIG, St. Jude Medical Inc., St. Paul, Minnesota) to improve steerability of the catheter during mapping of the left ventricle in patients with postinfarction VT. This sheath was positioned in the thoracic aorta just prior to the arch. For patients with idiopathic VT, a 11-F, 12-cm-long sheath (DAIG, St. Jude Medical Inc., St. Paul, Minnesota) was used. In general, only the clinical VT was targeted during the procedure.

For postinfarction VT, cryothermia was applied at sites with isolated diastolic potentials or, if these were absent, at sites with presystolic activity. In both instances, pacing needed to entrain VT with concealed fusion and either a postpacing interval tachycardia cycle length difference $\leq 30 \mathrm{~ms}$ or a stimulus to QRS interval within 20 ms of the electrogram to QRS interval was required. ${ }^{11}$ For idiopathic VT, the selection of the appropriate site for cryoablation was based on activation and pace mapping during VT. In all patients with idiopathic VT, we performed detailed mapping for endocardial activation preceding the QRS complex such as Purkinje activity during those with right bundle branch block (RBBB)-shape or muscular tissue in or around the pulmonary artery du- 
ring those with left bundle branch block (LBBB)-shape. An optimal pace map was defined as a 12-lead ECG obtained during pacing with an identical QRS complex as during spontaneous VT.

Cryothermia was delivered during VT for 5 minutes. If within 30-45 seconds, no termination of the VT was observed, the application was stopped and the ablation catheter was repositioned. These incomplete applications were classified as test applications. The ablation was considered successful when VT was not re-inducible with programmed stimulation using up to 3 extrastimuli. For patients with idiopathic VT, the noninducibility after ablation was confirmed after isoproterenol infusion. In case of LBBB-shaped idiopathic VT, right ventricular angiographies were made with the ablation catheter positioned at the site of successful application. This allowed visualization of the exact ablation site in relation to the pulmonary artery and pulmonary valve leaflets.

All patients were treated with aspirin $100 \mathrm{mg}$ daily for 8 weeks or re-started coumadin after the procedure. Patients with postinfarction VT continued the same antiarrhythmic drugs as prior to the procedure and, if indicated, an implantable cardioverter defibrillator (ICD) was implanted thereafter. In those with idiopathic VT, antiarrhythmic drugs were stopped.

\section{Follow-up}

Every patient underwent 24-hour Holter monitoring after the procedure. Symptoms of VT recurrence and/or ICD stored data were collected and evaluated at the 1, 3, and 6 months follow-up visits. If a patient reported symptoms, a 12-lead ECG and an additional 24-hour Holter or ICD interrogation were performed to determine if the symptoms correlated with VT recurrence. Long-term success was defined as no recurrence of the ablated VT after a follow-up of 6 months.

The evaluation of the safety of cryoablation was based on the occurrence of complications, during the procedure and for the following 30 days.

\section{Results}

\section{Patient population}

Of the 25 enrolled patients, there were 15 with postinfarction VT and 10 with idiopathic VT. Of the 15 patients with postinfarction VT, the arrhythmia was not inducible in 2 and antiarrhythmic drugs were prescribed. In 1 patient, the 10-F cryoablation catheter (and sheath) could not be positioned in the left ventricle due to aortoiliac obstructive disease and necessitated the use of a (smaller) RF ablation catheter to perform the procedure. An additional 2 patients were excluded from the study as they exhibited multiple, hemodynamically unstable, VTs at the time of the electrophysiological study. Both patients were ablated 
using RF energy guided by voltage mapping during sinus rhythm. In 3 of the 10 patients with idiopathic VT, the arrhythmia was not inducible despite pacing during isoproterenol infusion. These 3 patients remained without VT on a betablocking agent.

The clinical characteristics of the remaining 17 patients treated with cryoablation are shown in Tables 1 and 2.

Table 1 Clinical characteristics of the patients with postinfarction ventricular tachycardia treated with cryoablation

\begin{tabular}{|c|c|c|c|c|c|c|}
\hline $\begin{array}{l}\text { Patient } \\
\text { No. }\end{array}$ & Age/Sex & LVEF, \% & Infarction Site & $\begin{array}{l}\text { VT Mor- } \\
\text { phology }\end{array}$ & AAD at EPS & ICD \\
\hline P-1 & $73 / \mathrm{F}$ & 63 & Inferior & RBBB, LA & $\begin{array}{l}\text { Metoprolol, } \\
\text { amiodarone }\end{array}$ & No \\
\hline P-2 & $60 / \mathrm{M}$ & 38 & $\begin{array}{l}\text { Inferior + } \\
\text { posterior }\end{array}$ & RBBB, NW & $\begin{array}{l}\text { Metoprolol, } \\
\text { amiodarone }\end{array}$ & After ablation \\
\hline P-3 & $65 / \mathrm{M}$ & 40 & $\begin{array}{l}\text { Lateral + } \\
\text { posterior }\end{array}$ & RBBB, RA & Amiodarone & After ablation \\
\hline P-4 & $73 / \mathrm{M}$ & 55 & Inferior & RBBB, NW & Metoprolol & No \\
\hline P-5 & $67 / M$ & 25 & Anterior & RBBB, RA & Amiodarone & After ablation \\
\hline P-6 & $71 / \mathrm{M}$ & 40 & Inferior & RBBB, LA & Sotalol & After ablation \\
\hline P-7 & $64 / \mathrm{M}$ & 20 & $\begin{array}{l}\text { Anterior + } \\
\text { inferior }\end{array}$ & RBBB, NW & Metoprolol & After ablation \\
\hline P-8 & $70 / \mathrm{M}$ & 20 & $\begin{array}{l}\text { Anterior + } \\
\text { inferior }\end{array}$ & LBBB, IA & Amiodarone & $\begin{array}{l}5 \text { years prior } \\
\text { to ablation }\end{array}$ \\
\hline P-9 & $68 / M$ & 20 & Anterior & RBBB, LA & $\begin{array}{l}\text { Metoprolol, } \\
\text { amiodarone }\end{array}$ & After ablation \\
\hline P-10 & $42 / \mathrm{M}$ & 19 & Anterior & RBBB, LA & Metoprolol & After ablation \\
\hline
\end{tabular}

$\mathrm{AAD}=$ antiarrhythmic drug; $\mathrm{EPS}=$ electrophysiological study; $\mathrm{F}=$ female; $\mathrm{IA}=$ intermediate axis; ICD = implantable cardioverter defibrillator; $\mathrm{LA}=$ left axis; LBBB = left bundle-branch block; LVEF = left ventricular ejection fraction; $\mathrm{M}=$ male; $\mathrm{NW}=$ north-west axis; $\mathrm{P}-=$ number of patient with postinfarction VT; RA = right axis; RBBB = right bundle-branch block.

Table 2 Clinical characteristics of the patients with idiopathic ventricular tachycardia treated with cryoablation

\begin{tabular}{llllllll}
\hline $\begin{array}{l}\text { Patient } \\
\text { No. }\end{array}$ & Age/Sex & LVEF, \% & $\begin{array}{l}\text { Symptom } \\
\text { Duration }\end{array}$ & $\begin{array}{l}\text { Clinical } \\
\text { Arrhythmia }\end{array}$ & $\begin{array}{l}\text { VT Mor- } \\
\text { phology }\end{array}$ & $\begin{array}{l}\text { VT-CL, } \\
\text { ms }\end{array}$ & $\begin{array}{l}\text { AAD before } \\
\text { EPS }\end{array}$ \\
\hline I-1 & 66/F & 63 & 16 months & SMVT & LBBB, RA & 370 & Metoprolol \\
I-2 & 18/M & 60 & 2 months & SMVT & RBBB, RA & 500 & Verapamil \\
I-3 & $65 / M$ & 58 & 1 month & RMVT & LBBB, IA & 320 & Metoprolol \\
I-4 & $58 / M$ & 59 & 1 year & RMVT & LBBB, IA & 340 & Sotalol \\
I-5 & $27 / M$ & 63 & 11 years & SMVT & RBBB, LA & 475 & No \\
I-6 & $35 / M$ & 65 & 3 years & SMVT & LBBB, RA & 290 & Verapamil \\
I-7 & 34/M & 62 & 12 years & SMVT & RBBB, LA & 345 & Sotalol \\
\hline
\end{tabular}

$\mathrm{AAD}=$ antiarrhythmic drug; $\mathrm{CL}=$ cycle length; $\mathrm{EPS}=$ electrophysiological study; $\mathrm{F}=$ female; $\mathrm{I}-$ = number of patient with idiopathic VT; IA = intermediate axis; LA = left axis; LBBB = left bundlebranch block; $\mathrm{LVEF}=$ left ventricular ejection fraction; $\mathrm{M}=$ male; $\mathrm{RA}=$ right axis; $\mathrm{RBBB}=$ right bundle-branch block; RMVT $=$ repetitive monomorphic VT; SMVT = sustained monomorphic VT. 
The postinfarction VT group had 9 men and 1 woman with a mean age of $65 \pm 9$ years. All 10 patients presented with palpitations; 3 also complained of dyspnea and fatigue, and 3 had near syncope. The patient with a previously implanted ICD experienced, 2 months before the ablation, several discharges for a slow VT. The mean cycle length of the clinical VTs and the mean left ventricular ejection fraction were $461 \pm 71 \mathrm{~ms}$ and $34 \pm 16 \%$, respectively. An ICD was implanted in 7 patients after the ablation.

The 7 patients with idiopathic VT had no evidence of structural heart disease as documented by physical examination, 12-lead ECG during sinus rhythm, exercise testing, echocardiography, coronary angiography (performed in the 3 patients $>40$ years) and MRI. There were 6 men and 1 woman with a mean age of $43 \pm 19$ years. Five of them presented with sustained monomorphic VT and 2 with recurrent runs of nonsustained monomorphic VT. The mean cycle length and left ventricular ejection fraction were $377 \pm 80 \mathrm{~ms}$ and $61 \pm 3 \%$, respectively.

\section{Electrophysiological characteristics}

The clinical VT in the group with a prior myocardial infarction was induced by programmed electrical stimulation in 9 patients and was incessant in 1 (P-7). Nine patients had sustained VT that was hemodynamically well tolerated to allow entrainment mapping. In 1 patient (P-10), despite having sustained VT the day before the procedure, the arrhythmia was non-sustained during the study.

Two patients had a frequently induced VT that prevented adequate mapping of the clinical one. These VTs were also targeted for ablation. One of those VTs had a LBBB-like morphology with an intermediate axis (P-1) and the other, a RBBB-like morphology with left axis (P-8).

The VT of the 7 patients in the idiopathic group was induced with programmed electrical stimulation (one patient [I-3] was inducible only after isoproterenol infusion). Six patients had VT induced by ventricular extrastimuli and 1 patient (I-2) by rapid ventricular pacing. The induced VT was sustained in all patients.

\section{Mapping and ablation procedure}

Tables 3 and 4 summarize the mapping and ablation parameters in patients with postinfarction and idiopathic VT. 
Table 3 Mapping and ablation parameters in patients with postinfarction ventricular tachycardia at the successful cryoablation site

\begin{tabular}{|c|c|c|c|c|c|c|c|c|c|c|c|c|}
\hline $\begin{array}{l}\text { Patient, } \\
\text { No. }\end{array}$ & IDP & ECF & $\begin{array}{l}\text { PPI, } \\
\text { ms }\end{array}$ & $\begin{array}{l}\text { VT- } \\
\text { CL, } \\
\text { ms }\end{array}$ & $\begin{array}{l}\mathrm{S}- \\
\mathrm{QRS}, \\
\mathrm{ms}\end{array}$ & $\begin{array}{l}\text { EG- } \\
\text { QRS, } \\
\text { ms }\end{array}$ & Cryo Site in LV & $\begin{array}{l}\text { Cryo, } \\
\mathrm{n}\end{array}$ & $\begin{array}{l}\text { Mean } \\
\text { Tempera- } \\
\text { ture, }{ }^{\circ} \mathrm{C}\end{array}$ & $\begin{array}{l}\text { Cryo } \\
\text { Test, } \\
\mathrm{n}\end{array}$ & $\begin{array}{l}\text { Procedure, } \\
\text { min }\end{array}$ & $\begin{array}{l}\text { Fluoroscopy, } \\
\text { min }\end{array}$ \\
\hline \multirow[t]{2}{*}{ P-1 } & Yes & Yes & 500 & 460 & 120 & 100 & posterolateral & 10 & -81 & 4 & 254 & 83 \\
\hline & Yes & Yes & 480 & 470 & 150 & 150 & inferoseptal & 2 & -81 & 1 & & \\
\hline $\mathrm{P}-2$ & No & Yes & 380 & 380 & 50 & 50 & inferior & 7 & -80 & 6 & 191 & 52 \\
\hline$P-3$ & No & Yes & 350 & 340 & 80 & 80 & posterolateral & 5 & -80 & 7 & 273 & 75 \\
\hline P-4 & No & Yes & 460 & 460 & 50 & 50 & inferior & 2 & -80 & 2 & 236 & 61 \\
\hline P-5 & Yes & Yes & 490 & 480 & 160 & 160 & anteroseptal & 2 & -80 & 3 & 165 & 26 \\
\hline P-6 & Yes & Yes & 430 & 430 & 170 & 170 & inferior & 1 & -81 & 1 & 185 & 49 \\
\hline $\mathrm{P}-7^{*}$ & Yes & NA & NA & 600 & 260 & 260 & inferior & 2 & -71 & No & 95 & 26 \\
\hline \multirow[t]{2}{*}{ P-8 } & Yes & Yes & 520 & 500 & 220 & 250 & inferior & 4 & -85 & 3 & 195 & 34 \\
\hline & Yes & Yes & 580 & 580 & 140 & 140 & $\begin{array}{l}\text { posteroseptal } \\
\text { (basal) }\end{array}$ & 2 & -85 & No & & \\
\hline P-9 & Yes & Yes & 500 & 500 & 100 & 100 & inferoseptal & 2 & -82 & 2 & 251 & 67 \\
\hline P-10† & No & NA & NA & 460 & 40 & 50 & inferoposterior & 2 & -89 & No & 190 & 45 \\
\hline
\end{tabular}

Note that the second VT of patients 1 and 8 was the frequently induced (during the electrophysiological study), not clinical VT. CL = cycle length; Cryo = cryothermy application; Cryo Test = cryothermy test application; ECF = entrainment with concealed fusion; EG-QRS = electrogram to QRS interval; IDP = isolated diastolic potentials; $\mathrm{LV}=$ left ventricle; $\mathrm{NA}=$ not applicable; $\mathrm{P}-$ = number of patient with postinfarction VT; PPI = postpacing interval; S-QRS = stimulus to QRS interval; VT = ventricular tachycardia; * catheter-induced termination of incessant VT; † non-sustained VT during the ablation procedure.

Table 4 Mapping and ablation parameters in patients with idiopathic ventricular tachycardia at the successful cryoablation site

\begin{tabular}{|c|c|c|c|c|c|c|c|c|}
\hline $\begin{array}{l}\text { Patient } \\
\text { No. }\end{array}$ & $\begin{array}{l}\text { Pace Map, } \\
\text { QRS }_{\mathrm{P}} / \mathrm{QRS} \mathrm{VT}_{\mathrm{VT}}\end{array}$ & $\begin{array}{l}\text { EAT, } \\
\text { ms }\end{array}$ & Cryo Site & $\begin{array}{l}\text { Cryo, } \\
\mathrm{n}\end{array}$ & $\begin{array}{l}\text { Mean } \\
\text { Tempera- } \\
\text { ture, }{ }^{\circ} \mathrm{C}\end{array}$ & $\begin{array}{l}\text { Cryo } \\
\text { Test, } \\
\mathrm{n}\end{array}$ & $\begin{array}{l}\text { Procedure, } \\
\text { min }\end{array}$ & $\begin{array}{l}\text { Fluoroscopy, } \\
\text { min }\end{array}$ \\
\hline $\mathrm{I}-1$ & $12 / 12$ & -12 & Septal side RVOT & 1 & -76 & 1 & 215 & 62 \\
\hline $\mathrm{I}-2$ & $12 / 12$ & -50 & $\begin{array}{l}\text { Anterior side mitral } \\
\text { annulus }\end{array}$ & 2 & -79 & No & 221 & 51 \\
\hline $\mathrm{I}-3$ & $12 / 12$ & -45 & Midseptal side RVOT & 4 & -81 & 3 & 218 & 29 \\
\hline $\mathrm{I}-4$ & $12 / 12$ & -25 & Free wall RVOT & 1 & -85 & No & 180 & 21 \\
\hline $\mathrm{I}-5$ & $11 / 12$ & -45 & $\begin{array}{l}\text { Inferoposteroseptal } \\
\text { region LV }\end{array}$ & 1 & -89 & No & 225 & 28 \\
\hline $\mathrm{I}-6$ & $12 / 12$ & -37 & Midseptal side RVOT & 2 & -85 & 7 & 200 & 47 \\
\hline $\mathrm{I}-7$ & $12 / 12$ & -32 & $\begin{array}{l}\text { Inferoposteroseptal } \\
\text { region LV }\end{array}$ & 1 & -87 & No & 160 & 31 \\
\hline
\end{tabular}

Cryo $=$ cryothermy application; Cryo Test $=$ cryothermy test application; EAT $=$ earliest (endocar dial) activation time; I- = number of patient with idiopathic VT; $L V=$ left ventricle; $Q R S_{\mathrm{P}} / \mathrm{QRS}_{\mathrm{VT}}=$ match between QRS morphology during pace mapping and clinical VT, with the number representing the number of ECG leads with identical QRS morphology; RVOT = right ventricular outflow tract.

Postinfarction VT. Of the 10 patients in the postinfarction group, 8 with 10 targeted VTs could be entrained with concealed fusion at the successful site of ablation. According to previously published entrainment criteria, ${ }^{11}$ cryothermy was successfully delivered in the central part of the isthmus of the re-entry cir- 
cuit in 4 VTs and in the exit site in 6 VTs (Fig. 1 and 2). In the patient with incessant VT (P-7), ablation was applied at the site where placement of the cryocatheter resulted in termination and noninducibility of the VT. In the remaining patient (P-10), sustained VT could not be induced during the electrophysiological study, so the entrainment criteria could not be applied. Ablation was performed at the exit site determined by a short stimulus-QRS and electrogramQRS interval. Of note, 3 of the target sites showed significant calcification near the application site (P-7 to P-9). Overall, all 10 clinical and 2 frequently induced VTs were acute successfully ablated after a median number of 2 applications with an average temperature of $-81 \pm 4^{\circ} \mathrm{C}$. Mean procedure and fluoroscopy times were $204 \pm 52$ and $52 \pm 20 \mathrm{~min}$, respectively. After ablation of the $12 \mathrm{VTs}$, 5 different sustained VTs were inducible in 4 patients (P-2, P-3, P-7 (2 VTs) and P-8).

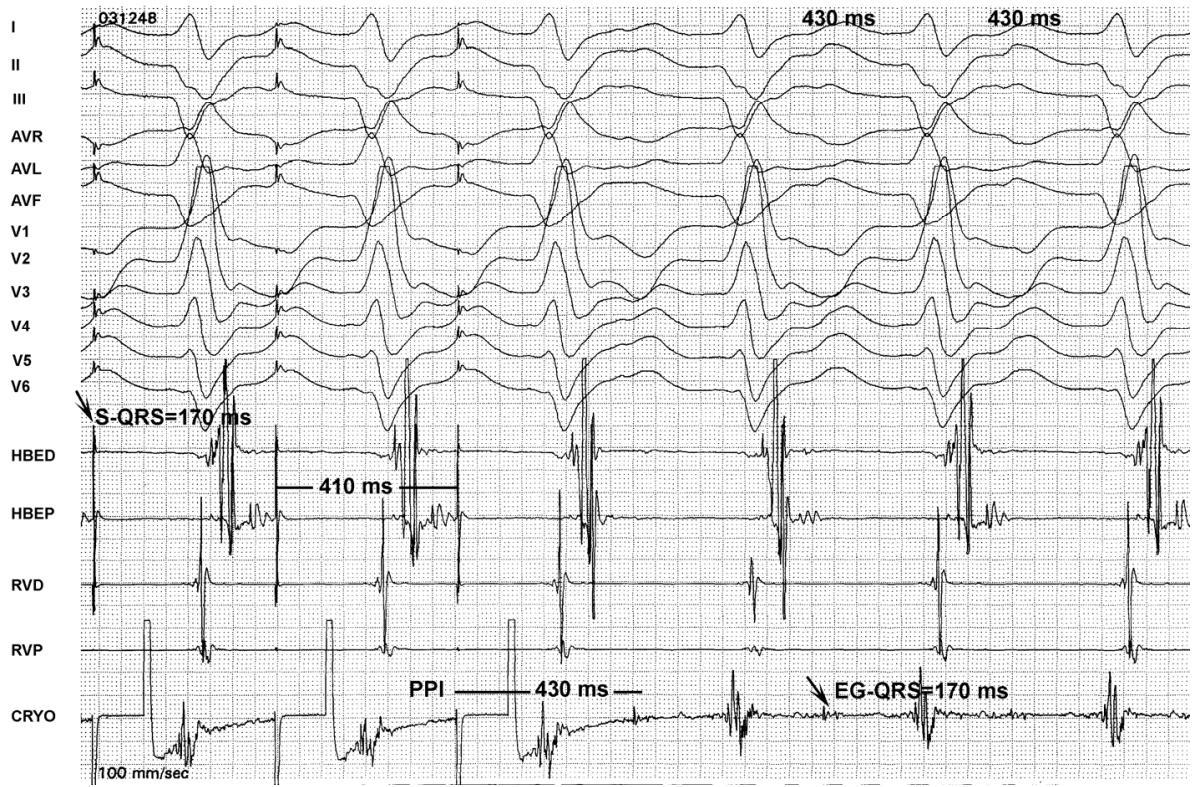

Figure 1. Mapping parameters at the site of successful cryoablation of a postinfarction VT (P-6). Pacing from the cryoablation catheter (cryo) with a slightly faster rate $(410 \mathrm{~ms}$ ) than the clinical VT (430 ms), at a site where a mid-diastolic potential was present, showed entrainment with concealed fusion. The postpacing interval (PPI) matched the ventricular tachycardia cycle length. The stimulus (first arrow) to QRS (S-QRS) interval was exactly equal to the electrogram (second arrow) to QRS (EG-QRS) interval (170 ms). This indicated that the cryoablation site was in the central part of the isthmus of the reentry circuit. From top to bottom, 12-lead ECG; bipolar endocardial recordings from distal (HBED) and proximal (HBEP) His bundle and from distal (RVD) and proximal (RVP) right ventricle. 


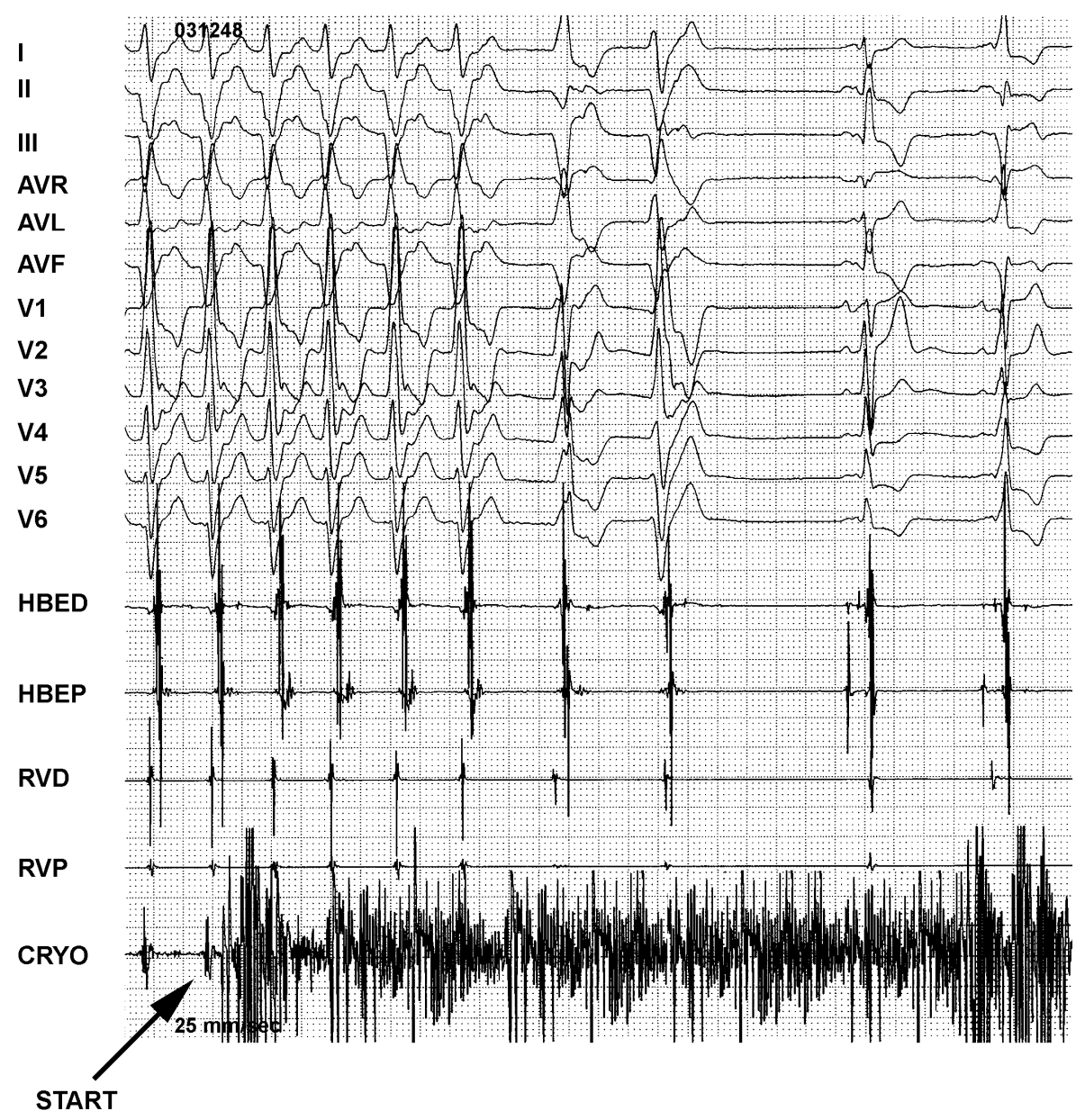

Figure 2. The application of cryothermy (START) at the site showed in Fig. 1 terminated the postinfarction VT within a few seconds. Abbreviations as in Fig. 1.

Left-sided idiopathic VT. In all 3 patients with RBBB-VT, a potential preceded the onset of the QRS during VT by a mean of $42 \pm 9$ ms. In 2 of these 3 patients (I-5, I-7), a sharp potential, compatible with Purkinje activity, was recorded at the inferoposteroseptal area of the left ventricle. In the remaining patient (I-2) a potential was recorded at the anterior side of the mitral annulus. In those patients, VT terminated during cryoablation and was no longer inducible (Fig. 3). A median of 1 application with an average temperature of $-85 \pm 5^{\circ} \mathrm{C}$ was used. Mean procedure and fluoroscopy times were $202 \pm 36$ and $37 \pm 13 \mathrm{~min}$, respectively.

Right-sided idiopathic VT. Electrical activation started before the VT QRS complex, with a mean earliest endocardial activation time of $-30 \pm 14 \mathrm{~ms}$. A 
12/12 pace map was obtained in all patients. All 4 patients with LBBB-VT were successfully ablated on the septal side (1 patient), the midseptal side ( 2 patients) or the free wall (1 patient) of the RVOT. Right ventricular angiography confirmed that the position of the cryoablation catheter at the sites of successful ablation was always located under the pulmonary valve. The median number of applications was 2 with an average temperature of $-82 \pm 4^{\circ} \mathrm{C}$. Mean procedure and fluoroscopy times were $203 \pm 17$ and $40 \pm 18 \mathrm{~min}$, respectively.

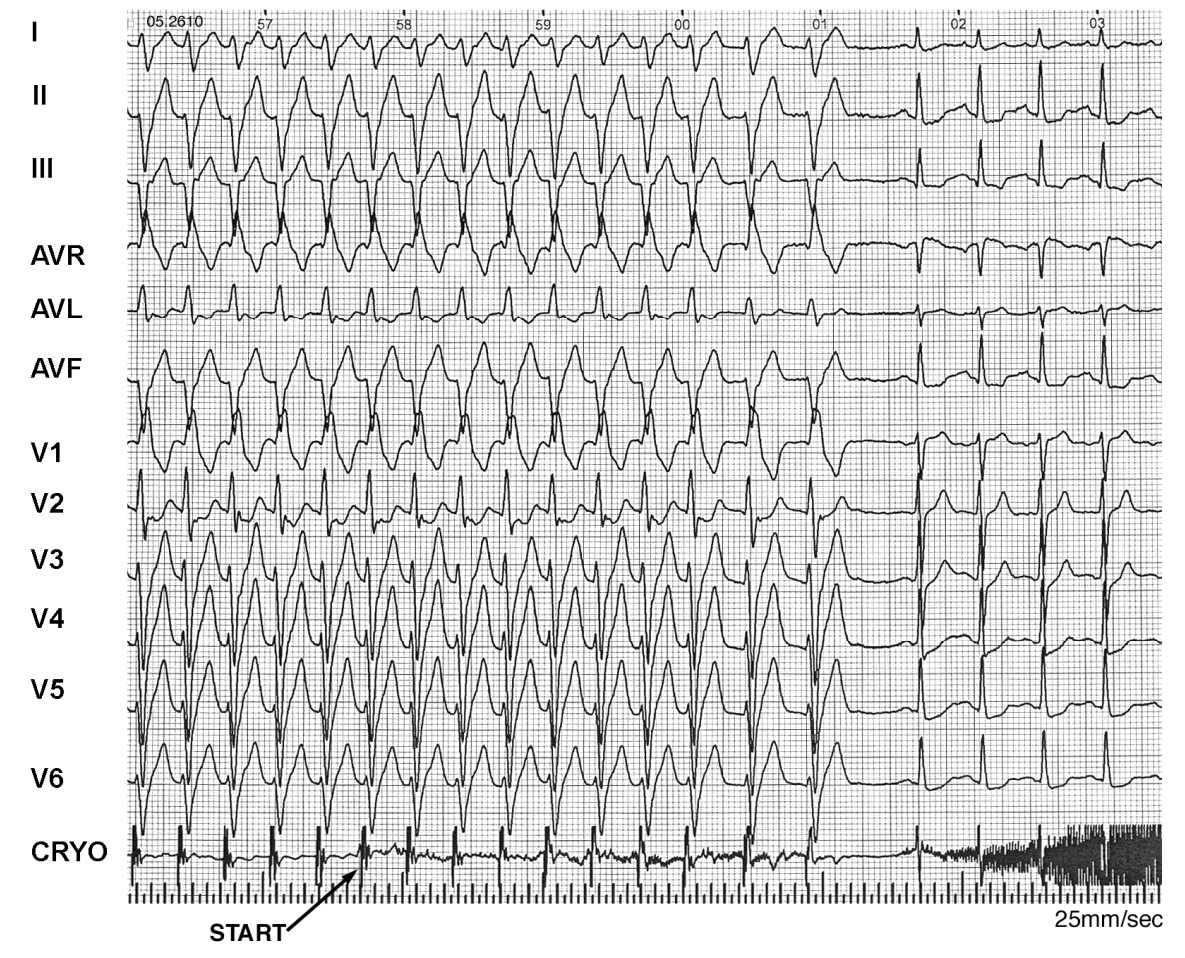

Figure 3. The 12-lead ECG and endocardial recording from the cryoablation catheter (CRYO) during idiopathic RBBB-shaped VT in patient I-7. The application of cryothermy (START) permanently interrupted the VT. Note the deceleration of the VT before termination due to cooling of the cryocatheter.

\section{Follow-up}

Postinfarction VT. Of the 10 patients who underwent cryoablation, 4 had a VT recurrence (P-6 to P-8, P-10), with cycle lengths detected by the ICD similar to the ones treated by cryothermy. The recurrences occurred within 4 weeks in 3 patients (P-7, P-8, P-10) and after 2 months in the remaining patient (P-6). Of these 4 patients, 3 received ICD therapy delivered for their VT. The fourth patient had a recurrence of his incessant VT. This patient was treated with RF le- 
sions guided by voltage mapping during sinus rhythm and has had no additional recurrences of VT. Therefore, the overall 6-month efficacy for cryoablation was $60 \%$.

Idiopathic VT. During a follow-up of 6 months, all 4 patients who had rightsided VT were without clinical recurrence. Of the 3 patients with left-sided VT, 1 had a recurrence at the time of the 6 month follow-up (I-2). The patient had a non-sustained VT on 12-lead Holter monitoring and underwent a successful second cryoablation procedure. The 6-month efficacy for cryoablation of idiopathic VT was $86 \%$.

\section{Complications}

Overall, 1 patient with a postinfarction VT (P-4) had a complication associated with the procedure: a pericardial effusion. During the index procedure, the right ventricular pacing catheter was pushed through the right ventricular free-wall resulting in perforation that became apparent after withdrawal of the catheter at the end of the study. In this patient, the cryoablation catheter was in the left ventricle and hence was though to be unlikely the cause of the perforation. The pericardial effusion was treated with pericardio-centesis and no further intervention was required. There was no residual defect. No further complications were seen, including lack of groin haematoma or pseudo-aneurysm formation despite the large diameter of the sheath used. Lastly, no complications were observed in the following 30 days.

\section{Discussion}

This study demonstrated the safety and efficacy of cryoablation of VT, of both postinfarction and idiopathic origin. The overall acute efficacy for cryoablation in this study was $100 \%$. The 6-month efficacy for postinfarction and idiopathic VT was $60 \%$ and $86 \%$, respectively. Theoretically, one may consider the patient with postinfarction VT and aortoiliac obstructive disease, in whom the cryoablation catheter (and sheath) could not be inserted in the left ventricle, as a failure of cryoablation. Nevertheless, we have chosen to evaluate the outcome of the procedure based on the successful or unsuccessful effect of cryoenergy delivery.

Regarding postinfarction VT, our study is the first to demonstrate the feasibility of catheter-based cryoablation for the treatment of this arrhythmia. Since we did not have a 12-lead ECG of the recurrent VT in all patients with an ICD, the exact percentage of recurrence of the index VT remains unknown but we speculate they were the same due to the similarities in cycle length. The use of a 6.5$\mathrm{mm}$ ablation catheter-tip and the large cryolesions 7,8 may permit ablation at the exit site without the need to place the electrode in the central part of the reentry circuit's isthmus while maintaining adequate clinical efficacy. 
The use of cryoablation in patients with idiopathic, monomorphic ventricular extrasystoles or non-sustained VT of the RVOT has been reported..$^{9}$ Long-term efficacy in this initial study was defined at 9 weeks with 13 of 14 patients exhibiting no recurrence of their treated arrhythmia. In our study, with longer followup, 6 of 7 patients with both forms of idiopathic VT were without recurrence. Therefore, our efficacy compares favourably to this initial study of cryoablation of VT.

One disadvantage of this system and likely catheter-based cryoablation in general, is the handling characteristics of the catheter. Due to the internal mechanisms necessary to deliver the refrigerant to the catheter-tip and a hollow shaft necessary to return the spent refrigerant, the catheter has lower torque transmission and manoeuvrability as compared to RF ablation catheters. While this does not significantly limit the system for the treatment of supraventricular tachycardia, in the more confined space of the ventricle and the serpentine manipulations necessary to reach certain areas of desired ablation, these characteristics of the cryoablation catheter can be a limitation for VT ablation. Despite the difficult manipulation of the cryoablation catheter, the fluoroscopy and procedure times were comparable to previous studies.

There was only a single complication in our study. This was most likely related to the right ventricular pacing catheter and was not believed to be associated with the delivery of cryoenergy nor the cryoablation catheter itself.

\section{Limitations}

The obvious limitation of this study is its small sample size. But, as our intent was to evaluate only feasibility and safety, we consider our findings both interesting and valid in meeting our objectives. Larger trials will be required to confirm the results presented herein. Also, our population of patients was highly selected and considered for ablation only if they had a hemodynamically well tolerated single VT. Future studies may include a direct comparison to RF ablation of VT in a randomized trial.

\section{Conclusion}

Although a limited number of highly selected patients were enrolled, catheterbased cryoablation of both postinfarction and idiopathic VT is safe and effective. Despite the larger catheter and new energy source, there were no cryocatheter or cryoenergy delivery complications. Further studies need to determine if cryoablation can increase the therapeutic efficacy for postinfarction VTs. 


\section{References}

1. Rodriguez LM, Geller JC, Tse HF, Timmermans C, Reek S, Lee K LF, Ayers GM, Lau CP, Klein HU, Crijns HJGM: Acute results of transvenous cryoablation of supraventricular tachycardia (atrial fibrillation, atrial flutter, Wolff-Parkinson-White syndrome, atrioventricular nodal reentry tachycardia). J Cardiovasc Electrophysiol 2002; 13:1082-1089.

2. Timmermans C, Ayers GM, Crijns HJGM, Rodriguez LM: Randomized study comparing radiofrequency ablation with cryoablation for the treatment of atrial flutter with emphasis on pain perception. Circulation 2003; 107:1250-1252.

3. Skanes AC, Dubuc M, Klein GJ, Thibault B, Krahn AD, Yee R, Roy D, Guerra P, Talajic M: Cryothermal ablation of the slow pathway for the elimination of atrioventricular nodal reentrant tachycardia. Circulation 2000; 102:2856-2860.

4. Tse HF, Reek S, Timmermans C, Lee KLF, Geller JC, Rodriguez LM, Ghaye B, Ayers GM, Crijns HJGM, Klein HU, Lau CP: Pulmonary vein isolation using transvenous catheter cryoablation for treatment of atrial fibrillation without risk of pulmonary vein stenosis. J Am Coll Cardiol 2003; 42:752-758.

5. Khairy P, Chauvet P, Lehmann J, Lambert J, Macle L, Tanguay JF, Sirois MG, Santoianni D, Dubuc M: Lower incidence of thrombus formation with cryoenergy versus radiofrequency catheter ablation. Circulation 2003; 107:2045-2050.

6. Rodriguez LM, Leunissen J, Hoekstra A, Korteling BJ, Smeets JLRM, Timmermans C, Vos M, Daemen M, Wellens HJJ: Transvenous cold mapping and cryoablation of the AV node in dogs. Observations of chronic lesions and comparison to those obtained using radiofrequency ablation. J Cardiovasc Electrophysiol 1998; 9:1055-1061.

7. Wadhwa MK, Rahme MM, Dobak J, Li H, Wolf P, Chen P, Feld GK: Transcatheter cryoablation of ventricular myocardium in dogs. J Interv Card Electrophysiol 2000; 4:537-545.

8. Reek S, Geller JC, Schildhaus HU, Ripley KL, Klein HU: Feasibility of catheter cryoablation in normal ventricular myocardium and healed myocardial infarction. Pacing Clin Electrophysiol 2004; 27:1530-1539.

9. Kurzidim K, Schneider HJ, Kuniss M, Sperzel J, Greiss H, Berkowitsch A, Pitschner HF: Cryocatheter ablation of right ventricular outflow tract tachycardia. J Cardiovasc Electrophysiol 2005; 16:1-4.

10. Timmermans C, Rodriguez LM, Crijns HJGM, Moorman AFM, Wellens HJJ: Idiopathic left bundlebranch block-shaped ventricular tachycardia may originate above the pulmonary valve. Circulation 2003; 108:1960-1967.

11. Stevenson WG, Friedman PL, Sager PT, Saxon LA, Kocovic D, Harada T, Wiener I, Khan H: Exploring postinfarction reentrant ventricular tachycardia with entrainment mapping. J Am Coll Cardiol 1997; 29:1180-1189. 
Chapter VIII

General discussion and future perspectives 
Throughout years of ongoing developments cryothermia finally found its way for catheter-based applications. Almost exclusively relying on animal studies and cryosurgical experience using different probes and ablation protocols it remained questionable if cryothermia could keep up the high expectations when endocardial applications in different regions of the heart were performed. We were among the first to report the long-term results of cryothermia for arrhythmia treatment. By using atrial flutter (AFL) ablation as a model to confirm long-term efficacy and test different catheters and ablation protocols we were able to reduce the amount of cryoenergy to equal with radiofrequency catheter ablation (RF) application times, while maintaining the high safety profile of cryoablation. Applying cryothermia in other regions of the heart to treat atrial fibrillation (AF) and ventricular tachycardia proved to be feasible, effective and safe. The properties of catheter-based cryothermia are of indispensible value in the current arrhythmia management with its growing demand for transvenous catheter ablation more frequently involving extensive ablation strategies that may jeopardize a safe outcome.

\section{Atrial flutter ablation as an ablation model for optimizing cryoablation}

To optimize cryodelivery and to evaluate ablation protocols in other regions of the heart, we relied on the efficacy of linear ablation of the isthmus between the tricuspid ring and the orifice of the inferior caval vein known as the cavotricuspid isthmus (CTI), an integral part of the AFL circuit. The concept of AFL being a macro-reentrant circuit was long time described before invasive treatments were initiated. ${ }^{1}$

'Atrial flutter is a condition in which, as has recently been shown, the contraction wave follows a circular and never ending path in the auricle, the circuits being completed at a rate of from 240 to 350 per minute in different subjects. ${ }^{1}$ Sir Thomas Lewis, 1920

Since catheter ablation of typical, 'sawtooth-like' $\mathrm{AFL}^{2,3}$ was proposed during the early nineties, it became clear that the long-term efficacy of the procedure depended on the ablation targets, a critical or non-critical part of the typical AFL circuit. ${ }^{4-9}$ Several mapping studies have linked the rotational route of common, typical AFL to the essential part, the CTI, that proved to be very accessible for percutaneous ablation to permanently interrupt the flutter circuit if properly confirmed. ${ }^{8}$ An excellent outcome of an ablation procedure requires reliable procedural endpoints. Lack of AFL reinduction after a line of conduction block was created, proved of limited value and has a long-term efficacy of $76 \%{ }^{4}, 10,11$ 
Bidirectional isthmus conduction block became the hallmark of procedural efficacy and generally results in a $90 \%$ long-term efficacy. ${ }^{12}$ Some authors relied on sequential activation mapping from both pacing from the right free atrial wall and the coronary sinus. Others proposed a minimal double potential interval of $90 \mathrm{~ms}$ with a variation of $15 \mathrm{~ms}$ along the entire ablation line. ${ }^{13}$ Differential pacing has been shown to accurately assess isthmus conduction block by pacing close to the ablation line and then marking the change in the timing of the double potentials while pacing away from the ablation line. ${ }^{14} \mathrm{~A}$ change in bipolar electrogram morphology during sequential activation mapping has been used in verifying bidirectional conduction block. ${ }^{15,16}$ Differences in catheter positioning were also investigated. Some operators preferred to bridge the isthmus by positioning a duodecapolar catheter at the right atrial wall, overlying the isthmus with its distal electrodes inserted in the coronary sinus to distinguish between (very) slow conduction and conduction block. ${ }^{17}$ Once these endpoints had been established, operators evaluated different catheters to secure a line of block at the CTI, by increasing lesion size. Although not frequent, complications as a result of inadequate catheter positioning, the energy source and the vicinity of the right coronary artery ${ }^{18}$ and the AV-node were reported..$^{19}$ Post-mortem studies, angiographic and echocardiographic imaging revealed CTI dimensions and individual variations, ${ }^{20-23}$ whereupon others based catheter positioning and catheter type ${ }^{24,25}$ in accordance with in vivo and in vitro studies of catheter type related tissue destruction. ${ }^{26-28}$ By using a duodecapolar catheter around the tricuspid valve and a decapolar catheter inserted in the coronary sinus, we were able to show permanent bidirectional isthmus conduction block after a postablation 30-minutes waiting period and isoproterenol infusion (chapter II-V) known to decrease the refractory period of myocardial tissue and facilitate (re-) conduction..$^{29,30}$ Due to an increased operator experience in catheter handling (chapter II) and a reduction in the number and duration of cryothermia applications, (chapter II-V) we increased procedural efficiency during ablation of the CTI while maintaining a long-term efficacy of more than $90 \%$. During the treatment of more than 150 patients using different ablation protocols and tip-sizes, no complications related to the use of cryothermia, occurred. Based on the results of these studies, an ablation protocol for the treatment of other arrhythmias like atrial fibrillation and ventricular tachycardia was developed. We demonstrated a high safety and favorable outcome of single 3-5 minutes cryoapplications in these particular regions (Chapter VI, VII), despite the differences in regional blood flow, wall thickness and catheter orientation to the underlying tissue. Future studies are needed to evaluate the effect of catheter-based cryoablation in a larger group of patients, especially those with ventricular tachycardia. 


\section{Clinical impact of atrial flutter ablation}

To alter the ablation strategy we recruited more than 150 patients with AFL to undergo ablation (chapter II-V). All patients were symptomatic, refractory to one or more anti-arrhythmic agents and had at least one 12-lead ECG documentation of typical AFL. In addition more than $60 \%$ of the patients also suffered from AF. Considering the close inter-relationship between $\mathrm{AFL}$ and $\mathrm{AF}^{31-38}$ one could question the primary target for the treatment of AFL: CTI ablation or pulmonary vein isolation (PVI). Although this cannot be answered from our studies since we did not systematically evaluate AF (re-) occurrence during the followup, it remains an intriguing question. Estimated to occur about 88/100,000 person-years in the United States with 200,000 new patients annually and in up to $10 \%$ of patients presenting supraventricular tachycardias ${ }^{39}$, it places a heavy burden on modern society and health care services..$^{40}$ If left untreated it has a higher mortality than controls suggesting prompt treatment when diagnosed. ${ }^{41}$ The average age at which AFL occurs is about 70 years. ${ }^{40,42}$ In accordance with our own findings more than half of the AFL population suffers from AF also known to increase mortality. ${ }^{41}$ These data support previous electrophysiological studies showing the requirement of triggers to initiate (by inducing unidirectional block at the CTI) and perpetuate (by causing functional block at the terminal crest ${ }^{43}, 44$ ) the peritricuspid rotating wavefront. Experiments have shown that AFL has a low tendency to convert in $\mathrm{AF}$ and requires multiple critically timed triggers to destabilize and sustain $\mathrm{AF}^{37}$ Microscopic structural changes affecting cell-to-cell coupling 45 and action potential duration behavior due to an ageing heart facilitate anistropic conduction, ${ }^{46,47}$ persistent intercaval block ${ }^{48,49}$ and unidirectional rotation of the activation front initiated by rapidly firing triggers. The dominant counterclockwise rotating wavefront, reproduced by paraseptal pacing ${ }^{50}$ suggests initiating paraseptal activation fronts that empirically arise from within the pulmonary veins. ${ }^{51}$ However, it remains unclear how the occurrence of AFL relates to patients that have successfully been treated by means of trigger isolation at the pulmonary veins. Pulmonary vein isolation (PVI) seems to have a positive impact on the occurrence of AFL. Some operators disconnect the pulmonary veins-left atrial junction alone, instead of a combined PVI en CTI ablation, to eliminate both arrhythmias. ${ }^{52}$ Despite these promising ablation strategies the incidence of AFL remains unclear. Most patients with symptomatic AF use class IC drugs ${ }^{53}$ and amiodarone ${ }^{54}$ to suppress recurrent episodes, drugs known to facilitate the occurrence of AFL. Pulmonary vein isolation, weather this involves isolation of all veins or only the arrhythmogenic ${ }^{55}$ pulmonary veins, seems most effective when performed early in the disease in relative young patients, ${ }^{56-58}$ as opposed to the majority of AFL patients that are affected at an older age. This may indicate that structural changes of an ageing heart underlie the induction and perpetuation of $\mathrm{AFL}^{48}$ often originating from a diseased, fibrotic left atrium more resistant to ablation than from the pulmonary 
veins. In addition, AFL may degenerate more easily into smaller wavelets if right to left paraseptal conduction ${ }^{59}$ is redirected by anatomic ostia and various zones of slow conduction due to intense fibrosis. In this case AFL has become the trigger for AF induction and CTI ablation may be indicated to eliminate AF. In general, this may imply an ablation strategy to be directed at first at the CTI when relative old patients are involved, whereas younger patients may benefit more from primary PVI and the cessation of anti-arrhythmic drugs to evaluate the resumption of AFL. To improve the outcome, some operators proposed to combine CTI ablation and PVI in a single procedure resulting in increased procedure time. This strategy may be reserved for those cases where there appears to be an overlap in underlying disease and patient characteristics or doubt about the initiating trigger of both arrhythmias.

\section{Practical consideration of contemporary cryoablation}

\section{Cooling temperatures}

One of the most important concerns in cold application is how to obtain the coldest temperature. Already from the beginning, using cold applications in a limited area of skin diseases, it became clear that in order to reach deeper layers low temperatures were mandatory. ${ }^{60}$ Refrigerant usage and containment of a refrigerant restricted the use of liquid nitrogen for oncologic cryosurgery, which generated very low temperatures that could be safely contained and applied. Today, nitrous oxide has become the primary refrigerant for cryoablation. Using nitrous oxide, we obtained freezing temperatures $-80^{\circ} \mathrm{C}$, measured at the catheter-tip. Cooper concluded that a tissue temperature of $-20^{\circ} \mathrm{C}$ held for $1 \mathrm{~min}$ was sufficient to produce necrosis of tissue. ${ }^{61}$ Irreversible cell damage is already achieved at a freezing temperature of $-50^{\circ} \mathrm{C}$ irrespective of the duration or repetition. ${ }^{62}$ These observations allowed shorter cryodelivery, which formed an aspect of this thesis. During freezing the initiated cold front spreads radially but stabilizes after a certain time for a given temperature. ${ }^{63}$ The lower the temperature the more time it takes to reach the maximum effect, affecting more tissue at the beginning of a freeze. ${ }^{63}$ Visualization of the iceball during percutaneous cryoablation by intracardiac echocardiography showed stabilization at 3 minutes at minimum temperatures of $-60^{\circ} \mathrm{C} .{ }^{64}$ Although current ablation equipment renders deeper cooling temperatures that may require more time to reach maximum freeze dimensions, rapid expansion of the initial cold front may alternatively offer comparable lesion sizes at a shorter time interval. We were able to generate a stepwise decrease in application time (chapter II, III) ultimately applying cryothermia during 1 minute (chapter IV) at the CTI without compromising overall efficacy. 


\section{Repeated delivery}

In 1968 Gill et al. highlighted the effects of repeated cryothermia delivery in an experimental model where the physical and the biological effects of the freezethaw cycle were studied to elucidate the change in freezing characteristics, to monitor the differences in lesion volumes and to determine the cytological effects during a repeated delivery. ${ }^{63}$ Cryolesions created on a rat liver were assessed by the surface measurement of their greatest diameter during single and repeated cryodelivery. Probe temperatures were set at $-50^{\circ} \mathrm{C}$ to $-180^{\circ} \mathrm{C}$ using time intervals of 1,5 and 10 minutes for each freezing episode. The animals were sacrificed to analyse the lesion depth. Important observations were made favoring repeated cryodelivery both from an effective as an efficient point of view. First, by lowering the probe temperatures, the maximum freezing radius and the time to reach it, increased progressively. Second, at constant probe temperatures, repeated freeze-thaw cycles caused a gradual enlargement of the frozen tissue volume with each consecutive freeze. Third, the cold front traveled through the tissue at a greater rate with each successive cycle compared to the preceding cycle even though the additional amount of tissue involved decrease until a new maximum freezing radius was attained. For any cryoprobe temperature a series of maximum freezing radii is possible, namely that obtained by a single application and those resulting from repeated cycles of varying duration. The maximum freeze radius which results from repeated freeze-thaw cycles is greater than which can be obtained by a single application of the probe at the corresponding temperature. The histological changes in a lesion resulting from repeated freezing were more intense but basically similar to those after a single freeze. While these observations provided an excellent base for cardiac cryosurgery where probe orientation and pressure can easily be manipulated to ensure an optimal tissue interface similar to the experimental study design, during percutaneous cryoablation other variables like superfusate flow, catheter-tip malalignment and low torque transmission may reduce these effects. In 1999 Dubuc et al. investigated the efficacy of single versus double freeze-thaw cycles during catheter-based cryoablation of the AV node in 12 mongrel dogs. ${ }^{65}$ By using a 9-F steerable catheter with a 4-mm catheter-tip and AZ-20 as refrigerant, minimum temperatures of $-60^{\circ} \mathrm{C}$ were reached. Persistent AV-block was obtained in 6/6 dogs after repeated applications versus 1/6 dogs treated with single cryoapplications of 5 minutes. Animals were sacrificed between 7 and 42 days to evaluate microscopic changes in lesion formation. Lesion volumes were more than 4 times larger on gross pathological examination when repeated applications were used. Microscopic analysis showed homogeneous replacement fibrosis without viable cells after repeated applications compared to incomplete necrosis and viable cells after a single cryodelivery. Maximum lesion volume after a single cryoapplication was $51.3 \mathrm{~mm}^{3}$. Later on, the same authors ablated the AV node in patients with AF.64 Permanent AV nodal block was ob- 
tained in 8/10 patients after a mean of 5 applications, using a double freezethaw cycle of 5 minutes at the last ablated site. However, the concept of a repeated freeze-thaw cycle remains controversial during focal ablation, where serial single applications may essentially be the same and at most differ in delaying thaw or interfreeze duration. Based on the damaging effects of intracellular ice crystal formation, which is more pronounced during a longer thawing phase, the interfreeze period needs to increase until stasis of microvessels prevent the necessary heatsink to allow a more gradual freezing that generates large crystals. ${ }^{66}$ This suggests that multiple single applications during focal ablation may be more effective than repeated ones. Even during ablation of the CTI partial overlap between consecutive applications due to radial distribution of the expanding coldfront is unavoidable exposing intermediate tissue to a repeated freeze-thaw cycle. We no longer deliver repeated cryoapplications, ${ }^{67}$ and use single 3-minutes applications while maintaining a high procedural and longterm efficacy (chapter III). This modification in the ablation protocol significantly reduced the total procedure time by half an hour.

\section{Application duration}

Cooper found that a tissue temperature of $-20^{\circ} \mathrm{C}$ held for 1 minute was sufficient to produce necrosis of tissue. ${ }^{61}$ Gage, another founder of cryoablation, summarized the deleterious effects of freezing temperatures below $-50^{\circ} \mathrm{C}$ by stating that irreversible cell damage is inflicted if this boundary was met during freezing obviating the need for longer or repeated freezes at lower temperatures. ${ }^{62}$ During PVI, we stopped cryoapplications if no abolishment or changes in pulmonary potential activation sequence occurred after 20s despite a catheter-tip temperature of $-90^{\circ} \mathrm{C}$ (chapter IV) Other investigators waited $60 \mathrm{~s}$ during CTI ablation, after which an application was aborted if 30-40 ms conduction delay at the isthmus could not be obtained. ${ }^{68,69}$ These data suggest a rapid ice spread that incorporates most of the final lesion during the onset of freezing and favors the reduction of the duration of a cyoapplication. In contrast to initial reports that suggested no further lesion enlargement after 3 minutes of cryoablation as low as $-100^{\circ} \mathrm{C}, 63,64,70$ longer applications have been used during cryoablation probably due to suboptimal tissue contact that allows the warming effect of circulating blood to interfere with ice-ball formation. Frozen blood that is incorporated in the ice-ball reduces the amount of affected tissue and the lesion dimensions. The resultant shallow freezes obtained at higher isotherms result in a more rapid thaw that may cause less destruction. Consecutive applications may also be less effective as a smaller synctitium will be formed preventing deeper penetration and formation of transmural lesions. We studied the acute and longterm efficacy of single one-minute applications along the CTI to treat patients with AFL. We found a considerable decrease in procedure time compared to our initial experience (192 \pm 78 (chapter I) vs $110 \pm 28 \mathrm{~min}$ (chapter VI)) without 
affecting the clinical recurrence rate. A high CTI reconduction rate, 4 months after ablation, may signify the limit of cryodelivery using this configuration (10mm catheter-tip in combination with single one-minute applications).

\section{Catheter orientation}

The first developed cryoablation catheters lacked steerabilty and electrodes for mapping and optimal catheter alignment to the underlying surface. New catheter designs included these essential components together with a thermocouple located at the catheter-tip, which allowed prompt catheter repositioning if the preset temperature was not reached. Tse et al evaluated the effect of a vertical and horizontal tip orientation in thigh muscle preparations at target temperatures of $-70^{\circ} \mathrm{C}$. Single 2.5 -minutes cryoapplications delivered in a vertical position created the smallest lesion, compared to single 5- and repeated 2.5- and 5minutes applications in any orientation. ${ }^{71}$ At worst, lesion depth measured $9.4 \pm$ $2.4 \mathrm{~mm}$, sufficient to create a transmural isthmus lesion. ${ }^{22}$ Later on, Wood et al studied the lesion sizes of a 4- and 8-mm cryocatheter-tip in a model of fresh harvested porcine hearts, while adjusting the contact pressure, tip temperatures and superfusate flow. ${ }^{72}$ Lesion volumes were greater in the absence of superfusate flow and were greater for the 8-mm electrode compared to the 4-mm electrode. Superfusate flow had a dramatic effect on lesion dimensions, reducing lesion volume up to $72 \%$. Regardless of electrode temperatures, both a horizontal orientation and a high contact pressure produced greater lesion length, depth, and volume but had less effect on lesion width. For each electrode size separately, there were more than 4-fold differences in the lesion size resulting from identical electrode temperatures under differing conditions of superfusate flow, orientation, and contact pressure. In other words, lesion dimensions can be enhanced if a low tip temperature (pre-cooling console, refrigerant and refrigerant flow), a high contact pressure and horizontal orientation (torque transmission and catheter handling) are obtained to minimize the effect of regional differences in superfusate flow (surrounding blood). We demonstrated the impact of these variables by generating a stable catheter-tip temperature of $80^{\circ} \mathrm{C}$ using pre-cooled nitrous oxide as the primary refrigerant and by improved catheter handling which decreased the amount of cryodelivery. The clinical efficacy of the treatment for AFL remained similar, while using the lowest amount of cryoenergy reported to date (chapter V).

\section{Safety of cryoablation}

An important feature of cryothermia is its ability to preserve tissue architecture, which can be attributed to the resilience of collagen and fibroblasts to hypothermal injury. ${ }^{73}$ This proved of great value during ostial pulmonary vein ablation (chapter IV), where RF may cause stenosis ${ }^{74-78}$ necessitating wider encir- 
clements. Cryothermia remains the preferred energy source if focal intrapulmonary vein ablation cannot be avoided, due to an increased atrial wall thickness or an unstable catheter positioning that prevents effective energy delivery. ${ }^{79}$ In addition, cryothermia has a low tendency for endothelial thrombus formation..$^{80-82}$ This may be of benefit during ablation inside vascular structures like the pulmonary artery, aorta or pulmonary veins for the treatment of idiopathic ventricular tachycardia and focal AF respectively, ${ }^{79}$ where intravascular obstruction due to thrombosis causes dreadful complications. Furthermore, cryothermia causes adherence to the underlying tissue that enables stable catheter positioning during ablation and prevent inadvertent dislodgement e.g. at the onset or termination of a tachycardia. This may be especially useful when targeting septal accessory pathways or automatic foci in the vicinity of the AV node. ${ }^{83,}, 84$ Moreover, several reports underline the creation of homogenous and well-delineated lesions ${ }^{85,} 86$ that have a low arrhythmogenic potential. Definite lesion formation is dominated by the destructive effects of deprived blood supply, low cellular metabolism, osmotic fluid shifts and ice crystallization that cause disruption of cell membranes, haemorrhage, oedema and inflammation. After 1 week, a sharp demarcated lesion is formed that consists of dense collagen. This lesion is infiltrated by fatty tissue after 4 weeks. ${ }^{73,87,88}$

Lastly, the ability to monitor a physiologic response prior to cell death that can be reversed at the operator's convenience provides a safety margin for applications near the specialized conduction system. This concept of ice-mapping was already explored during the first experiences of cryosurgery. ${ }^{89}$ Dubuc et al. confirmed the capability of ice-mapping during catheter-based cryoablation in a dog model were AV-conduction could be temporarily depressed at electrode temperatures of $-40^{\circ} \mathrm{C}$, allowing complete recovery at normal temperatures. ${ }^{65}$ Thereafter, several studies have described the use of cryothermia in regions were ablation may jeopardize the conduction system.

\section{Pain perception during cryoablation}

The analgesic effect of cold has already been recognized in the first cold applications by James Arnott in the nineteenth century. He recommended the use of cold to anaesthetize the skin before an operation, because of its 'benumbing' effect and advocated it as an alternative to contemporary anesthetics. ${ }^{60}$ While pain perception during ablation is of no concern during cardiac surgery it can be cumbersome in percutaneous RF ablation. Painful energy delivery may complicate an application due to patient movements that may cause inadvertent catheter displacement. Several regions of the heart are notorious for their pain perception like the inferior caval vein during CTI ablation ${ }^{67}$ or the coronary sinus during slow pathway ablation..$^{90}$ Cryothermia causes a significantly lower pain perception compared to RF obviating the need for conscious sedation or general anesthesia. ${ }^{67,90-92}$ Most of these anesthetic agents are well tolerated but may not 
be desired or even contraindicated in a subset of patients (COPD, heart failure) because of their side effects or hemodynamic and respiratory depression. ${ }^{93-95}$

\section{Permanent conduction loss after cryoablation?}

In chapter IV we described a considerable number of patients with CTI reconduction, but without symptomatic recurrence of AFL, 4 months after documentation of bidirectional conduction block. Other studies, using cryothermia or RF, also showed a high CTI reconduction rate during a repeat electrophysiological study. Anselme et al. reported conduction recovery in up to $45 \%$ of patients $(18 / 40)$ treated with RF 1 month after the index-procedure. ${ }^{96}$ Montenero et al. described a CTI recovery rate of $44 \%$, at 3 months post-ablation, with only a small number of clinical recurrences. ${ }^{68,69,97,98}$ Cappato et al. noted a reconduction rate of $32 \%, 5$ months after electrical disconnection of the pulmonary veins, using RF, without AF recurrence. ${ }^{99}$ This finding suggests that also a favorable clinical outcome of PV electrical disconnection may be achieved, at least for sometime, despite conduction recurrence. Cell injury during an ablation procedure not always results in cell death with permanent conduction loss nor an arrhythmia recurrence in case of cell survival. Deprived blood supply and difference in cell-to-cell (mal) orientation ${ }^{45}$ may alter conduction properties of the affected cells and subsequently their critical coupling necessary for the development of AFL or AF.

\section{Future perspectives}

Despite several unique properties of cryothermia, cryoablation is less frequently used because the more complex catheter design decreases the handling characteristics. New materials, for example to isolate the refrigerant flow, may allow more flexibility and bidirectional curving of the catheter, a reduction of its diameter to create a torque transmission similar to RF and may prevent deformation after manipulation of the shaft. Novel catheter designs adjusted to the ablation target, like the cryoballoon for pulmonary vein isolation, showed to be very effective and is used by many physicians. Linear cryocatheters, eventually in combination with a steerable sheath, to modify the substrate in patients with unmappable ventricular tachycardia or persistent atrial fibrillation need to be developed and their safety and efficacy need to be investigated. With the currently available catheters, epicardial cryoablation requires evaluation. Due to the absence of blood flow in the pericardial space, less convective warming occurs and larger lesions may be created. Further studies need to determine if cryoablation can increase the therapeutic efficacy for ventricular tachycardia, 
especially after an old myocardial infarction. A 3-D navigation system allowing cryothermia for ablation, at the present time only feasible with the EnSite NavX ${ }^{\mathrm{TM}}$ system, most likely will be of great value for substrate modification in patients with unmappable or complex tachyarrhythmia. Future investigations may include a direct comparison to RF ablation in large, multicenter, randomized trials with a long follow-up to determine if both energy sources have a similar clinical outcome. 


\section{References}

1. Lewis T: Atrial flutter. Clinical Disorders of the Heartbeat London: Shaw \& Sons, 1920, pp. 76.

2. Medi C, Kalman JM: Prediction of the atrial flutter circuit location from the surface electrocardiogram. Europace 2008; 10:786-796.

3. Cosio FG: Atrial flutter update. Card Electrophysiol Rev 2002; 6:356-364.

4. Fischer B, Haissaguerre M, Garrigues S, Poquet F, Gencel L, Clementy J, Marcus FI: Radiofrequency catheter ablation of common atrial flutter in 80 patients. J Am Coll Cardiol 1995; 25:1365-1372.

5. Iesaka Y, Yamane T, Goya M, Takahashi A, Fujiwara H, Okamoto Y, Soejima Y, Nitta J, Nogami A, Aonuma K, Hiroe M, Marumo F, Hiraoka M: A jump in cycle length of orthodromic common atrial flutter during catheter ablation at the isthmus between the inferior vena cava and tricuspid annulus; evidence of dual isthmus conduction directed to dual septal exits. Europace 2000; 2:163171.

6. Poty H, Anselme F, Saoudi N: Inferior vena cava-tricuspid annulus isthmus is a critical site of unidirectional block during the induction of common atrial flutter. J Interv Card Electrophysiol 1998; 2:57-69.

7. Poty H, Saoudi N, Nair M, Anselme F, Letac B: Radiofrequency catheter ablation of atrial flutter. Further insights into the various types of isthmus block: application to ablation during sinus rhythm. Circulation 1996; 94:3204-3213.

8. Nakagawa H, Lazzara R, Khastgir T, Beckman KJ, McClelland JH, Imai S, Pitha JV, Becker AE, Arruda M, Gonzalez MD, Widman LE, Rome M, Neuhauser J, Wang X, Calame JD, Goudeau MD, Jackman WM: Role of the tricuspid annulus and the eustachian valve/ridge on atrial flutter. Relevance to catheter ablation of the septal isthmus and a new technique for rapid identification of ablation success. Circulation 1996; 94:407-424.

9. Isber N, Restivo M, Gough WB, Yang H, el-Sherif N: Circus movement atrial flutter in the canine sterile pericarditis model. Cryothermal termination from the epicardial site of the slow zone of the reentrant circuit. Circulation 1993; 87:1649-1660.

10. Schumacher B, Pfeiffer D, Tebbenjohanns J, Lewalter T, Jung W, Luderitz B: Acute and long-term effects of consecutive radiofrequency applications on conduction properties of the subeustachian isthmus in type I atrial flutter. J Cardiovasc Electrophysiol 1998; 9:152-163.

11. Schwartzman D, Callans DJ, Gottlieb CD, Dillon SM, Movsowitz C, Marchlinski FE: Conduction block in the inferior vena caval-tricuspid valve isthmus: association with outcome of radiofrequency ablation of type I atrial flutter. J Am Coll Cardiol 1996; 28:1519-1531.

12. Hsieh MH, Tai CT, Chiang CE, Tsai CF, Yu WC, Chen YJ, Ding YA, Chen SA: Recurrent atrial flutter and atrial fibrillation after catheter ablation of the cavotricuspid isthmus: a very long-term follow-up of 333 patients. J Interv Card Electrophysiol 2002; 7:225-231.

13. Tada H, Oral H, Sticherling C, Chough SP, Baker RL, Wasmer K, Pelosi F, Jr., Knight BP, Strickberger SA, Morady F: Double potentials along the ablation line as a guide to radiofrequency ablation of typical atrial flutter. J Am Coll Cardiol 2001; 38:750-755.

14. Shah D, Haissaguerre M, Takahashi A, Jais P, Hocini M, Clementy J: Differential pacing for distinguishing block from persistent conduction through an ablation line. Circulation 2000; 102:15171522.

15. Andronache M, de Chillou C, Miljoen H, Magnin-Poull I, Messier M, Dotto P, Beurrier D, Doan T, Houriez P, Bineau-Jorisse A, Thiel B, Brembilla-Perrot B, Massing JL, Sadoul N, Aliot E: Correlation between electrogram morphology and standard criteria to validate bidirectional cavotricuspid block in common atrial flutter ablation. Europace 2003; 5:335-341.

16. Tada H, Oral H, Sticherling C, Chough SP, Baker RL, Wasmer K, Kim MH, Pelosi F, Jr., Michaud GF, Knight BP, Strickberger SA, Morady F: Electrogram polarity and cavotricuspid isthmus block during ablation of typical atrial flutter. J Cardiovasc Electrophysiol 2001; 12:393-399.

17. Chen J, de Chillou C, Hoff PI, Rossvoll O, Andronache M, Sadoul N, Magnin-Poull I, Erga KS, Aliot E, Ohm OJ: Identification of extremely slow conduction in the cavotricuspid isthmus during common atrial flutter ablation. J Interv Card Electrophysiol 2002; 7:67-75. 
18. Ouali S, Anselme F, Savoure A, Cribier A: Acute coronary occlusion during radiofrequency catheter ablation of typical atrial flutter. J Cardiovasc Electrophysiol 2002; 13:1047-1049.

19. Anselme F, Klug D, Scanu P, Poty H, Lacroix D, Kacet S, Cribier A, Saoudi N: Randomized comparison of two targets in typical atrial flutter ablation. Am J Cardiol 2000; 85:1302-1307.

20. Okumura Y, Watanabe I, Ashino S, Kofune M, Yamada T, Takagi Y, Kawauchi K, Okubo K, Hashimoto K, Shindo A, Sugimura H, Nakai T, Saito S: Anatomical characteristics of the cavotricuspid isthmus in patients with and without typical atrial flutter: Analysis with two- and threedimensional intracardiac echocardiography. J Interv Card Electrophysiol 2006; 17:11-19.

21. Cabrera JA, Sanchez-Quintana D, Ho SY, Medina A, Wanguemert F, Gross E, Grillo J, Hernandez E, Anderson RH: Angiographic anatomy of the inferior right atrial isthmus in patients with and without history of common atrial flutter. Circulation 1999; 99:3017-3023.

22. Cabrera JA, Sanchez-Quintana D, Ho SY, Medina A, Anderson RH: The architecture of the atrial musculature between the orifice of the inferior caval vein and the tricuspid valve: the anatomy of the isthmus. J Cardiovasc Electrophysiol 1998; 9:1186-1195.

23. Scaglione M, Caponi D, Di Donna P, Riccardi R, Bocchiardo M, Azzaro G, Leuzzi S, Gaita F: Typical atrial flutter ablation outcome: correlation with isthmus anatomy using intracardiac echo 3D reconstruction. Europace 2004; 6:407-417.

24. Lo LW, Tai CT, Lin YJ, Chang SL, Wongcharoen W, Tuan TC, Udyavar AR, Hu YF, Ueng KC, Tsai WC, Chang CJ, Tsao HM, Higa S, Chen SA: Characteristics of the cavotricuspid isthmus in predicting recurrent conduction in the long-term follow-up. J Cardiovasc Electrophysiol 2009; 20:3943.

25. Cabrera JA, Sanchez-Quintana D, Farre J, Rubio JM, Ho SY: The inferior right atrial isthmus: further architectural insights for current and coming ablation technologies. J Cardiovasc Electrophysiol 2005; 16:402-408.

26. Yokoyama K, Nakagawa H, Wittkampf FH, Pitha JV, Lazzara R, Jackman WM: Comparison of electrode cooling between internal and open irrigation in radiofrequency ablation lesion depth and incidence of thrombus and steam pop. Circulation 2006; 113:11-19.

27. Matsumoto N, Kishi R, Kasugai H, Sakurai T, Osada K, Ryu S, Arai M, Miyazu O, Watanabe Y, Kimura M, Nanke T, Nakazawa K, Kobayashi S, Miyake F: Experimental study on the effectiveness and safety of radiofrequency catheter ablation with the cooled ablation system. Circ J 2003; 67:154-158.

28. Igawa O, Adachi M, Hisatome I, Matsui Y: Histopathologic background for resistance to conventional catheter ablation of common atrial flutter. J Cardiovasc Electrophysiol 2004; 15:829-832.

29. Matsuda JJ, Lee H, Shibata EF: Enhancement of rabbit cardiac sodium channels by betaadrenergic stimulation. Circ Res 1992; 70:199-207.

30. Szekeres L, Papp JG: Effect of adrenergic activators and inhibitors on the electrical activity of the heart. In Szekeres L, ed: Adrenergic Activators and Inhibitors. Berlin, Germany: Springer-Verlag, 1980, pp. 597-634.

31. Waldo AL: Mechanisms of atrial flutter and atrial fibrillation: distinct entities or two sides of a coin? Cardiovasc Res 2002; 54:217-229.

32. Moreira W, Timmermans C, Wellens HJ, Mizusawa Y, Philippens S, Perez D, Rodriguez LM: Can common-type atrial flutter be a sign of an arrhythmogenic substrate in paroxysmal atrial fibrillation? Clinical and ablative consequences in patients with coexistent paroxysmal atrial fibrillation/atrial flutter. Circulation 2007; 116:2786-2792.

33. Nabar A, Rodriguez LM, Timmermans C, van den Dool A, Smeets JL, Wellens HJ: Effect of right atrial isthmus ablation on the occurrence of atrial fibrillation: observations in four patient groups having type I atrial flutter with or without associated atrial fibrillation. Circulation 1999; 99:1441-1445.

34. Wu TJ, Yashima M, Xie F, Athill CA, Kim YH, Fishbein MC, Qu Z, Garfinkel A, Weiss JN, Karagueuzian HS, Chen PS: Role of pectinate muscle bundles in the generation and maintenance of intra-atrial reentry: potential implications for the mechanism of conversion between atrial fibrillation and atrial flutter. Circ Res 1998; 83:448-462. 
35. Wu TJ, Kim YH, Yashima M, Athill CA, Ting CT, Karagueuzian HS, Chen PS: Progressive action potential duration shortening and the conversion from atrial flutter to atrial fibrillation in the isolated canine right atrium. J Am Coll Cardiol 2001; 38:1757-1765.

36. Waldo AL, Feld GK: Inter-relationships of atrial fibrillation and atrial flutter mechanisms and clinical implications. J Am Coll Cardiol 2008; 51:779-786.

37. Morton JB, Byrne MJ, Power JM, Raman J, Kalman JM: Electrical remodeling of the atrium in an anatomic model of atrial flutter: relationship between substrate and triggers for conversion to atrial fibrillation. Circulation 2002; 105:258-264.

38. Roithinger FX, Karch MR, Steiner PR, SippensGroenewegen A, Lesh MD: Relationship between atrial fibrillation and typical atrial flutter in humans: activation sequence changes during spontaneous conversion. Circulation 1997; 96:3484-3491.

39. Bialy D, Lehman MH: Hospitalization for arrhythmias in the United States: importance of atrial fibrillation. J Am Coll Cardiol 1992; 19:716. Abstract.

40. Granada J, Uribe W, Chyou PH, Maassen K, Vierkant R, Smith PN, Hayes J, Eaker E, Vidaillet H: Incidence and predictors of atrial flutter in the general population. J Am Coll Cardiol 2000; 36:2242-2246.

41. Vidaillet H, Granada JF, Chyou PH, Maassen K, Ortiz M, Pulido JN, Sharma P, Smith PN, Hayes J: A population-based study of mortality among patients with atrial fibrillation or flutter. Am J Med 2002; 113:365-370.

42. Halligan SC, Gersh BJ, Brown RD, Jr., Rosales AG, Munger TM, Shen WK, Hammill SC, Friedman PA: The natural history of lone atrial flutter. Ann Intern Med 2004; 140:265-268.

43. Uno K, Kumagai K, Khrestian CM, Waldo AL: New insights regarding the atrial flutter reentrant circuit : studies in the canine sterile pericarditis model. Circulation 1999; 100:1354-1360.

44. Arenal A, Almendral J, Alday JM, Villacastin J, Ormaetxe JM, Sande JL, Perez-Castellano N, Gonzalez S, Ortiz M, Delcan JL: Rate-dependent conduction block of the crista terminalis in patients with typical atrial flutter: influence on evaluation of cavotricuspid isthmus conduction block. Circulation 1999; 99:2771-2778.

45. Spach MS: The role of cell-to-cell coupling in cardiac conduction disturbances. Adv Exp Med Biol 1983; 161:61-77.

46. Spach MS: The discontinuous nature of electrical propagation in cardiac muscle. Consideration of a quantitative model incorporating the membrane ionic properties and structural complexities. The ALZA distinguished lecture. Ann Biomed Eng 1983; 11:209-261.

47. Spach MS: Anisotropy of cardiac tissue: a major determinant of conduction? J Cardiovasc Electrophysiol 1999; 10:887-890.

48. Kobayashi T, Kimura M, Owada S, Ashikaga K, Sasaki S, Higuma T, Iwasa A, Kamata Y, Motomura S, Okumura K: Impaired longitudinal conduction in crista terminalis is necessary for sustenance of experimental atrial flutter. Pacing Clin Electrophysiol 2003; 26:2008-2015.

49. Mizumaki K, Fujiki A, Nagasawa H, Nishida K, Sakabe M, Sakurai K, Inoue H: Relation between transverse conduction capability and the anatomy of the crista terminalis in patients with atrial flutter and atrial fibrillation: analysis by intracardiac echocardiography. Circ J 2002; 66:11131118.

50. Olgin JE, Kalman JM, Saxon LA, Lee RJ, Lesh MD: Mechanism of initiation of atrial flutter in humans: site of unidirectional block and direction of rotation. J Am Coll Cardiol 1997; 29:376-384.

51. Haissaguerre M, Jais P, Shah DC, Takahashi A, Hocini M, Quiniou G, Garrigue S, Le Mouroux A, Le Metayer P, Clementy J: Spontaneous initiation of atrial fibrillation by ectopic beats originating in the pulmonary veins. N Engl J Med 1998; 339:659-666.

52. Wazni O, Marrouche NF, Martin DO, Gillinov AM, Saliba W, Saad E, Klein A, Bhargava M, Bash D, Schweikert R, Erciyes D, Abdul-Karim A, Brachman J, Gunther J, Pisano E, Potenza D, Fanelli R, Natale A: Randomized study comparing combined pulmonary vein-left atrial junction disconnection and cavotricuspid isthmus ablation versus pulmonary vein-left atrial junction disconnection alone in patients presenting with typical atrial flutter and atrial fibrillation. Circulation 2003; 108:2479-2483. 
53. Nabar A, Rodriguez LM, Timmermans C, van Mechelen R, Wellens HJ: Class IC antiarrhythmic drug induced atrial flutter: electrocardiographic and electrophysiological findings and their importance for long term outcome after right atrial isthmus ablation. Heart 2001; 85:424-429.

54. Tai CT, Chen SA, Feng AN, Yu WC, Chen YJ, Chang MS: Electropharmacologic effects of class I and class III antiarrhythmia drugs on typical atrial flutter: insights into the mechanism of termination. Circulation 1998; 97:1935-1945.

55. Chen YJ, Chen SA, Chang MS, Lin CI: Arrhythmogenic activity of cardiac muscle in pulmonary veins of the dog: implication for the genesis of atrial fibrillation. Cardiovasc Res 2000; 48:265273.

56. Nanthakumar K, Lau YR, Plumb VJ, Epstein AE, Kay GN: Electrophysiological findings in adolescents with atrial fibrillation who have structurally normal hearts. Circulation 2004; 110:117123.

57. Gerstenfeld EP, Guerra P, Sparks PB, Hattori K, Lesh MD: Clinical outcome after radiofrequency catheter ablation of focal atrial fibrillation triggers. J Cardiovasc Electrophysiol 2001; 12:900908.

58. Oral H, Chugh A, Good E, Sankaran S, Reich SS, Igic P, Elmouchi D, Tschopp D, Crawford T, Dey S, Wimmer A, Lemola K, Jongnarangsin K, Bogun F, Pelosi F, Jr., Morady F: A tailored approach to catheter ablation of paroxysmal atrial fibrillation. Circulation 2006; 113:1824-1831.

59. Ndrepepa G, Zrenner B, Weyerbrock S, Schneider MA, Schmitt C: Activation patterns in the left atrium during counterclockwise and clockwise atrial flutter. J Cardiovasc Electrophysiol 2001; 12:893-899.

60. Cooper SM, Dawber RP: The history of cryosurgery. J R Soc Med 2001; 94:196-201.

61. Cooper IS: Cryobiology as Viewed by the Surgeon. Cryobiology 1964; 51:44-51.

62. Gage AA, Baust J: Mechanisms of tissue injury in cryosurgery. Cryobiology 1998; 37:171-186.

63. Gill W, Fraser J, Carter DC: Repeated freeze-thaw cycles in cryosurgery. Nature 1968; 219:410413.

64. Dubuc M, Khairy P, Rodriguez-Santiago A, Talajic M, Tardif JC, Thibault B, Roy D: Catheter cryoablation of the atrioventricular node in patients with atrial fibrillation: a novel technology for ablation of cardiac arrhythmias. J Cardiovasc Electrophysiol 2001; 12:439-444.

65. Dubuc M, Roy D, Thibault B, Ducharme A, Tardif JC, Villemaire C, Leung TK, Talajic M: Transvenous catheter ice mapping and cryoablation of the atrioventricular node in dogs. Pacing Clin Electrophysiol 1999; 22:1488-1498.

66. Whittaker DK: Mechanisms of tissue destruction following cryosurgery. Ann R Coll Surg Engl 1984; 66:313-318.

67. Timmermans C, Ayers GM, Crijns HJ, Rodriguez LM: Randomized study comparing radiofrequency ablation with cryoablation for the treatment of atrial flutter with emphasis on pain perception. Circulation 2003; 107:1250-1252.

68. Montenero AS, Bruno N, Antonelli A, Mangiameli D, Barbieri L, Andrew P, Murphy O, O'Connor S, Zumbo F: Long-term efficacy of cryo catheter ablation for the treatment of atrial flutter: results from a repeat electrophysiologic study. J Am Coll Cardiol 2005; 45:573-580.

69. Montenero AS, Bruno N, Antonelli A, Mangiameli D, Barbieri L, Zumbo F, Andrew P: Low clinical recurrence and procedure benefits following treatment of common atrial flutter by electrogramguided hot spot focal cryoablation. J Interv Card Electrophysiol 2006; 15:83-92.

70. Hunt GB, Chard RB, Johnson DC, Ross DL: Comparison of early and late dimensions and arrhythmogenicity of cryolesions in the normothermic canine heart. J Thorac Cardiovasc Surg 1989; 97:313-318.

71. Tse HF, Ripley KL, Lee KL, Siu CW, Van Vleet JF, Pelkey WL, Lau CP: Effects of temporal application parameters on lesion dimensions during transvenous catheter cryoablation. J Cardiovasc Electrophysiol 2005; 16:201-204.

72. Wood MA, Parvez B, Ellenbogen AL, Shaffer KM, Goldberg SM, Gaspar MP, Arief I, Schubert CM: Determinants of lesion sizes and tissue temperatures during catheter cryoablation. Pacing Clin Electrophysiol 2007; 30:644-654. 
73. Harrison L, Gallagher JJ, Kasell J, Anderson RH, Mikat E, Hackel DB, Wallace AG: Cryosurgical ablation of the A-V node-His bundle: a new method for producing A-V block. Circulation 1977; 55:463-470.

74. Arentz T, Jander N, von Rosenthal J, Blum T, Furmaier R, Gornandt L, Josef Neumann F, Kalusche D: Incidence of pulmonary vein stenosis 2 years after radiofrequency catheter ablation of refractory atrial fibrillation. Eur Heart J 2003; 24:963-969.

75. Berkowitsch A, Neumann T, Ekinci O, Greiss H, Dill T, Kurzidim K, Kuniss M, Schneider HJ, Pitschner HF: A decrease in pulmonary vein diameter after radiofrequency ablation predicts the development of severe stenosis. Pacing Clin Electrophysiol 2005; 28 Suppl 1:S83-85.

76. Burgstahler C, Trabold T, Kuettner A, Kopp AF, Mewis C, Kuehlkamp V, Claussen CD, Schroeder S: Visualization of pulmonary vein stenosis after radio frequency ablation using multi-slice computed tomography: initial clinical experience in 33 patients. Int J Cardiol 2005; 102:287291.

77. Dong J, Vasamreddy CR, Jayam V, Dalal D, Dickfeld T, Eldadah Z, Meininger G, Halperin HR, Berger R, Bluemke DA, Calkins H: Incidence and predictors of pulmonary vein stenosis following catheter ablation of atrial fibrillation using the anatomic pulmonary vein ablation approach: results from paired magnetic resonance imaging. J Cardiovasc Electrophysiol 2005; 16:845-852.

78. Purerfellner H, Cihal R, Aichinger J, Martinek M, Nesser HJ: Pulmonary vein stenosis by ostial irrigated-tip ablation: incidence, time course, and prediction. J Cardiovasc Electrophysiol 2003; 14:158-164.

79. Kenigsberg DN, Wood MA, Alaeddini J, Ellenbogen KA: Cryoablation inside the pulmonary vein after failure of radiofrequency antral isolation. Heart Rhythm 2007; 4:992-996.

80. van Oeveren W, Crijns HJ, Korteling BJ, Wegereef EW, Haan J, Tigchelaar I, Hoekstra A: Blood damage, platelet and clotting activation during application of radiofrequency or cryoablation catheters: a comparative in vitro study. J Med Eng Technol 1999; 23:20-25.

81. Khairy P, Chauvet P, Lehmann J, Lambert J, Macle L, Tanguay JF, Sirois MG, Santoianni D, Dubuc M: Lower incidence of thrombus formation with cryoenergy versus radiofrequency catheter ablation. Circulation 2003; 107:2045-2050.

82. Khairy P, Rivard L, Guerra PG, Tanguay JF, Mawad W, Roy D, Talajic M, Thibault B, Macle L, Dubuc M: Morphometric ablation lesion characteristics comparing 4, 6, and $8 \mathrm{~mm}$ electrode-tip cryocatheters. J Cardiovasc Electrophysiol 2008; 19:1203-1207.

83. Schluter M, Geiger M, Siebels J, Duckeck W, Kuck KH: Catheter ablation using radiofrequency current to cure symptomatic patients with tachyarrhythmias related to an accessory atrioventricular pathway. Circulation 1991; 84:1644-1661.

84. Bar-Cohen Y, Khairy P, Morwood J, Alexander ME, Cecchin F, Berul CI: Inaccuracy of WolffParkinson-white accessory pathway localization algorithms in children and patients with congenital heart defects. J Cardiovasc Electrophysiol 2006; 17:712-716.

85. Rodriguez LM, Leunissen J, Hoekstra A, Korteling BJ, Smeets JL, Timmermans C, Vos M, Daemen M, Wellens HJ: Transvenous cold mapping and cryoablation of the AV node in dogs: observations of chronic lesions and comparison to those obtained using radiofrequency ablation. J Cardiovasc Electrophysiol 1998; 9:1055-1061.

86. Timmermans C, Rodriguez LM, Van Suylen RJ, Leunissen J, Vos M, Ayers GM, Crijns HJ, Wellens HJ: Catheter-based cryoablation produces permanent bidirectional cavotricuspid isthmus conduction block in dogs. J Interv Card Electrophysiol 2002; 7:149-155.

87. Mikat EM, Hackel DB, Harrison L, Gallagher JJ, Wallace AG: Reaction of the myocardium and coronary arteries to cryosurgery. Lab Invest 1977; 37:632-641.

88. Holman WL, Kirklin JK, Anderson PG, Pacifico AD: Variation in cryolesion penetration due to probe size and tissue thermal conductivity. Ann Thorac Surg 1992; 53:123-126.

89. Lister JW, Hoffman BF, Kavaler F: Reversible Cold Block of the Specialized Cardiac Tissues of the Unanaesthetized Dog. Science 1964; 145:723-725.

90. Chan NY, Choy CC, Lau CL, Lo YK, Chu PS, Yuen HC, Choi YC, Lau ST: Cryoablation versus Radiofrequency Ablation for Atrioventricular Nodal Reentrant Tachycardia: Patient Pain Perception and Operator Stress. Pacing Clin Electrophysiol. 
91. Jais P, Shah DC, Haissaguerre M, Hocini M, Garrigue S, Le Metayer P, Clementy J: Prospective randomized comparison of irrigated-tip versus conventional-tip catheters for ablation of common flutter. Circulation 2000; 101:772-776.

92. Kirkorian G, Moncada E, Chevalier P, Canu G, Claudel JP, Bellon C, Lyon L, Touboul P: Radiofrequency ablation of atrial flutter. Efficacy of an anatomically guided approach. Circulation 1994; 90:2804-2814.

93. Harper MH, Hickey RF, Cromwell TH, Linwood S: The magnitude and duration of respiratory depression produced by fentanyl and fentanyl plus droperidol in man. J Pharmacol Exp Ther 1976; 199:464-468.

94. Forster A, Gardaz JP, Suter PM, Gemperle M: Respiratory depression by midazolam and diazepam. Anesthesiology 1980; 53:494-497.

95. Pandya K, Patel MB, Natla J, Dhoble A, Habetler T, Holliday J, Janes R, Punnam SR, Gardiner JC, Thakur RK: Predictors of hemodynamic compromise with propofol during defibrillator implantation: a single center experience. J Interv Card Electrophysiol 2009; 25:145-151.

96. Anselme F, Frederiks J, Papageorgiou P, Monahan KM, Epstein LM, Spach MS, Josephson ME: Nonuniform anisotropy is responsible for age-related slowing of atrioventricular nodal reentrant tachycardia. J Cardiovasc Electrophysiol 1996; 7:1145-1153.

97. Montenero AS, Bruno N, Antonelli A, Mangiameli D, Barbieri L, Andrew P, Zumbo F: Comparison between a 7 French $6 \mathrm{~mm}$ tip cryothermal catheter and a 9 French $8 \mathrm{~mm}$ tip cryothermal catheter for cryoablation treatment of common atrial flutter. J Interv Card Electrophysiol 2005; 13:59-69.

98. Montenero AS, Bruno N, Zumbo F, Antonelli A, Fiocca L, Barbieri L, De Bernardi F, Andrew P, Affinito V: Cryothermal ablation treatment of atrial flutter--experience with a new 9 French 8 mm tip catheter. J Interv Card Electrophysiol 2005; 12:45-54.

99. Cappato R, Negroni S, Pecora D, Bentivegna S, Lupo PP, Carolei A, Esposito C, Furlanello F, De Ambroggi L: Prospective assessment of late conduction recurrence across radiofrequency lesions producing electrical disconnection at the pulmonary vein ostium in patients with atrial fibrillation. Circulation 2003; 108:1599-1604. 



\section{Summary}

Through more than a century of ongoing technical developments cryoenergy has become a versatile and valuable tool that is appreciated for its unique features. In the last 40 years, biomedical engineering has transformed large cryosurgical probes into elegant cryoablation catheters capable of generating intracardiac cell death. In chapter one we summarized the most important developments responsible for the present design and clinical implementation of catheter-based cryoablation. We have learned that low freezing temperatures played a central role in the creation of deep and large lesions. The quest for the lowest freezing temperature using a safe and manageable device has taken most of the $20^{\text {th }}$ century, while during the early nineties a design that offered transluminal ablation capabilities was developed. Integrated thermocouples and bipolar electrodes were build into the catheter and made cryothernmia eligible for arrhythmia management. To overcome the extra heat load generated by the circulating blood flow, investigators used previous cryosurgical ablation protocols to maintain a high efficacy. Catheters were more rigid due to the larger diameter necessary for refrigerant transportation resulting in different catheter handling and maneuverability compared to standard radiofrequency ablation (RF) catheters. As a result, initial fluoroscopy and procedure time were long but the acute efficacy was comparable to RF.

If long-term follow-up could offer similar efficacy and more experience was gained in catheter handling to reduce procedure time, cryoablation would be a worthy alternative to RF. In chapter two we therefore focused on the chronic efficacy of cryoablation for the treatment of cavotricuspid isthmus (CTI) dependant atrial flutter (AFL). We also analyzed the effect of a learning curve on the procedure time. Thirty-five consecutive patients ( 28 men; mean age 53 years) underwent cryo of the CTI. Eleven patients had structural heart disease. Cryo was performed with a 10 -F catheter with a 6-mm tip-electrode. Applications (3-5 minutes each) were delivered by use of a point-by-point technique to create the ablation line. Patients were followed up at our outpatient clinic at 1 month and every 3 months thereafter. A 24-hour Holter monitor was given immediately after the procedure until hospital discharge and thereafter if symptoms suggested an arrhythmia recurrence. Patients were instructed to contact the nearest hospital for arrhythmia documentation in case of symptoms that could indicate a recurrence. Antiarrhythmic drugs were continued after the ablation procedure in those patients with antiarrhythmic drugs induced AFL. A median of 14 (range 4 to 30) applications at 10 (range 14 to 19) sites were given along the CTI with a mean temperature of $-80.0 \pm 5.0^{\circ} \mathrm{C}$. The mean fluoroscopy 
and procedure time were $40 \pm 26 \mathrm{~min}$ and $3.0 \pm 1.3$ hours, respectively. Of the 35 patients, 34 were acutely successfully ablated (97\%). After a mean follow-up of $17.6 \pm 6.2$ (range 9.6 to 26.1 ) months, 31 patients (89\%) did not have recurrence of AFL. Procedure times were long compared to RF but may be explained by a learning curve in the use of this new technology because the significant decrease in procedure time during the second half of the study population. We concluded that cryo was able to produce permanent bi-directional isthmus conduction block of the CTI with short- and long-term success rates comparable to those for RF.

The knowledge we obtained from previous experimental studies and from our previous experience where single 3-minutes applications per site were sufficient to create CTI block has encouraged us to investigate the use of repeated cryodelivery. In chapter 3 we compared single-3-minute (single-3) with double3-minute (double-3) cryothermia applications for the treatment of AFL. Forty patients (56 \pm 13 years) with AFL were randomized to single-3 $(n=20)$ or double-3 ( $n=20$ ) cryothermia applications at each site along the CTI. Half of the patients had a structurally normal heart. All but 1 patient (95\%) of the Single-3 group and all patients (100\%) of the double-3 group were successfully ablated. No differences were observed in cooling temperatures $\left(-79 \pm 6^{\circ} \mathrm{C}\right.$ (single-3) vs $80 \pm 4^{\circ} \mathrm{C}$ (double- 3 ) or number of ablation sites $(9 \pm 4$ (single- 3 ) vs $8 \pm 2$ (double-3). Fluoroscopy time did not differ between both groups, but the procedure time of the single-3 group was significantly shorter compared to the procedure time of the double-3 group (mean procedure duration $132 \pm 64$ vs $159 \pm 50 \mathrm{~min}$, $\mathrm{p}=0.04$ ). After a mean symptomatic oriented follow-up of $10.7 \pm 4.7$ months, two recurrences of AFL occurred in the double-3 group. We concluded that single cryothermia applications of 3 minutes produce permanent CTI conduction block in patients with AFL and significantly reduce procedure duration.

In comparison to the duration of an RF application, in general 1 minute, the duration of a cryoapplication is significantly longer. In chapter four we evaluated the efficacy of single 1-minute cryocatheter ablation by means of a repeated electrophysiological study. Thirty-seven consecutive patients (28 men; mean age $59 \pm 14$ years) with AFL underwent cryoablation of the CTI. Applications of 1 minute were delivered with a 10-F, 10-mm tipped cryocatheter. If bidirectional CTI block was not obtained after 12 1-minute applications, applications of 3 minutes were selectively delivered to areas of conduction breakthrough. The endpoint of the procedure was creation of bidirectional CTI block and non-inducibility of AFL. Electrophysiological re-evaluation was performed either after 4 months and/or if there was a recurrence of AFL. A median of 7 (range 3 to 12) 1-minute applications were given along the CTI with a mean temperature of $-88.6 \pm 2.3^{\circ} \mathrm{C}$. Mean fluoroscopy and procedure time were $27 \pm$ $14 \mathrm{~min}$ and $110 \pm 28 \mathrm{~min}$ respectively. Five patients required additional 3minutes applications; in 1 patient an overextended ablation catheter prevented the completion of the index-procedure. The acute success rate of the index- 
procedure was 97\%. In 12/24 patients, 2 with AFL recurrence, resumption of CTI conduction was found. In all patients bidirectional CTI block was reobtained after a median of one 1-minute application. No additional AFL recurrences occurred, after a mean follow-up of $37 \pm 3$ (range 30 to 44 ) months. We concluded that catheter-based cryoablation of AFL can successfully be performed using the same application duration as used for RF ablation with comparable acute and long-term results. AFL recurrences occurred in only a minority of patients with resumption of CTI conduction.

Besides a decrease in application duration to reduce the procedure time one may also increase the affected area per application by increasing the cathetertip size. This has proven to be effective for RF. In chapter five we compared the clinical efficacy of a $6.5-\mathrm{mm}, 10-\mathrm{mm}$ and $15-\mathrm{mm}$ cryoablation catheter-tip for the treatment of AFL. Forty-five consecutive patients (35 men, $60 \pm 13$ years) with AFL underwent catheter-based cryoablation of the CTI. Single applications of 3 minutes were delivered at each site along the CTI. The first 15 patients were treated using a 6.5-mm catheter-tip, the next 15 patients received cryoablation using a $10-\mathrm{mm}$ catheter-tip and the last 15 patients were treated using a $15-\mathrm{mm}$ catheter-tip. Baseline characteristics of the 3 groups were comparable. The overall acute success rate was $89 \%$ and there was no difference with respect to the tip-electrode size ( $\mathrm{p}>0.05)$. Fewer applications were required for a $10-\mathrm{mm}$ $(6 \pm 2$, range $3-7)$ and a $15-\mathrm{mm}(6 \pm 1$, range $4-8)$, compared to a $6.5-\mathrm{mm}$ catheter-tip ( $8 \pm 3$, range $4-14 ; \mathrm{p}<0.05)$. Procedure time was significantly shorter with the largest tip electrode ( $89 \pm 26 \mathrm{~min}$., versus $132 \pm 28 \mathrm{~min}$ (6.5mm tip), p<0.05). No complications occurred. After a mean follow-up of $51 \pm 5$ months, 43 patients (96\%) were without recurrence of AFL. We concluded that large cryocatheter-tip electrodes require fewer applications to create bidirectional CTI block, without compromising safety and efficacy. Compared to a conventional 6.5-mm tip, a significant decrease in fluoroscopy and procedure time was obtained by with a $15-\mathrm{mm}$ electrode tip, which may encourage its future implementation.

The work of Haisaguerre resulted in an enormous population of patients treated for atrial fibrillation (AF) by means of pulmonary vein (PV) ablation. To obtain a favourable outcome of this procedure, the appropriate patients need to be selected and followed during a sufficiently long period. The study described in chapter six was designed to evaluate the long-term effects of segmental PV cryoablation, targeting all or only the arrhythmogenic PVs, in patients with recent-onset paroxysmal AF. Since patients with paroxysmal AF may have more triggers to initiate and less substrate to sustain $\mathrm{AF}$, elimination of the potential initiators alone may be sufficient to abolish the arrhythmia. Seventy patients with paroxysmal AF and minimal or no heart disease (54 men; age $40 \pm 10$ years) were enrolled. The duration of AF was $4 \pm 1$ year. The left ventricular ejection fraction and left atrial size were $59 \pm 8 \%$ and $41 \pm 5 \mathrm{~mm}$, respectively. An arrhythmogenic PV was found in 10 patients (14\%). In these patients only 
cryoisolation of the arrhythmogenic PV(s) was performed. Otherwise, all PVs were isolated. Complications occurred in 3 patients (4\%). No PV stenosis or esophageal injury was detected by computed tomography during a mean followup of $33 \pm 15$ months. Thirty-four patients (49\%) achieved complete success (no $\mathrm{AF}$ and no $\mathrm{AAD}) ; 15$ patients (22\%) had no recurrences with antiarrhythmic drugs; and 8 patients (11\%), still with sporadic bursts of $A F$, improved $\geq 50 \%$ with antiarrhythmic drugs. Overall, $82 \%$ of the patients benefited from the procedure. Patients in whom the arrhythmogenic PV was identified and isolated had no recurrences. We concluded that PV cryoisolation is effective in $82 \%$ of patients with recent-onset paroxysmal AF during a mean follow-up of $33 \pm 15$ (range 15 to 60) months. Arrhythmogenic PV isolation has an excellent longterm outcome, indicating no need to isolate all PVs.

Transvenous cryoablation has proven to be safe and effective for the treatment of supraventricular arrhythmias. No study has evaluated the use of cryoablation for the treatment of ventricular tachycardia (VT). In Chapter seven we described the first experience of catheter-based cryoablation of postinfarction and idiopathic VT. Cryoablation was performed in 17 patients (15 men, $58 \pm 18$ years). VT occurred after a prior myocardial infarction in 10 and was idiopathic in 7 patients. Cryo was performed with a 10-F, 6.5-mm tipped catheter. The ablation site was selected using entrainment mapping techniques for postinfarction VT. The site of the earliest activation time with optimal pace mapping was used for ablation of idiopathic VT. All targeted VTs (12 postinfarction and 7 idiopathic) were acute successfully ablated after a median number of 2 applications of 5 minutes with an average temperature of $-82 \pm 4^{\circ} \mathrm{C}$. Mean procedure and fluoroscopy times were $204 \pm 52$ and $52 \pm 20 \mathrm{~min}$ for postinfarction VT and $203 \pm 24$ and $38 \pm 15 \mathrm{~min}$ for idiopathic VT. No cryocatheter or cryoenergy complications were observed. After a follow-up of 6 months, 4 of the 10 patients with postinfarction VT had a recurrence. In 1 of the 7 patients with idiopathic VT the index arrhythmia recurred. Our data shows that in a small patient population, catheter-based cryoablation of VT is safe and effective. Future studies are needed to evaluate the effect of cryothermy in a larger group of patients, especially those with postinfarction VT. 


\section{Samenvatting}

Na meer dan een eeuw van technische ontwikkeling wordt cryoenergie gebruikt als een veelzijdig en waardevolle energiebron, gewaardeerd vanwege unieke eigenschappen. In de laatste 40 jaar heeft aanhoudende biomedische ontwikkeling ertoe geleid dat grote cryochirurgische probes omgevormd werden tot veel kleinere cryoablatie katheters die in staat zijn om intracardiale celdood te bewerkstelligen. In hoofdstuk één worden de meest belangrijke ontwikkelingen beschreven die verantwoordelijk waren voor het huidige design en het klinische gebruik van transveneuze cryoablatie. We hebben geleerd dat lage temperaturen een centrale rol spelen in het maken van diepe en grote letsels. Het verkrijgen van zeer lage temperaturen met behulp van een veilig en hanteerbaar apparaat heeft het grootste deel van de $20^{\mathrm{e}}$ eeuw in beslag genomen, terwijl de vroege jaren negentig gedomineerd werden door het ontwikkelen van katheters, geschikt voor transveneus gebruik. Een thermokoppel en bipolaire elektroden werden in de katheter ingebouwd. Ze geven informatie over de intracardiale temperatuur en ligging van de katheter en maakten cryoablatie daarmee geschikt voor de behandeling van ritmestoornissen. Om de extra warmte van het circulerende bloed te trotseren en een hoge effectiviteit te behouden werden vroeger ontwikkelde cryochirurgische ablatie protocollen gebruikt. Daarnaast zijn cryoablatiekatheters stugger vanwege hun grotere diameter, noodzakelijk voor het transport van koelmiddel. Dit leidde tot een andere manier van hanteren en manoeuvreren van een cryoablatiekatheter in vergelijking met een radiofrequentie energie (RF) ablatiekatheter. Dientengevolge was de initiële doorlichtings- en procedure tijd lang ofschoon de acute effectiviteit vergelijkbaar was met RF.

Indien de lange termijn follow-up hetzelfde effect zou laten zien en indien er meer ervaring kon worden opgedaan met het hanteren van de cryoablatiekatheter om de procedure tijd te verkorten, zou cryothermie een waardig alternatief zijn voor RF. In hoofdstuk twee wordt het lange termijn resultaat van cryoablatie nagegaan bij 35 patiënten met cavotricuspid isthmus (CTI) afhankelijke atrium flutter (AFL). Omdat deze studie een van onze eerste ervaringen met het gebruik van cryothermie beschrijft, onderzochten we ook de bijdrage van een leercurve op de procedure tijd. Elf patiënten hadden structurele hartafwijkingen. Cryoablatie werd verricht met behulp van een 10-F katheter met een 6-mm tip elektrode. Tussen de tricuspidalisklepring en de vena cava inferior werd een ablatielijn gemaakt middels opeenvolgende cryo-applicaties met een duur variërend van 3 tot 5 minuten. Na de cryoablatie werden de patiënten na 1 maand en nadien om de 3 maanden poliklinisch gevolgd. Een 24-uur Holter registratie 
werd direct na de procedure verricht en nadien wanneer de patiënt klachten had. Bij patiënten met AFL geïnduceerd door anti-aritmica werden deze antiaritmica verder toegediend na de ablatie procedure. Er werd een mediaan van 14 (4 - 30) applicaties op 10 locaties (14 - 19) langs de CTI gegeven. De applicaties hadden een gemiddelde temperatuur van $-80.0 \pm 5.0^{\circ} \mathrm{C}$. De gemiddelde doorlichtings- en procedure tijd waren respectievelijk $40 \pm 26 \mathrm{~min}$ and $3.0 \pm 1.3$ uur. Vierendertig van de 35 patiënten waren acuut succesvol geableerd (97\%). $\mathrm{Na}$ een gemiddelde follow-up van $17.6 \pm 6.2$ (range 9.6 tot 26.1) maanden, ondervonden 31 patiënten $(89 \%)$ geen recidief van AFL. De procedure tijd was lang in vergelijking met RF, maar bleek afhankelijk te zijn van de ervaring van de katheteriseur gezien de significante daling ervan bij de tweede helft van de studiepopulatie. Onze gegevens tonen aan dat cryothermie in staat is om een blijvend bi-directional isthmus geleidingsblok van de CTI te maken met een acuut en chronisch succes percentage vergelijkbaar met RF.

De kennis die we verworven hebben via eerdere experimentele studies en via onze eerste ervaring zoals hierboven beschreven, waar enkelvoudige 3minuten applicaties voldoende waren om AFL te behandelen heeft ons aangezet om het tweemaal toedienen van cryothermie op elke locatie te verlaten. In hoofdstuk 3 vergelijken we eenmalige 3-minuten ( $1 \times 3)$ met tweemalige 3minuten $(2 \times 3)$ cryoapplicaties voor de behandeling van AFL. Veertig patiënten ( $56 \pm 13$ jaar) met AFL werden gerandomiseerd naar $1 \times 3$ of of $2 \times 3$ cryoapplicaties op elke ablatie plaats langs de CTI. De helft van de patiënten hadden een structureel normaal hart. Iedereen, behalve één patiënt (95\%) van de 1 x 3 groep en alle patiënten van de $2 \times 3$ groep werden succesvol geableerd. De gemiddelde temperatuur in de $1 \times 3$ groep was $-79 \pm 6^{\circ} \mathrm{C}$ en in de $2 \times 3$ groep $-80 \pm$ $4^{\circ} \mathrm{C}$ (NS). Het aantal ablatieplaatsen noodzakelijk om CTI blok te creëren was $9 \pm$ 4 ( 1 x 3$)$ en $8 \pm 2$ ( $2 \times 3)$ (NS). De doorlichtingstijd verschilde niet tussen beide groepen, maar de procedure tijd van de $1 \times 3$ groep was significant korter dan de procedure tijd van de $2 \times 3$ groep (132 \pm 64 versus $159 \pm 50 \mathrm{~min}, \mathrm{p}=0.04)$. Na een gemiddelde follow-up van $10.7 \pm 4.7$ maanden, waren er twee recidieven van AFL in de $2 \times 3$ groep. Bij patiënten met AFL die behandeld werden met enkelvoudige cryoapplicaties van 3 minuten bleek dus dat een blijvend CTI geleidingsblok verkregen wordt en dat de procedureduur significant afneemt.

In vergelijking met de duur van een $\mathrm{RF}$ applicatie, in de regel 1 minuut, is de duur een cryo-applicatie significant langer. In hoofstuk 5 evalueerden we de effectiviteit van enkelvoudige één-minuut cryoapplicaties met behulp van een herhaalde electrofysiologisch onderzoek. Bij 37 opeenvolgende patiënten (28 mannen met een gemiddelde leeftijd van $59 \pm 14$ jaar) met typische AFL werd een cryoablatie van de CTI verricht. Applicaties van 1 minuut werden toegediend met een 10-F cryokatheter met een 10-mm tipelectrode. Als bidirectioneel CTI blok niet werd verkregen na 12 applicaties van 1 minuut, werden applicaties van 3 minuten toegediend. Het eindpunt van de procedure was bidirectioneel CTI blok en de niet-induceerbaarheid van AFL. Een mediaan van 7 (3 - 12) 
1-minuut applicaties werden toegediend met een gemiddelde temperatuur van $-88.6 \pm 2.3^{\circ} \mathrm{C}$. De gemiddelde doorlichtings- en procedure tijd bedroeg respectievelijk $27 \pm 14$ min. en $110 \pm 28$ minuten. Bij 5 patiënten werden ook applicaties van 3 minuten toegediend. De procedure was succesvol in 35 (97\%) patiënten. Bij 12 van de 24 patiënten die een herhaald electrofysiologisch onderzoek ondergingen, inclusief 2 patiënten met een recidief AFL, was er opnieuw geleiding in de CTI. Bij alle patiënten werd weer bidirectioneel CTI blok verkregen met een mediaan van 1 applicatie van 1 minuut. Na een gemiddelde follow-up van $37 \pm 3$ (30 tot 44 ) maanden trad geen AFL recidief meer op. Deze studie toonde aan dat cryoablatie van AFL succesvol kan worden uitgevoerd met dezelfde applicatieduur als die van RF ablatie. Zowel de acute als lange termijn resultaten zijn vergelijkbaar met $\mathrm{RF}$ ablatie. Vroegtijdige recidieven van AFL traden alleen op bij een minderheid van de patiënten met herstel van geleiding in de CTI.

Naast het verkorten van de duur van een cryoapplicatie, zou ook een toename van het aangedane gebied per cryoapplicatie bewerkstelligd kunnen worden met een grotere kathetertip om de procedure tijd te verminderen. In hoofdstuk vijf wordt de klinische effectiviteit van een $6.5-\mathrm{mm}, 10-\mathrm{mm}$ and $15-\mathrm{mm}$ cryoablation kathetertip vergeleken voor de behandeling van AFL. Vijfenveertig opeenvolgende patiënten (leeftijd $60 \pm 13$ ) met AFL ondergingen een cryoablatie van de CTI. Enkelvoudige applicaties van 3 minuten werden toegediend. De eerste 15 patiënten werden behandeld met een 6.5- $\mathrm{mm}$ kathetertip, de volgende 15 patiënten met een 10 -mm kathetertip en de laatste 15 patiënten met een 15 mm kathetertip. Tussen de 3 groepen waren er geen verschillen in klinische en echocardiografische karakteristieken. Het globale acute succes percentage was $89 \%$ en er was geen verschil met betrekking tot de grootte van de tip-elektrode ( $p>0.05)$. Er waren minder applicaties nodig voor een $10-\mathrm{mm}(6 \pm 2)$ en een 15 $\mathrm{mm}(6 \pm 1)$, in vergelijking met de 6.5 -mm kathetertip $(8 \pm 3$; $\mathrm{p}<0.05)$. De procedure tijd was significant korter met de grootste tip-elektrode (89 \pm 26 min., versus $132 \pm 28 \mathrm{~min}(6.5-\mathrm{mm}$ tip), $\mathrm{p}<0.05)$. Er traden geen complicaties op. $\mathrm{Na}$ een gemiddelde follow-up van $51 \pm 5$ maanden, hadden 43 patiënten (96\%) geen recidief van AFL. Deze studie toonde aan dat grote cryoablatie tipelektroden minder applicaties nodig zijn om een bidirectioneel CTI geleidingsblok te creëren, zonder de veiligheid of effectiviteit te benadelen. In vergelijking met een conventionele 6.5-mm tip, was de doorlichtings- en procedure tijd significant korter met een 15-mm elektrodetip hetgeen toekomstige gebruik ervan bemoedigt.

De in 1995 gepubliceerde studie van Haisaguerre leidde tot een explosieve toename van de behandeling van patiënten met atriumfibrilleren (AF) door middel van pulmonaal vene (PV) isolatie. Een gunstig resultaat van deze behandeling vereist onder andere een juiste selectie van patiënten (die in aanmerking komen voor dergelijke procedure) in de afwezigheid van AF gedurende langdurige follow-up. In hoofdstuk 6 wordt de lange termijn resultaat beschreven van 
patiënten met recent ontstaan paroxysmaal AF die een segmentale PV cryoablatie ondergingen. Omdat patiënten met paroxysmaal AF meer triggers hebben om AF te initiëren en minder substraat om de aritmie te onderhouden, zou ablatie van potentiële initiatoren alléén voldoende kunnen zijn om AF te behandelen. Zeventig patiënten met paroxysmaal AF en minimaal of geen structureel hartlijden (54 mannen met een gemiddelde leeftijd van $40 \pm 10$ jaar) werden geïncludeerd. De gemiddelde duur van paroxysmaal AF was $4 \pm 1$ jaar. De linker kamer ejectiefractie en linker atrium grootte waren $59 \pm 8 \%$ and $41 \pm 5 \mathrm{~mm}$, respectievelijk. Een aritmogene PV werd gevonden in 10 patiënten (14\%) en alleen deze PV werd behandeld. Bij de overige 60 patiënten werd alleen cryoisolatie van de aritmogene PV(s) ondernomen. Anderszins werden alle PVs geïsoleerd. Complicaties kwamen voor in 3 patiënten (4\%). Er werd geen PV stenose of slokdarm beschadiging waargenomen met behulp van een CT-scan gedurende een gemiddelde follow-up van $33 \pm 15$ maanden. Vierendertig patiënten (49\%) hadden geen recidief van $\mathrm{AF}$ en werden niet meer behandeld met anti-aritmica en 15 patiënten $(22 \%)$ hadden geen recidief en werden wel behandeld met antiaritmica. Acht patiënten (11\%), waarbij nog sporadisch korte aanvallen van AF werden waargenomen en die nog medicamenteus behandeld werden, verbeterde met $50 \%$. Het globale succespercentage bedroeg $82 \%$. Patiënten waarbij enkel aritmogene PV(s) geïdentificeerd en geïsoleerd werden, hadden geen recidief. Uit deze studie blijkt dat cryoablatie van de longvenen een veilige behandeling is met een effectiviteit van $82 \%$ bij patiënten met recent ontstaan paroxysmaal $\mathrm{AF}$ na een gemiddelde follow-up van $33 \pm 15$ (15 - 60) maanden. De isolatie van een aritmogene PV gaf een beter lange termijn resultaat, hetgeen isolatie van alle PVs overbodig maakt.

De voorbije jaren werd angetoond dat katheterablatie met cryothermie veilig is voor de behandeling van supraventriculaire ritmestoornissen. Er is geen informatie beschikbaar over de behandeling van ventriculaire tachycardie (VT) met cryokatheterablatie. In hoofdstuk zeven beschreven we de eerste ervaring met cryoablatie van post-infarct en idiopathische kamertachycardieën. Cryokatheter ablatie werd uitgevoerd bij 17 patiënten (15 mannen met geen gemiddelde leeftijd van $58 \pm 18$ jaar). VT trad op na een eerder myocard infarct bij 10 en was idiopathisch bij 7 patiënten. Cryokatheter ablatie werd verricht met een 10F cryokatheter met een 6.5 -mm tip electrode. Het ablatie gebied werd geselecteerd met behulp van entrainment mapping technieken voor post-infarct VT. Het gebied met de vroegste activatietijd en waar optimale pace-mapping werd verkregen, werd gebruikt voor ablatie van idiopathische VT. Alle geselecteerde VTs (12 postinfarct en 7 idiopathische) werden met een mediaan van 2 applicaties van 5 minuten en een gemiddelde temperatuur van $-82 \pm 4^{\circ} \mathrm{C}$ acuut succesvol geableerd. De gemiddelde procedure and doorlichtingstijd was $204 \pm 52$ and $52 \pm 20$ minuten voor post-infarct VT en $203 \pm 24$ and $38 \pm 15$ minuten voor idiopathische VT. Er werden complicaties waargenomen. Na een follow-up van 6 maanden, hadden 4 van de 10 patiënten met post-infarct VT een recidief. Bij 1 
van de 7 patiënten met idiopathische VT, trad de index aritmie opnieuw op. Bij deze kleine patiëntengroep was cryoablatie van VT veilig en effectief gebleken. Het effect van cryoablatie dient geëvalueerd te worden bij een grotere groep patiënten met voornamelijk post-infarct VT. 



\section{Dankwoord}

Het opzetten, uitvoeren, analyseren en beschrijven van (promotie) onderzoek is een samenspel van vele factoren en individuen. Gedegen onderzoek plegen, zoals ondergebracht in een promotie-traject, komt in eerste instantie voort uit een reeks van opvoedkundige taken die een originele en klinisch relevant vraagstuk weten te kanaliseren tot een 'acceptabele' implementatie en beschrijving. Promoveren gaat ook niet over een nacht ijs, maar vraagt begeleiding, volharding en niet in de laatste plaats flexibiliteit. Mijn queeste begon in 2003 en bestrijkt een periode van 8 jaar, waarin naast 2 jaar full-time klinisch onderzoek, mijn opleiding tot cardioloog plaatsvond, mijn fellowship-electrofysiologie aanving, maar waarin zich ook een huwelijk voltrok en de geboorte van mijn beide kinderen plaatsvond. Lijnrecht hiertegenover staat het faillissement en overname van CryoCor $^{\mathrm{TM}}$ en het ziektebed met noodlottig overlijden van mijn copromotor die een belangrijke rol vervulde in dit geheel. Mijn dankwoord wordt daarom mede bepaald door de plaats en personen die tijdens deze 'levensfasen' mijn pad doorkruisten.

Ten eerste gaat mijn dank naar Dr. Luz-Maria Rodriguez uit. Luz, Ik kan me jouw voorstel deel te nemen aan een promotie-onderzoek nog levendig herinneren, evenals mijn antwoord die in eerste instantie een twijfelachtige 'oké' betrof; promotie stond toen nog niet zó hoog op mijn agenda. Je hebt moeite gedaan me op te voeden tot een volwaardig klinisch onderzoeker. Mijn interesse voor de klinische electrofysiologie is onder jouw regie nog verder opgebloeid. Je hebt me geïntroduceerd en gedoceerd in de katheter-ablatie, zodat ik de relatie met de kliniek nooit uit het oog zou verliezen. Ook ben ik je dankbaar voor de (sociale) begeleiding rondom mijn voordrachten. Een ervaring die nog eens onderstreept dient te worden nu je er helaas niet meer bij kunt zijn.

Mijn dank gaat ook uit naar Dr. Timmermans. Carl, ik ben je zeer dankbaar voor de tijd en energie die je in mijn promotie-onderzoek hebt gestoken. Het manuscript vielen zowel Luz als jou ten deel, maar in de latere fasen werd jouw inbreng noodzakelijkerwijs steeds belangrijker. Ik heb veel aan je te danken en je bijdrage, toewijding en ongelofelijke accuratesse in de voltooiing van het manuscript zal me altijd bijblijven. Geen dubbele spatie, punt (-komma), of foutief gespelde referentie ging aan jouw arendsblik voorbij. De publicatiestrijd heb ik mede hierdoor vaak met jou mogen winnen.

Prof. Crijns, bedankt voor uw inspiratie als opleider, cardioloog, electrofysioloog, (klinisch) onderzoeker en niet in de laatste plaats harde werker. Het ochtendrapport en de exploratie van het electrocardiogram genoot onder uw beheer altijd de nodige diepgang. De kritische noten die u in uw beschouwing van 
presentaties steeds naar voren wist te brengen, hebben me altijd geboeid en hebben een katalyserende invloed op mijn promotieonderzoek en mijn opleiding tot cardioloog gehad.

Verder gaat mijn dank uit naar Suzanne Philippens die met haar toewijding als onderzoeksverpleegkundige een belangrijke bijdrage heeft geleverd in het samenstellen van de data en het onderhoud met de onderzoekspopulatie. Suz', bedankt voor al die keren dat je voor me klaar stond en de data wist te verzorgen en/of de figuren wist te verfraaien!

Ik bedank Ashish Nabar, voor zijn onbaatzuchtige hulp en onderwijs in de analyse van pulmonaalvene potentialen hetgeen vele uren turen, meten en 'klikken' heeft gekost. In die tijd groeide mijn waardering voor het endocardiale electrogram, een onderdeel die nochtans niet in het reguliere curriculum is ingebouwd. Electrofysiologische beschouwingen en de interpretatie van modern electrofysiologisch onderzoek waren nooit meer hetzelfde.

Eveneens gaat mijn dank uit naar Paul Volders die me op belangrijke momenten een luisterend oor bood. Zijn deelname in de diverse brainstormsessies met zijn promovendi hebben me altijd gefascineerd en geïnspireerd.

Ik dank Roland voor zijn geruchtmakende 'blikje-blokje', waarin we het onderzoeksleven van alle dag met de nodige verve doornamen. Hij heeft me ook weten te inspireren met de originaliteit van en de volharding in zijn eigen promotie-onderzoek. Het is een eer jou als paranymf te mogen hebben!

In dat licht dank ik ook Vanessa die mij als paraymf steeds op gepaste wijze wist te motiveren in de slotfase van dit proefschrift. Onderdeel van deze keuze vormt ook haar sympathieke inbreng als naaste collega.

Ook Yves van Belle dank ik voor de heugelijke tijd waarin hij me vergezelde op de EFO- en researchkamer en de wandelingen naar de universiteitskeuken.

Eveneens gaat mijn dank uit naar mijn toenmalige naaste collega-assistenten, die als assistent-vertegenwoordiger of als invalskracht mij de gelegenheid boden het onderzoek tijdens mijn klinische werkzaamheden en verplichtingen te kunnen voort zetten. In het bijzonder valt hier te noemen: Sylvie, Bas, Stijn en Yuri.

Ook ben ik de fijne samenwerking van het electrofysiologisch team in het MUMC dankbaar.

Evenzo ben ik het electrofysiologisch team en de electrofysiologen in het Catharina Ziekenhuis Eindhoven dankbaar voor hun interesse in mijn onderzoek en de mogelijkheid die ze me geboden hebben om in de laatste fase meer tijd hieraan te besteden.

In de laatste plaats dank ik mijn vrienden en familie die me altijd door weer en wind gesteund hebben. Pap en mam, eveneens bedankt voor jullie interesse en steun in mijn onderzoek en de mogelijkheid die jullie mij geboden hebben om dit op een Mac-waardige manier te completeren. Monique, je hebt 8 jaar mijn 'koude' kant mogen ervaren en moeite gedaan om deze aandacht altijd in ons gezinsleven te passen. Ik ben daarom zeer verheugd dat we dit resultaat in ieder geval met ons beiden mogen vieren. 


\section{Curriculum vitae}

Randy Manusama, Geboren op 6 april 1975, te Heerlen

1987-1993 Albert Schweitzer Scholengemeenschap te Geleen

Diploma atheneum

1993-1994 Rijksuniversiteit Limburg Gezondheidswetenschappen

1994-2000 Rijksuniversiteit Limburg Geneeskunde

1998 (apr) Doctoraal Geneeskunde

2000 (sept) Artsendiploma

2000 (sept) ANIOS-cardiologie in het St. Joseph Ziekenhuis te Veldhoven

2001 (apr) ANIOS-cardiologie in het Maasland Ziekenhuis te Sittard

2002 (feb) Opleiding cardiologie Academisch Ziekenhuis Maastricht

2010 (feb) BIG-registratie cardioloog

2010 (feb) fellowship electrofysiologie Catharina Ziekenhuis Eindhoven

Randy Manusama werd geboren op 6 april 1975, te Heerlen. In 1993 behaalde hij zijn atheneumdiploma aan het Albert Schweitzer (ondergebracht in het huidige Graaf Huyn college) te Geleen. Nadien volgde hij een jaar gezondheidswetenschappen aan de Rijksuniversiteit Limburg te Maastricht (huidige UM) om later wel ingeloot te worden voor de studie geneeskunde in 1994. Hij behaalde zijn artsendiploma in september 2000. Met name tijdens de co-schappen groeide zijn interesse voor de cardiologie en zijn fascinatie voor het electrocardiogram. Er volgde anderhalf jaar agnio-schap verdeeld in het St. Joseph Ziekenhuis te Veldhoven (huidig Maxima Medisch Centrum) en het Maasland Ziekenhuis Sittard (huidig Orbis Medisch Centrum). De opleiding cardiologie werd vanaf 2002 gevolgd in het Academisch Ziekenhuis Maastricht (huidig MUMC). Deze opleiding werd in het kader van bovengenoemd promotie-onderzoek voor een periode van 2 jaar tijdelijk onderbroken. Dit klinisch gerelateerde onderzoek gefocussed op de evaluatie van een nieuwe technology in catheter ablatie sprak hem zeer aan. Een Zon Mw stipendium werd gehonoreerd. In 2005 werd de opleiding cardiologie hervat en in februari 2010 afgerond. Aansluitend mocht hij zijn fellowship Electrofysiologie aan het Catharina Ziekenhuis te Eindhoven aanvangen. 



\section{Publications}

\section{Articles}

Manusama R, Timmermans C, Limon F, Philippens S, Crijns HJGM, Rodriguez LM. Catheter-based cryoablation permanently cures patients with common atrial flutter. Circulation. 2004;109:1636-1639

Manusama R, Timmermans C, Philippens S, Crijns HJGM, Rodriguez LM. Do Single cryothermia applications of less than five minutes produce permanent cavotricuspid isthmus block in humans. Heart Rhythm. 2004, 1:594-9.

Moreira W, Manusama R*, Timmermans C, Ghaye B, Philippens S, Wellens HJ, Rodriguez LM. Long-term follow-up after cryothermic ostial pulmonary vein isolation in paroxysmal atrial fibrillation. J Am Coll Cardiol. 2008, 51:850-5. ( ${ }^{*}$ gedeelde eerste auteur)

Manusama R, Timmermans C, Pison L, Philippens S, Perez D, Rodriguez LM. Typical atrial flutter can effectively be treated using single one-minute cryoapplications: results from a repeat electrophysiological study. J Interv Card Electrophysiol. 2009, 26:65-72.

Alzand BSN, Manusama R, Gorgels APM, Wellens HJJ. An "Almost Wide" QRS tachycardia. Circulation: Arrhythmia and Electrophysiology. 2009;2:e1-e3

Timmermans C, Manusama R, Alzand B, Rodriguez LM. Catheter-Based Cryoablation of postinfarction and idiopathic ventricular tachycardia: initial experience in a selected population. J Cardiovasc Electrophysiol. 2010, 21:255-61.

Manusama R, Timmerman C, Van der Schoot M, Philippens S, Jillian A, Rodriguez LM. Comparison of a $6.5-\mathrm{mm}, 10-\mathrm{mm}$ and $15-\mathrm{mm}$ Cryoablation catheter-tip for the treatment of common atrial flutter. Submitted for publication

Manusama R, Crijns HJGM. Wanneer is er een indicatie voor ablatie bij hartritmestoornissen? Vademecum, Jaargang 21, nr.51

Alzand BSN, Manusama R, Geyik Z, Crijns HJGM. Initiated with a doublet, terminated with a VES!. Neth. Heart J. 2009; 17(6): 252

\section{Abstracts}

Manusama R, Timmermans C, Philippens S, Nabar A, Limon F, Crijns HJGM, Rodriguez LM. Long-term follow-up of patients undergoing catheter cryoablation for common atrial flutter. Neth Heart J; 2003:11;5

Manusama R, Timmermans C, Philippens S, Crijns HJGM, Rodriguez LM. Do single cryothermia applications of less than five minutes produce permanent cavotricuspid isthmus conduction block in humans? J Am Coll Cardiol; 2004:123A, 1090-217 
Belle van Y, Timmermans C, Manusama R, Philippens S, Nabar A, Crijns HJGM, Rodriguez LM. Chronic results of catheter-based cryoablation for classical supraventricular arrhythmias: a single center experience. Neth Heart J; 2004

Nabar A, Manusama R, Timmermans C, Philippens S, Crijns HJGM Rodriguez LM. Pulmonary vein electrophysiological characteristics and the effects of a cryoapplication in patients with atrial fibrillation. Neth Heart J; 2004

Van Belle Y, Manusama R, Van der Schoot M, Philippens S, Crijns HJGM, Rodriguez LM. Time course of atrial fibrillation recurrence after pulmonary vein isolation: Does AF slowly fade away? Heart rhythm 2005, 2(5): S231

Moreira W, Timmermans C, Manusama R, Philippens S, Perez D, Mizusawa, Ayers G, Rodriguez LM. Cryothermia can effectively be delivered with the same application duration as radiofrequency energy. Eur Heart J 2006, 27(1): 325-2082

Van der Schoot M, Timmermans C, Manusama R, Philippens S, Moreira W, Perez D, Mizusawa Y, Ayers G, Rodriguez LM. A large electrode tip is superior for RF ablation of atrial flutter- What about cryoablation? Neth Heart J; 2006

Moreira W, Rodriguez LM, Timmermans C, Manusama R, Philippens S, Perez D, Mizusawa. Long-term follow-up after cryo-isolation of the pulmonary veins in patients with recent onset atrial fibrillation. Eur Heart J 2006, 27(1): 7274429

Manusama R, Nabar A, Timmermans C, Philippens S, Rodriguez LM. Pulmonary vein potential behavior before and after cryoablation in patients with paroxysmal atrial fibrillation. Eur Heart J 200526 (1): 1-204

Manusama R, Moreira W, Timmermans C, Wellens HJJ, Philippens S, Rodriguez LM. Can common type atrial flutter be a sign of an arrhythmogenic substrate in paroxysmal atrial fibrillation. J Interv Card Electrophysiol 2008, 21:91-94

Manusama R, Moreira W, Timmermans C, Wellens HJJ, Philippens S, Rodriguez LM. Long-term outcome of cavotricuspid isthmus cryoablation for the treatment of common atrial flutter in 180 patients. J Interv Card Electrophysiol 2008, 21:129-132

Manusama R, Timmermans C, Pison L, Philippens S, Perez D, Rodriguez LM. Typical atrial flutter can effectively be treated using single one-minute cryoapplications: results from a repeat electrophysiological study. Journal of interventional electrophysiology. J Interv Card Electrophysiol 2009, 24:249254 